\title{
REPORT OF THE INTERAGENCY BIOLOGICAL
}

\section{METHODS WORKSHOP}

Edited by Martin E. Gurtz and Thomas A. Muir

\section{U.S. GEOLOGICAL SURVEY}

Open-File Report 94-490

Workshop Participants and Contributors:

INTERGOVERNMENTAL TASK FORCE ON MONITORING WATER QUALITY

U.S. ENVIRONMENTAL PROTECTION AGENCY

BUREAU OF LAND MANAGEMENT

BUREAU OF RECLAMATION

NATIONAL BIOLOGICAL SURVEY

NATIONAL PARK SERVICE

U.S. FISH AND WILDLIFE SERVICE

U.S. GEOLOGICAL SURVEY

U.S. FOREST SERVICE

NATIONAL OCEANIC AND ATMOSPHERIC ADMINISTRATION

U.S. ARMY CORPS OF ENGINEERS

OHIO RIVER VALLEY WATER SANITATION COMMISSION

TENNESSEE VALLEY AUTHORITY

NORTH CAROLINA DEPARTMENT OF ENVIRONMENT, HEALTH, AND NATURAL RESOURCES

OHIO ENVIRONMENTAL PROTECTION AGENCY

FEDERAL COORDINATING COUNCIL FOR SCIENCE, ENGINEERING AND TECHNOLOGY

Raleigh, North Carolina 


\section{U.S. DEPARTMENT OF THE INTERIOR}

BRUCE BABBITT, Secretary

U.S. GEOLOGICAL SURVEY

Gordon P. Eaton, Director

Any use of trade, product, or firm names in this report is for descriptive purposes only and does not imply endorsement by the U.S. Government.

For additional information write to:

District Chief

U.S. Geological Survey 3916 Sunset Ridge Road

Raleigh, North Carolina 27607
Copies of this report may be purchased from:

U.S. Geological Survey

ESIC, Open-File Reports Section

Box 25286, Mail Stop 517

Denver Federal Center

Denver, Colorado 80225 


\section{FOREWORD}

The Interagency Biological Methods Workshop and this report are part of an ongoing intergovernmental effort to improve water-quality monitoring nationwide. Beginning in 1992 under the leadership of the U.S. Geological Survey (USGS) and the U.S. Environmental Protection Agency, a partnership of Federal, State, and Tribal organizations initiated the Intergovernmental Task Force on Monitoring Water Quality (ITFM). Operating under the sponsorship of the Federal Water Information Coordination Program that is led by the USGS, the ITFM is evaluating waterquality monitoring and is developing recommendations to improve water-quality information at all levels of government and in the private sector. In 1995, the ITFM will submit its final report to the Office of Management and Budget, Congress, States, and others. Based on the recommendations of the ITFM, agencies will implement the proposed strategy to improve water-quality monitoring.

From its beginning, the ITFM has recognized the importance of biological monitoring that supports efforts to protect human health, to preserve and enhance ecological conditions, and to sustain a stable economy. The ITFM has identified as a priority the need to develop comparable biological and microbiological methods for interagency use. In response to this priority, the USGS National Water-Quality Assessment (NAWQA) Program hosted the Interagency Biological Methods Workshop to explore the development of comparable biological methods. Many ITFM member organizations participated in the workshop.
This report documents the results of these initial interagency deliberations. The participants identified similarities and differences in objectives, program designs, and methods among agencies. The workshop and this resulting report set the stage for future collaboration to foster the development and adoption of comparable methods wherever appropriate and consistent with agency missions and program objectives.

Interagency collaboration and the use of comparable biological methods can reduce costs, expand the base of biological information useful for decision making, and enhance scientific understanding of biological processes in relationship to physical and chemical processes in ecosystems. The ITFM appreciates the important step that the NAWQA Program and the workshop participants from other agencies have made toward improving water-quality monitoring generally and biological monitoring specifically.

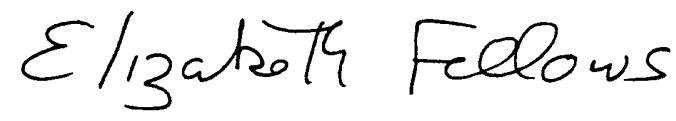

Elizabeth Fellows

U.S. Environmental Protection Agency Chairperson, ITFM 


\section{CONTENTS}

Abstract
Introduction
Purpose and scope

\section{FIGURES}

1-7. Comparison charts of:

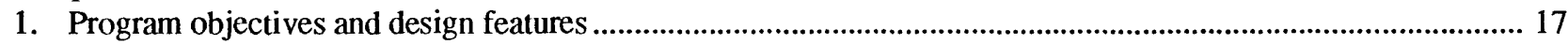

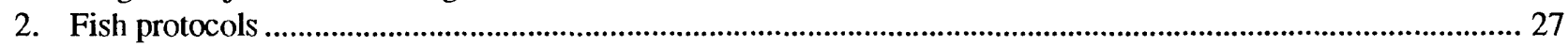

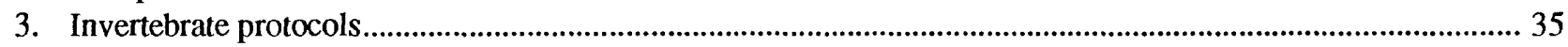

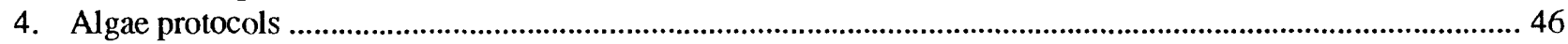

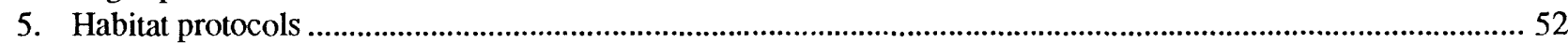

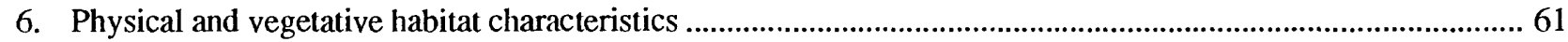

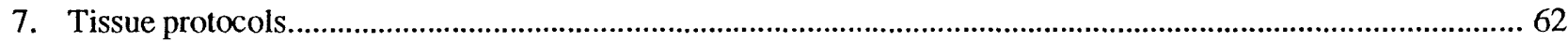




\begin{tabular}{rcl}
\hline Multiply & By & To obtain \\
\hline & Length & \\
micron $(\mu \mathrm{m})$ & 0.00003937 & inch \\
millimeter $(\mathrm{mm})$ & 0.03937 & inch \\
centimeter $(\mathrm{cm})$ & 0.3937 & inch \\
meter $(\mathrm{m})$ & 3.281 & foot \\
kilometer $(\mathrm{km})$ & 0.6214 & mile \\
& Area & \\
square centimeter $\left(\mathrm{cm}^{2}\right)$ & 0.001076 & square foot \\
square meter $\left(\mathrm{m}^{2}\right)$ & 10.76 & square foot \\
& Mass & ounce, avoirdupois \\
gram $(\mathrm{g})$ & 0.03527 & gallon \\
& Volume & gallon \\
liter $(\mathrm{L})$ & 0.264 & 0.000264 \\
milliliter $(\mathrm{mL})$ & &
\end{tabular}

Temperature: Water temperature in degrees Celsius $\left({ }^{\circ} \mathrm{C}\right)$ may be converted to degrees Fahrenheit $\left({ }^{\circ} \mathrm{F}\right)$ as follows:

$$
{ }^{\circ} \mathrm{F}=1.8\left({ }^{\circ} \mathrm{C}\right)+32
$$

Following is a list of abbreviations of agency and program names used throughout this report:

\begin{tabular}{|c|c|}
\hline BEST & $\begin{array}{l}\text { Biomonitoring of Environmental Status and Trends (NBS; part of USFWS at the } \\
\text { time of the workshop) }\end{array}$ \\
\hline BLM & Bureau of Land Management (DOI) \\
\hline BOR & Bureau of Reclamation (DOI) \\
\hline DOI & U.S. Department of the Interior \\
\hline EMAP & Environmental Monitoring and Assessment Program (USEPA) \\
\hline FDA & Food and Drug Administration (USDA) \\
\hline ITFM & Intergovernmental Task Force on Monitoring Water Quality \\
\hline NAWQA & National Water-Quality Assessment Program (USGS) \\
\hline NBS & National Biological Survey (DOI) \\
\hline NCBP & $\begin{array}{l}\text { National Contaminant Biomonitoring Program (NBS; part of USFWS at the time of } \\
\text { the workshop) }\end{array}$ \\
\hline NC-DEHNR & $\begin{array}{l}\text { North Carolina Department of Environment, Health, and } \\
\text { Natural Resources }\end{array}$ \\
\hline NOAA & National Oceanic and Atmospheric Administration (U.S. Department of Commerce) \\
\hline NPS & National Park Service (DOI) \\
\hline NS\&T & National Status and Trends Program (NOAA) \\
\hline Ohio EPA & Ohio Environmental Protection Agency \\
\hline ORSANCO & Ohio River Valley Water Sanitation Commission \\
\hline RAT & River Action Team (TVA) \\
\hline RBP's & Rapid Bioassessment Protocols (State Programs) \\
\hline TVA & Tennessee Valley Authority \\
\hline USDA & U.S. Department of Agriculture \\
\hline USEPA & U.S. Environmental Protection Agency \\
\hline USFS & U.S. Forest Service (USDA) \\
\hline USFWS & U.S. Fish and Wildlife Service (DOI) \\
\hline USGS & U.S. Geological Survey (DOI) \\
\hline
\end{tabular}


The following abbreviations are used in figures 1-7 of this report:

AHH

ANOVA

BI

CDF

CERCLA

DC

DDT

DNA

DTH

FY

GC/MS

GIS

GPS

IBI

ICI

MIWb

NASQAN

NATT

NAWQMN

NODC

NPDES

NPMP

PCB's

PVC

QA/QC

QCTV

QHEI

QMH

RCRA

RF3

RTH

SV

TMDL

VDC

WLA

WWTP
Aryl hydrocarbon hydroxylase

Analysis of Variance

Biotic index

Cumulative Distribution Function

Comprehensive Environmental Response, Compensation and Liabilities Act

Direct current

Dichlorodiphenyltrichloroethane

Deoxyribose nucleic acid

Depositional-targeted habitat (NAWQA)

Fiscal year

Gas chromatography/mass spectrometry

Geographic Information System

Global Positioning System

Index of Biotic Integrity

Invertebrate Community Index

Modified Index of Well-being

National Stream Quality Accounting Network (USGS)

National Target Taxa (NAWQA)

National Ambient Water Quality Monitoring Network

National Oceanographic Data Center

National Pollutant Discharge Elimination System

National Pollutant Monitoring Program

Polychlorinated biphenyls

Polyvinyl chloride

Quality assurance/quality control

Qualitative community tolerance value

Qualitative Habitat Evaluation Index

Qualitative multihabitat (NAWQA)

Resource Conservation and Recovery Act

River Reach File, Version 3

Richest-targeted habitat (NAWQA)

Screening Value

Total maximum daily load

Volts DC (direct current)

Waste load allocation

Wastewater treatment plant 


\title{
Report of the Interagency Biological Methods Workshop
}

\author{
Edited by Martin E. Gurtz and Thomas A. Muir
}

\section{ABSTRACT}

The U.S. Geological Survey hosted the Interagency Biological Methods Workshop in Reston, Virginia, during June 22-23, 1993. The purposes of the workshop were to (1) promote better communication among Federal agencies that are using or developing biological methods in water-quality assessment programs for streams and rivers, and (2) facilitate the sharing of data and interagency collaboration. The workshop was attended by 45 biologists representing numerous Federal agencies and programs, and a few regional and State programs that were selected to provide additional perspectives. The focus of the workshop was community assessment methods for fish, invertebrates, and algae; physical habitat characterization; and chemical analyses of biological tissues. Charts comparing program objectives, design features, and sampling methods were compiled from materials that were provided by participating agencies prior to the workshop and formed the basis for small workgroup discussions. Participants noted that differences in methods among programs were often necessitated by differences in program objectives. However, participants agreed that where programs have identified similar data needs, the use of common methods is beneficial. Opportunities discussed for improving data compatibility and information sharing included (1) modifying existing methods, (2) adding parameters, (3) improving access to data through shared databases (potentially with common database structures), and (4) future collaborative efforts that range from research on selected protocol questions to followup meetings and continued discussions.

\section{INTRODUCTION}

Development of water-quality assessment programs having regional or national scope requires the use of consistent methods wherever possible to facilitate comparative analyses of spatial and temporal patterns. Although biological methods have been used in water-quality assessments for many years, only recently has there been an effort made to develop and implement consistent methods on a national scale in Federal programs. The U.S. Geological Survey (USGS) has developed a series of biological sampling protocols for use in its National Water-Quality Assessment (NAWQA) Program. These protocols are designed to provide national consistency in collecting samples of biological communities, characterizing physical habitat conditions at several spatial scales (basin, segment, and reach), and collecting samples of biological tissues for chemical analyses of organic compounds and trace elements. In an effort to promote better communication among Federal agencies that are using or developing related methods for use in other programs of regional or national scope, and to facilitate the sharing of data and interagency collaboration, the USGS hosted the Interagency Biological Methods Workshop in Reston, Virginia, during June 22-23, 1993. This workshop also supported activities of the Intergovemmental Task Force on Monitoring Water Quality (ITFM) and the developing needs of the National Biological Survey (NBS). The workshop was attended by 45 biologists representing numerous Federal agencies and programs, as well as several regional and State programs selected to provide some perspectives from non-Federal biological monitoring programs (Appendix I). 
The objectives of the workshop were to

1. Discuss protocols for collecting and processing biological samples as part of water-quality or other resourceassessment activities (active or planned) having regional or national focus,

2. Compare sampling methods in the context of individual program objectives in order to highlight similarities and differences among programs, and

3. Increase the potential for data compatibility and interagency collaboration.

The scope of the workshop included biological water-quality assessment methods for streams and rivers, with emphasis on methods being used by NAWQA and corresponding methods of other programs. Thus, the focus was on community assessment methods for fish, invertebrates, and algae; physical habitat characterization; and chemical analyses of biological tissues. Other biological methods (such as toxicity studies or biomarkers) and other types of water bodies (such as lakes or estuaries) were generally considered to be beyond the scope of the workshop. However, such topics were included in the discussions where appropriate--for example, in comparisons of programs for tissue studies. Participants were, for the most part, scientists knowledgeable about the technical details of the protocols used by their respective agencies.

The workshop was structured around a series of workgroup discussions that focused on methods in each of the principal categories--fish, invertebrates, algae, habitat, and tissues (Appendix II). Following an overview of the NAWQA Program and its biological components, plenary talks were given on the role of biological monitoring in State programs and the activities of the biological indicators group within ITFM. The remainder of the 2-day meeting was spent predominantly in small-group discussions (Appendix III), focusing on each category of protocol, narrative summaries of which are included in this document.

Prior to the workshop, participating agencies were provided a series of protocol charts that presented details of the objectives, design, and methods used in the NAWQA Program, with blank space provided for entering comparable information for other programs. Each agency or program was requested to return the completed charts, and any appropriate protocols, or to bring them to the workshop. Copies of charts and protocols were distributed to participants at the beginning of the workshop and formed the basis for much of the discussion. Comparison charts (figs. 1-7 located at the back of this report) were compiled from materials provided by the participating agencies. To minimize duplication of information for programs rcpresented by more than one component, general program objectives and design features are presented for several programs in figure 1. The NBS's Biomonitoring of Environmental Status and Trends (BEST) Program is included only in figure 1 because specific protocols are still in the development stage. (This program was part of the U.S. Fish and Wildlife Service (USFWS) at the time of the workshop.) Comparison charts for fish (fig. 2), invertebrates (fig. 3), algae (fig. 4), habitat (figs. 5 and 6), and tissues (fig. 7) include programs that provided the required information.

The primary focus of the workshop was on national-scale Federal programs because of the particular challenges associated with comparability of methods across such a large spatial scale; most, but not all, major agencies and programs using related methods were represented in the workshop. Because many regional, State, and local organizations have long histories of conducting biological assessments, representatives of several regional and State programs were invited to participate in the workshop. An overview of rapid bioassessment protocols (RBP's) was provided as applicable to the majority of States. Completed protocol charts also were provided by the Ohio Environmental Protection Agency (Ohio EPA) for fish, invertebrates, and habitat, and by the Ohio River Valley Water Sanitation Commission (ORSANCO) for tissues; this information is included in the comparison charts. Several other agencies, such as the Tennessee Valley Authority (TVA) and the North Carolina Department of Environment, Health, and Natural Resources (NC-DEHNR), were represented in one or more workgroups and provided materials for discussion, but are not represented in the comparison charts.

\section{Purpose and Scope}

The purpose of this report is to summarize discussions that took place at the Interagency 
Biological Methods Workshop and facilitate communication and collaboration among Federal agencies using biological methods in water-quality assessments. A series of charts is provided that compares protocols in use or under development by the participating agencies. It is expected that this report will be a springboard for further discussion and future interagency collaborative efforts.

\section{Acknowledgments}

The success of this workshop was due in large part to the high degree of interest and support provided by all of the participating agencies. The editors particularly thank Elizabeth Fellows of the U.S. Environmental Protection Agency (USEPA) for encouraging the leaders of the NAWQA Program to take the initiative in hosting the workshop. Members of the interagency committee who met April 29, 1993, to plan the workshop included the following: Bill Breed of the U.S. Department of Energy, Wade Bryant of the USFWS, Tony Cappelucci of the Bureau of Reclamation (BOR), Chris Faulkner of the USEPA Office of Water, Marty Gurtz of the USGS, Ron Huntsinger of the Bureau of Land Management (BLM), Ron Preston of the USEPA Region III, Gary Rosenlieb of the National Park Service (NPS), Steve Sorenson of the USGS, and Rick Swanson of the BLM. Tom Muir also participated in the planning session, representing both the USFWS and the Implementation Committee of the NBS. The editors also thank Chris Yoder of the Ohio EPA, who gave a presentation at the workshop on the activities of ITFM related to biological indicators; Mike Barbour of Tetra Tech, Inc., who gave a presentation on biological monitoring activities of State agency programs; and Dallas Peck (then Director) of the USGS, who made the opening remarks at the workshop.

The protocol-comparison charts represent considerable effort on the parts of the participating agencies to provide summaries of program features and sampling methods in a consistent format. Contributors to those parts of this report include:

\section{Component}

Objectives/
Design Features

Fish

Invertebrates
Program (Agency)

\author{
NAWQA (USGS) \\ EMAP (USEPA) \\ RBP's (State Programs) \\ BEST (NBS) \\ Ohio EPA
}

NAWQA (USGS)

EMAP (USEPA)

RBP's (State Programs)

Ohio EPA
NAWQA (USGS)
EMAP (USEPA)
BLM/USFS
RBP's (State Programs)
Ohio EPA
Algae
NAWQA (USGS)
EMAP (USEPA)
Habitat

\section{Contributor}

\author{
Marty Gurtz \\ Steve Paulsen \\ Mike Barbour \\ Chris Schmitt \\ Chris Yoder
}

Mike Meador

Frank McCormick

Mike Barbour

Chris Yoder

\section{Tom Cuffney \\ Brian Hill \\ Mark Vinson \\ Mike Barbour \\ Chris Yoder}

\section{Stephen Porter \\ Brian Hill}

Cliff Hupp, Mike Meador

Phil Kaufmann

Mike Barbour

Chris Yoder 
Component

Tissues
Program (Agency)

NAWQA (USGS)

EMAP (USEPA)

Fish Contamination

Program (USEPA)

National Study of Chemical

Residues in Fish (USEPA)

National Contaminant Bio-

monitoring Program (NBS)

National Status and

Trends Program (NOAA)

ORSANCO

\section{Contributor}

Kent Crawford

Roger Yeardly

Skip Houseknecht

Ryan Childs

Chris Schmitt

Adriana Cantillo

Jerry Schulte
These contributors--except for Steve Paulsen, Phil Kaufmann, Roger Yeardly, and Jerry Schulte--were participants in the workshop.

\section{REPORT OF FISH WORKGROUP}

\section{by Michael R. Meador}

The fish workgroup was attended by Mike Meador (facilitator), USGS; Frank McCormick, (recorder/reporter), USEPA; Ron Preston, USEPA; Mike Rexrode, USEPA; Charlie Saylor, TVA; Terry Short, USGS; Chris Yoder, Ohio EPA; and Steve Zylstra, representing the BEST program of the USFWS (now NBS). Written protocols for sampling activities as part of NAWQA, EMAP, and Ohio EPA were contributed. A general discussion of sampling procedures conducted by TVA also was presented.

Discussion of the expectations of the workgroup revealed that the participants hoped to achieve a better understanding of how different programs conduct their respective sampling activities and the "why" behind decision-making. There was unanimous agreement that tremendous potential for cooperation and collaboration exists among the programs represented, and that these need to occur at the technical level. The goals of the workgroup were to (1) compare and contrast current protocols for sampling fish community structure, (2) complete a comparison chart of the protocol methods represented, (3) establish a working relationship for continued interagency cooperation, and (4) discuss opportunities for future research and collaboration. In order to accomplish goals (1) and (2), the similarities and differences among agency protocols (fig. 2) were examined.

\section{Similarities}

The USGS, USEPA, Ohio EPA, and TVA are currently involved in programs that describe fish community structure based on a representative sample of the fish community. In these programs, fish community structure is assessed by sampling all habitats within the selected stream reach, which is identified based on the geomorphology of the stream. Stream reach lengths range from a minimum of 150 meters (m) to a maximum of $500 \mathrm{~m}$. Sampling seasons vary but depend on specific sampling objectives and are related to ideal flow conditions; high flows and abnormal turbidity are avoided. Fish samples are collected in all programs by conducting at least one pass using a pulsed-DC electrofishing unit during daylight hours. The Ohio EPA and NAWQA Program recognize that night sampling of some rivers may be more effective than day sampling, especially in larger rivers; Ohio EPA conducts night sampling in the Ohio River. The Ohio EPA and NAWQA protocols recommend a minimum reach length of $500 \mathrm{~m}$ for nonwadeable sites. During electrofishing, wadeable sites are generally fished in an upstream direction, whereas nonwadeable sites are generally fished in a downstream direction.

All fish are identified to species in the field when possible, and examined for anomalies; some or all fish are measured. It was agreed that only ichthyologists should identify fish collected in the programs; however, there are no accepted criteria for establishing the credentials of an ichthyologist to make taxonomic identifications. This difficulty seems common to all programs. 
Specimens are retained for laboratory identification and (or) vouchers by fixing them in 10percent buffered formalin for later storage in alcohol. At minimum, data analysis consists of providing species richness and relative abundance information. In all programs, consideration is being given to the use of multimetric indices and multivariate analytical procedures depending upon objectives.

\section{Differences}

The only programs represented that include sampling of fish communities in nonwadeable streams were the Ohio EPA and NAWQA programs. The Environmental Monitoring and Assessment Program (EMAP) determines reach lengths in wadeable streams based on about 40 times the channel width. However, because EMAP protocols are designed for wadeable streams only, this channel width determination results in reach lengths that are within the $150-\mathrm{m}$ to $500-\mathrm{m}$ range for wadeable streams that is common to all programs. The Ohio EPA's method consists of two passes through a sampling reach, using electrofishing gear. NAWQA, EMAP, and TVA conduct multiplegear sampling using a combination of electrofishing and seining. However, NAWQA conducts electrofishing using two passes through a sampling reach; EMAP conducts electrofishing using one pass through a reach; and the number of passes conducted by TVA varies depending upon the number of fish and habitat types.

The participants generally felt that the differences in fish sample collection methods among programs were relatively minor and would not affect the ability to compare data among programs. None of the programs is designed to determine estimates of populations. Therefore, no program is designed to sample all individuals, and some rare and possibly some "canary" species (for example, highly sensitive species, or species that are indicative of a specific environmental condition) can be missed.

There was considerable discussion regarding the types of ancillary data that can contribute to the understanding of fish community structure as it relates to water quality. Ancillary data include information on length, weight, and external anomalies. The group agreed that such data are generally important, particularly in situations where species richness is naturally low.

\section{Opportunities for Collaboration and Research}

The participants emphasized the need to work closely with the USFWS (and State biologists) on endangered species issues as they relate to sampling efforts. Collaborative sampling efforts could help to reduce concerns regarding the effects of sampling activities on endangered species. Some discussion also focused on animal rights issues and fish sampling activities; all protocols are being examined regarding these issues.

Some discussion was generated regarding a common electronic database; however, there was not sufficient time to pursue this topic in detail. All agreed that efforts should be made to make the data broadly available on electronic media.

The use of relative abundance data for fish in relation to environmental conditions has grown in acceptance among the scientific community. All agreed that data from the programs must be reported not only internally, but through peer-reviewed scientific journals as well. However, there is still an indication that managers and policy makers lack an understanding of the use of such data analyses. It is hoped that the efforts of all programs will help advance the acceptance of such data analyses by the nonscientific community.

Opportunities for collaboration include joint coordination of workshops or symposia to address issues such as the need to identify qualified ichthyologists, field and laboratory quality assurance/ quality control, and the use of museums in archiving material from water-quality assessment programs. Pilot projects also provide opportunities to evaluate field approaches of the participating programs, as well as opportunities to examine data collected by the various agencies.

\section{REPORT OF INVERTEBRATES WORKGROUP}

\section{by Thomas F. Cuffney}

The invertebrates workgroup consisted of Tom Cuffney (facilitator/reporter), USGS; Marc Sylvester (recorder), USGS; Steve Ahlstedt, TVA; Ted Angradi, U.S. Forest Service (USFS); Marjorie Coombs, USEPA; Wayne Davis, USEPA; Chris Faulkner, USEPA; Brian Hill, USEPA; Roy Irwin, NPS; 
Dave Lenat, NC-DEHNR; Mark Nelson, BOR; and Mark Vinson, BLM.

Printed materials distributed to workgroup participants included descriptions of the following biomonitoring programs or activities of Federal agencies: NAWQA (USGS), EMAP and Rapid Bioassessment Protocols (RBP's) (USEPA), National Aquatic Monitoring Center (BLM/USFS), Biotic Condition Index protocol (USFS), and TVA's River Action Team (RAT) reconnaissance methods. Other written materials describing State programs of Ohio EPA, NC-DEHNR, and Kansas Department of Wildlife and Parks, and several volunteer streammonitoring programs (including Streamside Bioassessment--Izaak Walton League of America, Intensive Stream Bioassessment--Maryland Save Our Streams, and the River Watch Network) also were distributed. Protocol charts provided by NAWQA, EMAP, BLM/USFS, State programs (RBP's), and Ohio EPA are included in the comparison chart (fig. 3).

The session began with participants providing brief overviews of their biomonitoring programs, including NAWQA, EMAP, RBP's, RAT, North Carolina's stream-monitoring program, and the BLM/ USFS stream-biomonitoring programs. Dave Lenat presented some preliminary results from a collaborative study that investigated the comparability of benthic invertebrate-based water-quality assessment techniques used by several State and Federal agencies. Discussions then centered on similarities and differences among the programs, issues of common interest, and data comparability among programs. Principal discussion points included issues related to program objectives, reference sites, gear type (including mesh size), sampling designs, metrics, taxonomic resolution, sampling season, appropriate effort for objectives, and subsampling (100- and 300organism counts). Because of time constraints, discussions emphasized mesh size, identification of midges (Chironomidae), reference sites, and subsampling.

\section{Similarities}

All invertebrate biomonitoring programs discussed by the workgroup have a similar objective-to provide an accurate assessment of the structure of the benthic invertebrate community that has relevance to water-quality conditions. Programs are oriented toward documenting the status of invertebrate communities, determining trends (spatial and temporal) in community condition, and establishing cause-and-effect relations. Other major areas of similarity include the following:

1. All programs integrate physical, chemical, and biological approaches to some extent.

2. Sampling is generally focused within a defined length of stream (sampling reach) associated with a sampling site. The size of the sampling reach and the criteria for establishing the sampling reach vary among programs.

3. Sampling within the sampling reach typically involves single-habitat sampling (usually a riffle) supplemented with a composite sample collected from multiple habitats within the reach.

4. All programs use multimetric approaches to data analysis, although some also use multivariate techniques.

5. Reference sites are important for data comparisons and interpretations in all programs, although the dependence on reference sites varies among programs.

\section{Differences}

The various biomonitoring programs differ in the size of mesh used in sampler netting. USEPA uses 595-micron $(\mu \mathrm{m})$ mesh for EMAP and recommends it for use in RBP's, though specific mesh requirements are not included in the RBP's. Mesh sizes of $425 \mu \mathrm{m}$ and $210 \mu \mathrm{m}$ are used by NAWQA; the BLM/USFS program uses $280-\mu \mathrm{m}$ mesh, and the TVA programs use 900 - to $1,000-\mu \mathrm{m}$ mesh. The consensus of the group was that any mesh size from 210 to $1,000 \mu \mathrm{m}$ could be (and has been) successfully used for waterquality assessment. In theory, the smaller the mesh size the more complete the representation of the community. However, this theoretical consideration must be balanced with the drawbacks associated with smaller mesh size: sampler backwash, large sample volumes, increased sample-processing costs, and increased numbers of partially identified small organisms. A mesh size of 300 to $600 \mu \mathrm{m}$ was offered as a good operational range for community 
assessments. However, the choice of mesh size needs to be determined by the objectives of the individual program and its budget and should include considerations of available historical data and the taxonomic groups deemed important to the interpretation of water-quality conditions. For example, if the program needs to represent smaller invertebrate groups, such as the chironomids, then a smaller mesh size is appropriate. Programs that focus on "EPT" taxa (Ephemeroptera, Plecoptera,

Trichoptera) may prefer a larger mesh size.

Most programs select sampling locations on the basis of anticipated effects (point source or desired combination of environmental conditions). EMAP is unique in that it randomly selects sampling sites according to a national sampling grid. Differences in selection of sampling sites reflect the differences in objectives of each monitoring program. For example, some monitoring programs (RBP's and RAT) focus on rapidly identifying sites with degraded water-quality conditions and emphasize sampling large numbers of sites, quickly and inexpensively, to identify relatively large changes in water quality. Other programs focus on relating physical and chemical water-quality changes to biological changes (NAWQA), or to assessing water-quality conditions over broad geographic areas (EMAP), and require different siteselection procedures, sampling equipment, sampleprocessing strategies, and data-analysis procedures to support their objectives.

Programs differ in the degree of sample processing (field picking and subsampling) used to determine community structure. EMAP and NAWQA process samples with the intent of achieving a high level of taxonomic resolution (usually identification to lowest practicable taxon) and processing at least onefourth of the entire sample. RBP's, TVA, and BLM/ USFS typically base processing on the removal of a minimum specified number of organisms $(100,200$, or 300) from the sample. Identifications for RBP's may be at the lowest practicable taxon or at a higher level depending upon the level of RBP's used. TVA and RBP's procedures also can involve field picking of samples, whereas EMAP, NAWQA, and BLM/USFS depend upon picking of invertebrates in the laboratory. It was apparent from some of the experiences of the workshop participants that employing 100 - or 300 count field picks expedited sample processing considerably but missed substantial numbers and varieties of small invertebrates, particularly small chironomids and oligochaetes. Preliminary analyses of NAWQA Program pilot-study samples also indicated that 100 - or 300 -count subsamples of invertebrates would have lead to significant underestimation of benthic invertebrate community composition and richness. However, 100- and 300-count subsamples have been used with great success in the RBP's and other State and Federal programs. Thus, decisions on sample-processing techniques should be based on the objectives of the various programs.

Programs also differ in whether taxonomic identifications include a detailed (genus or species) assessment of the chironomid community. For example, most current bioassessment metrics focus on EPT taxa and have relatively little emphasis on chironomid identifications made beyond family level. The major problems are the increased sampling effort and costs associated with collecting representative samples of midges, and identifying and quantifying midges. These problems must be balanced with the realization that in many instances the family Chironomidae constitutes more than half of the species at a site. Further, chironomid taxonomy has improved to the point that most individuals can be readily identified at least to genus, and chironomids are becoming increasingly diagnostic (increase information and differentiation) in bioassessment programs that include identifications at the genus or species level. The inclusion of chironomid identifications beyond family is largely dependent upon the program's objectives. Identification to family level is probably adequate for screening or impact assessment studies. However, for diagnostic studies of source, cause and effect, and trends, identification of chironomids to genus or species is probably preferable.

\section{Opportunities for Collaboration and Research}

The group discussed the possibility of establishing a single approach to benthic-invertebrate biomonitoring that could be used for all agencies and programs, but the majority of the group felt that each program must use sampling methods and design that support its objectives and fit within budget constraints. It is apparent that the programs represented here constitute a continuum in effort that ranges from quick screenings intended to rapidly and inexpensively identify significant water-quality problems (the "scratch and sniff" approach as described by Steve 
Ahlstedt) to detailed cause-and-effect studies that require integrated physical, chemical, and biological assessments. Consequently, it would be very difficult to develop a unified set of methods that could be readily adapted to the multiple objectives of all existing State and Federal water-quality assessment programs.

Discussions on data comparability focused on two issues: (1) integrating data sets and (2) comparing assessment results. Because of the different objectives and techniques employed by the various State and Federal programs, the group agreed that combining data sets should be done very cautiously. This is particularly true when combining quantitative information (densities or relative abundances). However, qualitative data, particularly the presence of a taxon at a site, presented fewer problems provided that there was sufficient confidence (quality assurance) in the identification. Unfortunately, data on the absence of a taxon are much more sensitive to differences in sampling design and need to be interpreted cautiously. There was basic agreement that the water-quality assessments produced by different programs could be fairly easily used among the various programs, particularly as a guide to the selection of sites. Additional interagency efforts to compare and contrast assessment results, such as one conducted by NC-DEHNR in January 1993, are needed to fully define data comparability issues.

A potential area for collaboration is in establishing reference sites and determining reference conditions. All programs recognized the value of reference sites and their use in ranking biological conditions among sites. Key issues related to the use of reference sites are (1) the availability of reference sites for certain types of streams (particularly, larger rivers), (2) criteria for selecting reference sites and matching them with assessment sites, and (3) the evaluation of the natural temporal (seasonal and annual) variability within, and spatial variability among, reference sites.

The efforts of the various State and Federal programs can and should be highly complementary, despite their apparent differences. Mutual benefits will accrue from continued communication and collaboration on methods, site selection, qualityassurance and quality-control techniques, databases, assessment metrics, taxonomy, reference site selection, and assessment of variability related to sampling method, season, year, site, and metric. Interagency efforts, such as the development of an interagency taxonomic database (National Oceanic and
Atmospheric Administration (NOAA), USEPA, and USGS) and the comparison of field methods, are important steps to fostering the exchange of consistent high-quality data among State and Federal agencies.

\section{REPORT OF ALGAE WORKGROUP}

\section{by Stephen D. Porter}

The algae workgroup was attended by Stephen Porter (facilitator/reporter), USGS; Brian Hill (recorder), USEPA; Steve Sorenson, USGS; and Marty Gurtz, USGS. Other informal discussions held with Chris Faulkner (USEPA), Ted Angradi (USFS), Mark Nelson (BOR), and Chris Yoder (Ohio EPA) during the course of the workshop contributed additional information concerning existing or proposed uses of algae for environmental assessments. The objectives of the workgroup meeting were to (1) compare and discuss current protocols and methods for using benthic algae (periphyton) for regional and national assessments of water quality, (2) compare and contrast program objectives and approaches relative to site selection, sampling strategies, methods of laboratory analyses, and data interpretation, (3) determine compatible uses of interagency algal data, (4) establish a working relationship for continued interagency cooperation and information exchange, and (5) discuss opportunities for future research and collaboration. Regional- or national-scale programs presently involved in sampling algal communities for waterquality assessments include only NAWQA and EMAP (fig. 4).

\section{Similarities}

The NAWQA and EMAP programs use similar approaches to collecting and processing algal samples, and analyzing data. Following are the similarities in algal protocols between these two programs:

1. Benthic algal samples are collected from natural substrates in conjunction with the collection of invertebrate samples.

2. Samples are collected from erosional and depositional habitats using similar (or compatible) methods; however, the habitats are targeted in the NAWQA program and randomized in the EMAP program. 
3. Areas of benthic substrate sampled according to each protocol are similar, although the composite area of each habitat sampled by EMAP varies with the relative abundance of erosional and depositional areas in the sampling reach.

4. In both programs, quantitative periphyton samples are analyzed for species composition and abundance, chlorophyll $\underline{\text { a }}$, and ash-free dry mass (although these analyses are a studyunit option for NAWQA, rather than a protocol requirement).

5. The same sample preservatives are used by both programs.

6. Both EMAP and NAWQA target sampling activities to be conducted during stable, low-flow hydrologic conditions, and similar (at least qualitatively) ancillary information is collected by both programs.

Brian Hill indicated that EMAP will consider adding qualitative multihabitat sampling of periphyton to its algal protocol, as well as adopting protocols similar to NAWQA for sampling epipsammic and epipelic microhabitats. If EMAP personnel record the predominant microhabitat sampled in erosional and depositional habitats, certain algal data (quantitative epilithic, epipsammic, and epipelic samples) should be compatible with NAWQA data. Qualitative multihabitat periphyton samples collected by certain State agencies (for example, Kentucky and Montana) appear to be compatible with NAWQA protocols for the purpose of documenting a list of algal taxa and estimating taxa richness. Other State agencies (for example, Ohio and North Carolina) are in the process of establishing procedures for sampling benthic algae and have expressed interest in the NAWQA algal protocol.

\section{Differences}

With the exception of NAWQA, EMAP, and State monitoring programs, most agencies have not incorporated algal sampling into environmental assessment programs except for the purposes of (1) monitoring phytoplankton chlorophyll a concentrations to evaluate eutrophication processes or taste-and-odor problems; (2) using periphyton (including aquatic mosses) to evaluate contaminant sources (for example, bioconcentration of metals (BOR) and acidification (USFS) from mine drainage, and numerous studies concerning effects of pointsource discharges (State agencies)); and (3) reconstruction of historical changes in the $\mathrm{pH}$ or trophic state of lakes by examining diatom-frustule assemblages from sediment cores (EMAP-Great Lakes).

The primary differences between NAWQA and EMAP algal protocols include differences in the selection of instream sampling habitats, methods of sample compositing, and relative emphasis on obtaining structural or process measures of the algal community to assess spatial variation. These issues correspond to differences in the statistical design criteria and approaches of NAWQA and EMAP. Other differences include sampling frequency (NAWQA samples once per year for 3 successive years, with multiple-reach replication, at intensive ecological assessment sites; EMAP samples once every 4 years, with 10-percent annual resampling of sites).

The EMAP protocol calls for routine determinations of chlorophyll a ash-free dry mass, alkaline/acid phosphatase, and benthic metabolism, whereas the NAWQA protocol lists determinations of chlorophyl and ash-free dry mass as study-unit options. Further, the EMAP protocol presently does not provide for qualitative sampling of periphyton, quantitative sampling of phytoplankton, or alternative methods for sampling periphyton when the prescribed sampling gear cannot be used effectively (for example, methods for sampling epiphytic and epidendric microhabitats and certain epilithic microhabitats such as gravel substrates).

Quantitative algal protocols for NAWQA and EMAP differ considerably from those used by other agencies. Although the use of artificial substrates by State agencies meets their objectives for water-quality monitoring purposes, algal data obtained by this method are not comparable with NAWQA or EMAP data from natural substrates. However, artificial substrates are listed as a study-unit option in the NAWQA protocol (for example, for synoptic or case studies); study units could benefit from State-agency data and collaboration in cases where the type of artificial substrate and length of exposure period can be standardized. Phytoplankton chlorophyll samples are routinely collected by a number of agencies to assess 
trophic conditions in lakes and reservoirs and to evaluate the effects of nutrient enrichment in large rivers. Quantitative phytoplankton samples (for analyses of chlorophyll and algal community structure) are listed as a study-unit option in the NAWQA algal protocol. However, the NAWQA data may not be directly comparable with data reported by other agencies because of differences in sample-collection methodology (width- and depth-integrated samples collected by the NAWQA program compared with subsurface or euphotic-zone samples collected by other agencies); these differences apply equally to waterchemistry data.

\section{Opportunities for Collaboration and Research}

Opportunities for future collaboration and research include (1) increased standardization of collection and analysis protocols within the constraints of specific program objectives and approaches, (2) field testing the comparability of sampling procedures, (3) interagency cooperation concerning the development and enhancement of taxonomic and autecological databases, (4) development of protocols for assessments of large rivers, and (5) sharing of compatible data to supplement interpretation and synthesis of factors that contribute to observed environmental conditions. Interagency collaboration can ensure that protocols are continually refined to maximize information content for evaluating environmental differences and change, and to enhance the transferability of data among agency programs with different objectives or approaches. The costs of compiling and maintaining large taxonomic databases (including associated physical and chemical data) could be shared among environmental-assessment agencies. Similar cost savings can accrue by developing a common mechanism for taxonomic verifications, voucher repositories, quality-assurance procedures (for example, evaluation of sample variance associated with specific field and laboratory procedures), and integrated databases.

Workgroup members agreed that all programs would benefit from identifying key scientists and other individuals involved with regional-scale biological assessments of water quality and establishing informal interagency networks and coordination mechanisms. This process could be enhanced by developing interagency training programs, conducting periodic workshops, and circulating protocols and experimental results. Improved standardization (or understanding of compatibility among protocol procedures) should increase the transferability of biological and waterchemistry data among programs. This understanding could potentially allow each program to interpret greater spatial resolution of factors that control water chemistry, habitat, and biological communities. For example, NAWQA could benefit from greater spatial characterization of reference reaches (particularly lower-order streams). and EMAP could benefit from information obtained from larger streams that integrate one or more human factors within distinct ecoregions. Collaboration with State agencies could enhance both programs and possibly lead to the development of opportunities for basic research and cooperative studies.

\section{REPORT OF HABITAT WORKGROUP}

\section{by Cliff R. Hupp}

This workgroup was composed of Cliff Hupp (facilitator), USGS; Mike Barbour (recorder/reporter), Tetra Tech, Inc.; George Gibson (reporter), USEPA; Susan Jackson, USEPA; Kerry Overton, USFS; Rick Swanson, BLM; Ron Parker, USEPA (one day); Stephen Porter, USGS (one day); and Dick Smythe, USFS (one day). The EMAP program was represented by the written comments provided by Phil Kaufmann (Oregon State University) prior to the meeting. The group established four goals for this meeting: (1) determine compatible uses of interagency habitat data, (2) discuss reasons for various elements in each protocol, (3) relate purpose/objective for conducting assessments to the methods used, and (4) establish a foundation for continued interagency cooperation and information exchange. For the most part all of these goals were attained, although there was insufficient time for detailed discussions of advantages and disadvantages of particular approaches. Participants now have a much clearer idea of the habitat programs in other agencies, which is a substantial achievement in itself.

The group listed several justifications for habitat descriptions that were common to all of the programs represented:

\section{Habitat description provides the} foundation for assessing and 
interpreting the status of the biological communities.

2. Habitat description is necessary for the characterization of fluvial geomorphic and vegetative conditions, which are highly important parameters regardless of instream biota.

3. Habitat description is necessary to document habitat or environmental impairment or degradation.

4. Habitat description is necessary to distinguish between habitat alteration and other forms of environmental degradation--for example toxins, nutrients, and sediment--that may be of interest where biota are used as environmental barometers.

In order to facilitate mutual understanding, a distinction in general objectives of the programs was made early in the discussions. A habilat characterization was defined as an attempt to objectively describe the composition and structure of the physical and vegetative environment. A habitat assessment further included judgments of the quality of the habitat for support of the biotic feature of interest. No program objective was strictly one or the other, but some clearly leaned toward assessment or characterization. The NAWQA Program is oriented strongly toward characterization, whereas State programs are focused toward assessment. EMAP, USFS, BLM, and BEST have a nearly equal split in general objectives between characterization and assessment. Thus, most agencies used habitat description to relate habitat to biota, to characterize the composition and structure of the local environment, to determine impaired habitats, and to distinguish habitat alterations from other perturbations that can affect instream biotic communities.

Other major points that were raised during the workgroup's discussion of program objectives included the following:

1. Reference sites were the cornerstones of most programs;

2. Objectives and questions drive the scale of the programs;

3. What constitutes "good" habitat can be defined; and

4. As objectives tend to converge, the various protocols should become more similar.
Topics 1, 2, and 4 require further interagency discussion if the programs are to minimize duplication of effort and improve opportunities for cooperation and sharing of mutually useful information and data. All felt it was imperative to continue such discussions, especially considering current executive and departmental objectives.

\section{Similarities}

The protocol-comparison chart (fig. 5) compares approaches for four programs that completed the matrix prior to the workshop. Discussions also included BEST, as well as monitoring activities in the USFS and BLM. Although no two programs were identical, NAWQA, BEST, and EMAP are reach-based and share, in a general way, many approaches. USFS and BLM are very similar to each other but are both non-reach based systems. Nearly half of the discussion focused on delineating individual elements of the various protocols, including aspects of the riparian zone (fig. 6). The similarities substantially exceeded the differences in both parameters and measurement tools.

\section{Differences}

Several significant differences among programs were identified by the workgroup. Future discussions and probable protocol alteration will be necessary for data to be fully compatible among agencies for the following protocol elements:

1. Light measurement--All agencies would like to see improvement on quantification of this parameter. Some agencies use a canopy densiometer or direct light measurement at specific times or light conditions; nothing has been standardized.

2. Measurement of canopy cover/density-As with light measurement, the group felt that using a canopy densiometer would help quantify the light parameter beyond canopy opening. All felt the solar pathfinder has some advantages but is not yet standard.

3. Bank angle determination--Some agencies measure bank angle as degrees from vertical, others as degrees from horizontal. 


\section{Velocity and discharge measurement--}

The various agencies noted a wide range of effort in obtaining data for these parameters. Most programs incorporate some measurements of current velocity, although they vary in the methods used and in the procedures for determining locations for the measurements. Only the USGS routinely measures stream discharge continuously at fixed sites; this approach was recognized as being desirable, but participants doubted whether continuous discharge records were achievable for all important sites for other agencies nationwide.

5. Reach definition/transect location--No two agencies have exactly the same definition of reach or approach to delineation and sub-reach sampling. This is an area that could use more interagency priority attention. However, the group found no insurmountable differences among the reach-based assessments that would seriously limit data exchange, although neither USFS nor BLM has a reach-based approach.

Approaches for describing the extent and character of the riparian zone also differed among agencies and programs. The group unanimously viewed the riparian zone as one of the most important aspects of stream assessments and noted that this zone has only recently received the attention deserved. The level of effort made to describe the extent and character of the riparian zone varies widely among agencies. The USFS and BLM have the most complete protocols for characterizing the riparian zone, spending as much effort there as on instream assessment. The USFS uses a longitudinal transect for visual estimates and a "greenline" riparian survey for quantitative data. The BLM also conducts visual estimates for the entire reach, with transects that yield quantitative information; additionally, BLM conducts intensive quantitative riparian surveys. NAWQA uses a plotless technique (point-quarter method) for quantifying riparian woody vegetation at all fixed sites, and permanent riparian plots at a subset of sites. EMAP uses both visual observations and quantitative transects of riparian vegetation. State programs typically do not quantify characteristics of riparian zones, but rely solely on visual estimation techniques.

\section{Opportunities for Collaboration and Research}

Opportunities and needs for future interagency collaboration include

1. Identifying key individuals, sharing staff directories, and regional coordination among programs, surveys, and field work;

2. Ensuring that all protocols are evolving documents so that programs remain flexible to converge in methods where appropriate;

3. Seeking standardization of parameters and sampling methods where possible;

4. Demonstrating common use of data among agencies;

5. Documenting and sharing exact methodology;

6. Identifying a minimum data set that is common to all programs at regional and national scales;

7. Developing a comparison of riparian classification systems among agencies; and

8. Developing interagency training, workshops, and information-transfer networks.

The group noted that the most immediate steps should include exchange of staff directories, resolution of methodology differences, identification of common reference sites, and evaluation of other habitat methods.

\section{REPORT OF TISSUES WORKGROUP}

\section{by Steven Goodbred and J. Kent Crawford}

Members of this workgroup included Kent Crawford (facilitator), USGS; Chris Schmitt (reporter), USFWS; Steve Goodbred (recorder), USFWS; Sarah Gerould, USGS; Ryan Childs, USEPA; Skip Houseknecht, USEPA; and Jim Lazorchak, USEPA. Adriana Cantillo, NOAA, and Candy Brassard, USEPA, each participated for one day only; Steve Sorenson, USGS, and Roy Irwin, NPS, also participated in a portion of the discussions. The workgroup defined the basic objective of the workshop 
as completion of the protocol-comparison chart (fig. 7). Presentations were made describing objectives, design, target organisms, analyte list, analytical methods, and quality assurance for the following programs: NAWQA, EMAP, BEST, National Study of Chemical Residues in Fish (USEPA), Fish Contamination Program (USEPA), National Status and Trends Program (NOAA), and National Contaminant Biomonitoring Program (USFWS; now NBS). These presentations continued into the second day of the workshop, and were followed by a general discussion.

\section{Similarities}

The degree of similarity among programs was highly dependent on program objectives, which generally could be categorized as follows: (1) human health, (2) water quality, and (3) ecological health. Programs that focus on human health issues emphasize the analysis of edible portions of biota (for example, fish fillets or soft tissues of mussels). Water-quality programs use biological tissues as a tool to assess the occurrence and distribution of contaminants that are bioavailable. Other programs assess ecological health through indicator species and an understanding of trophic transfer. Greatest similarities occurred among programs with similar objectives. Fish were included among target taxa for all programs, and there was substantial similarity among lists of target analytes.

\section{Differences}

Each tissue analysis program represented at the workshop specifies a list of target taxa for collection and analysis. Each program includes fish as a target group, but all three USEPA programs and ORSANCO target only fish. The NAWQA Program lists the Asiatic clam as the preferred target taxon for both trace elements and organic compounds; in addition to fish, aquatic insects and aquatic plants also are targeted for trace elements in NAWQA. NOAA's National Status and Trends Program targets mussels and oysters in the Mussel Watch Project, and fish in the Benthic Surveillance Project.

Selection of target analytes commonly followed the reasoning used by USEPA's National Study of Chemical Residues in Fish, in which three criteria were applied for selecting a contaminant:
1. How much of a contaminant is in the environment and what portion will bioaccumulate in biota and the food chain?

2. How persistent is this contaminant and what are its sources-- past, present, and future?

3. How toxic is it?

A notable difference among analyte lists of different programs is polychlorinated biphenyls (PCB's). Some agencies are analyzing only total PCB's; some are analyzing specific congeners (not always the same ones); and some are summing congener-specific PCB's to get a total concentration. Even with congener-specific PCB data, which are very expensive to obtain, the toxicologically significant congeners--the aryl hydrocarbon hydroxylase (AHH) inducers--are usually present in very small quantities that are masked in gas chromatography by the less toxic and more common PCB's. A unique tiered approach is being proposed by BEST, using total PCB concentrations as a screen and then doing a followup immunoassay analysis (using H4IIE, a continuous line of laboratory rat cells, which are exposed to contaminants and monitored for mutations or other responses) for samples with high total $\mathrm{PCB}$ concentrations to determine if toxicologically significant PCB congeners are present. This test is apparently cost effective and may be relevant for many lissue programs.

\section{Opportunities for Collaboration and Research}

The most important recommendation for future collaboration among agencies is that national, regional, and State laboratories become involved in NOAA's Quality Assurance (QA) Project for tissue. This Project consists of a series of interlaboratory comparison exercises wherein each laboratory analyzes a variety of tissue matrices (currently both inorganic and organic); however, the number of participating laboratories may be limited by the amount of tissue sample material available. Results from these "round-robin" exercises will enable comparison of tissue data among programs and agencies. At this point, the National Contaminant Biomonitoring Program (NCBP), BEST, and NAWQA Program will be participating in NOAA's QA Project. 
Compatibility and availability of tissue databases also were discussed. For example, USEPA's STORET database has been valuable in many ways but is still difficult to use. The BEST program is exploring the possibility of using USGS's National Water Information System database.

The workgroup concluded that improving compatibility of tissue data among programs requires answers to several critical research questions, including the following:

1. How are edible portions related to whole fish body burdens? What ancillary variables should be measured? If conversion factors can be developed, what degree of confidence do they have?

2. How important are interspecific differences in contaminant body burdens? Are there ecologically homologous species that are similar in their ability to accumulate and transfer contaminants? Are there differences in trophic transfers to humans as opposed to wildlife?

3. Can we identify levels of concern for contaminants that bioaccumulate in fish? The group felt that there is a substantial need for a comprehensive and thorough update of national wildlife contaminant criteria; the only published criteria were developed by the National Academy of Sciences/ National Academy of Engineering Committee on Water Quality Criteria more than 20 years ago (in 1972).

4. How can we optimize sampling effectiveness (maximize information return per dollar invested in sampling and analysis)? This can be achieved by optimizing compositing strategy, species selection, time of sampling, and ancillary variables.

The meeting ended with several participants discussing the possibility of a followup meeting to work on target analyte lists to make the various tissue programs more compatible. The session was successful in the exchange of protocols, compilation of information for the comparison chart, establishment of a dialogue, and identification of directions for future collaboration and research.

\section{SUMMARY}

\section{by Martin E. Gurtz and Thomas A. Muir}

The Interagency Biological Methods Workshop succeeded in its principal goal of promoting better communication among governmental organizations that use biological methods in water-resources programs. Participants freely exchanged information about existing and planned program activities and sampling protocols. Improving data comparability among programs can be accomplished only after first assessing differences and similarities and discussing the reasons for methods chosen by different programs. This workshop accomplished that important first step. This meeting and associated efforts are part of a larger process to consolidate protocols among Federal, State, local, and private agencies and organizations.

A consistent theme throughout the workshop was that differences in methods among programs largely occur because of differences in objectives of the individual programs. For example, programs represented in this workshop use different approaches to conducting tissue-analysis studies; depending on whether the objectives are driven by considerations for human health, water-quality assessment, or ecological health, the lists of target taxa (or target tissues within selected taxa) and target analytes vary substantially. Participants also noted some important similarities; EMAP and the NAWQA Program, for example, have converged on many aspects of sampling methods, including a stream-reach based approach for both biological sampling and habitat characterization. However, key differences in how reaches are selected and in how the sampling effort is distributed throughout the reach (for example, random transects as opposed to targeted habitats), are driven by basic design considerations of the programs and may influence the comparability of the data.

The consensus of the workshop participants was that the differences in objectives and sampling designs were appropriate and necessary, and that the programs represented were complementary rather than duplicative because the different approaches allow different questions to be addressed. Where programs have identified similar data needs, however, the use of common methods is mutually beneficial. Each workgroup was able to identify several opportunities for improving data compatibility and information sharing among programs. These opportunities could be 
categorized as (1) modifying existing methods, (2) adding parameters, (3) improving access to data through shared databases (potentially with common database structures), and (4) encouraging future collaborative efforts that range from research on selected protocol questions to followup meetings and continued discussions.

Most programs incorporate "reference," or "minimally impaired," conditions into the sampling design in some way, but programs differ in how those reference conditions are defined and whether reference comparisons need to be regional or site specific. Some participants felt that defining reference conditions might be an appropriate role for State agencies; such information is essential for the development of biological criteria by States and would be valuable information in support of numerous regional and national programs. A continuing dialogue among Federal and State programs would help to prioritize regional characteristics for which reference conditions need to be defined. Future partnerships among government agencies could lead to identification of types of data, and methods to be used, that represent a consistent common denominator among State and Federal programs--for example, in the characterization of reference conditions.

Compatibility of databases was another consistent theme among workgroup discussions.
Ongoing efforts through the Intergovernmental TaskForce on Monitoring Water Quality have begun the process of exchanging information about database and communication systems currently in use or being designed by Federal agencies. Participants in the workshop seemed unanimous in their view that these efforts deserve high priority.

Interagency discussions occur routinely among government biologists, through coincidental or planned exchanges at professional society meetings, participation on advisory panels, and collaboration involving informal comparative studies or formal interagency memoranda. Nevertheless, the Interagency Biological Methods Workshop provided a unique opportunity for biologists from a broad spectrum of agencies, with diverse missions and program objectives, to meet and exchange information about the programs they represent and the methods presently in use or under consideration. Participants agreed that the workshop was a successful forum for communication and improved understanding. The protocol charts in this report are expected to stimulate additional discussions among the workshop participants and other scientists who were not present at the workshop. We hope that this workshop report will provide a valuable framework for developing future interagency collaborative efforts. 


\section{COMPARISON CHARTS}

Following are figures 1-7, which provide comparison charts of program objectives of the various participating agencies in the Interagency Biological Methods Workshop, as well as protocol comparisons for fish, invertebrates, algae, habitat, and tissues. (Lists of abbreviations and units of measure used in figures 1-7 are on page VI and VII at the front of this report.) 


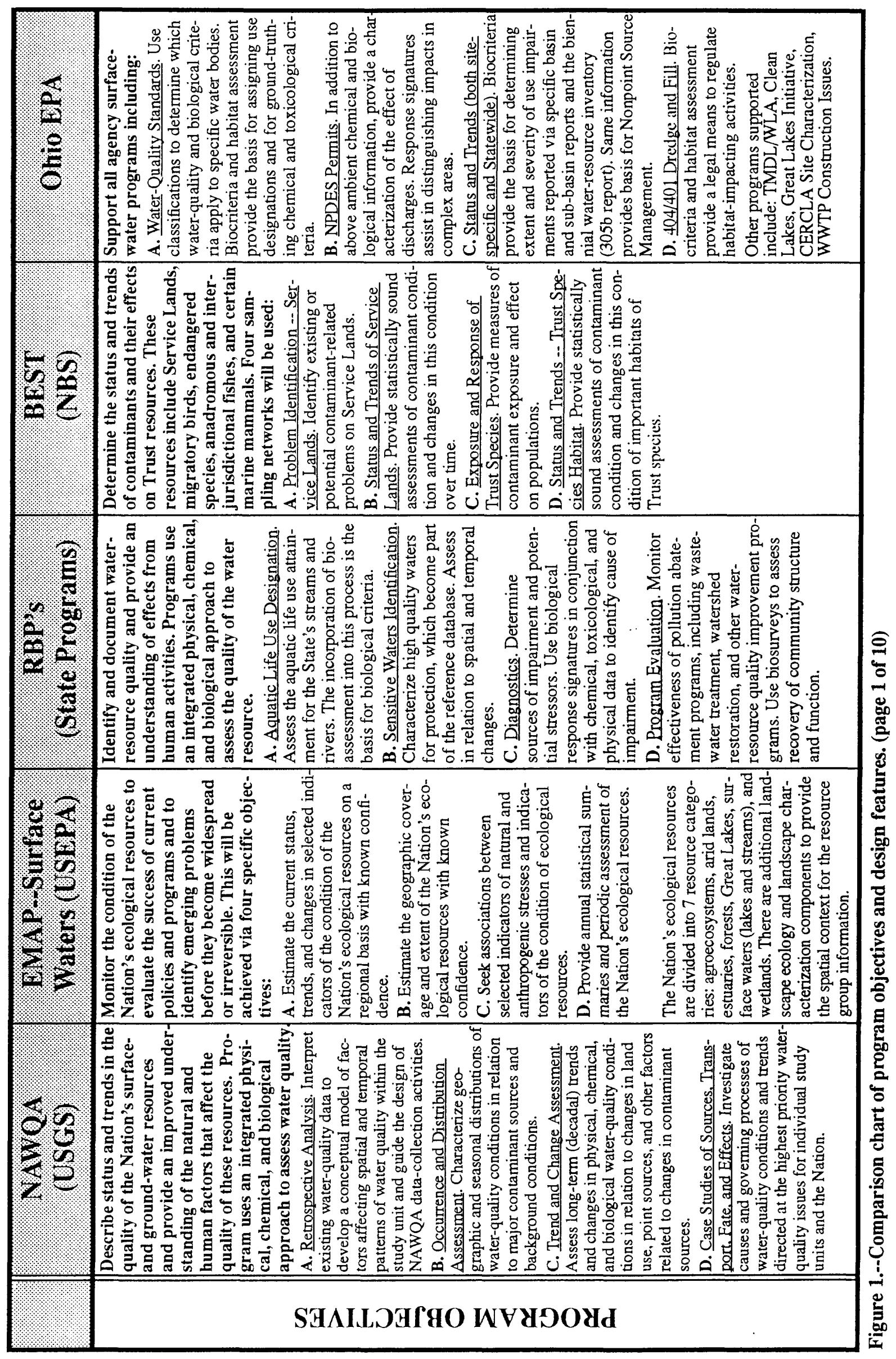




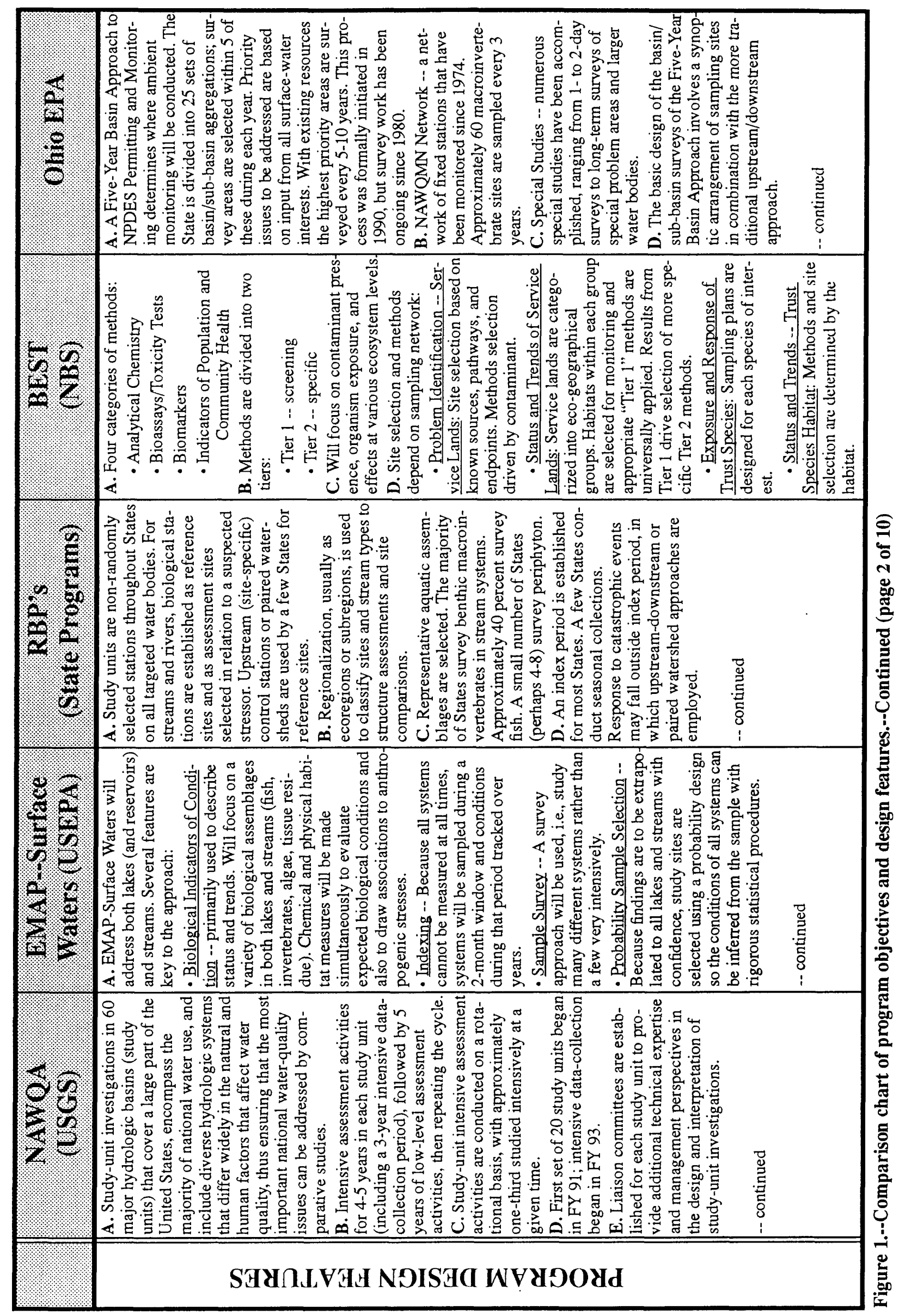




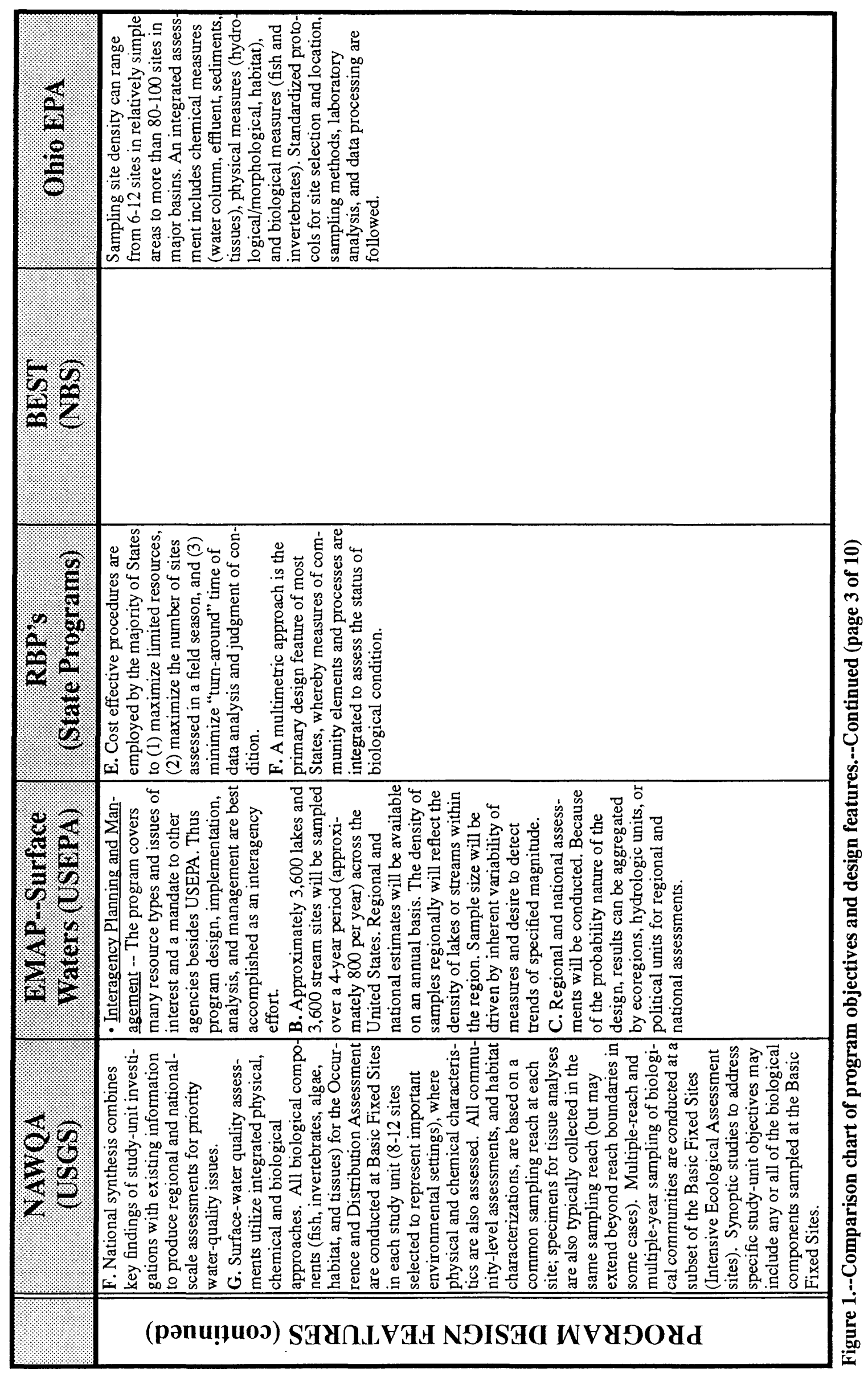




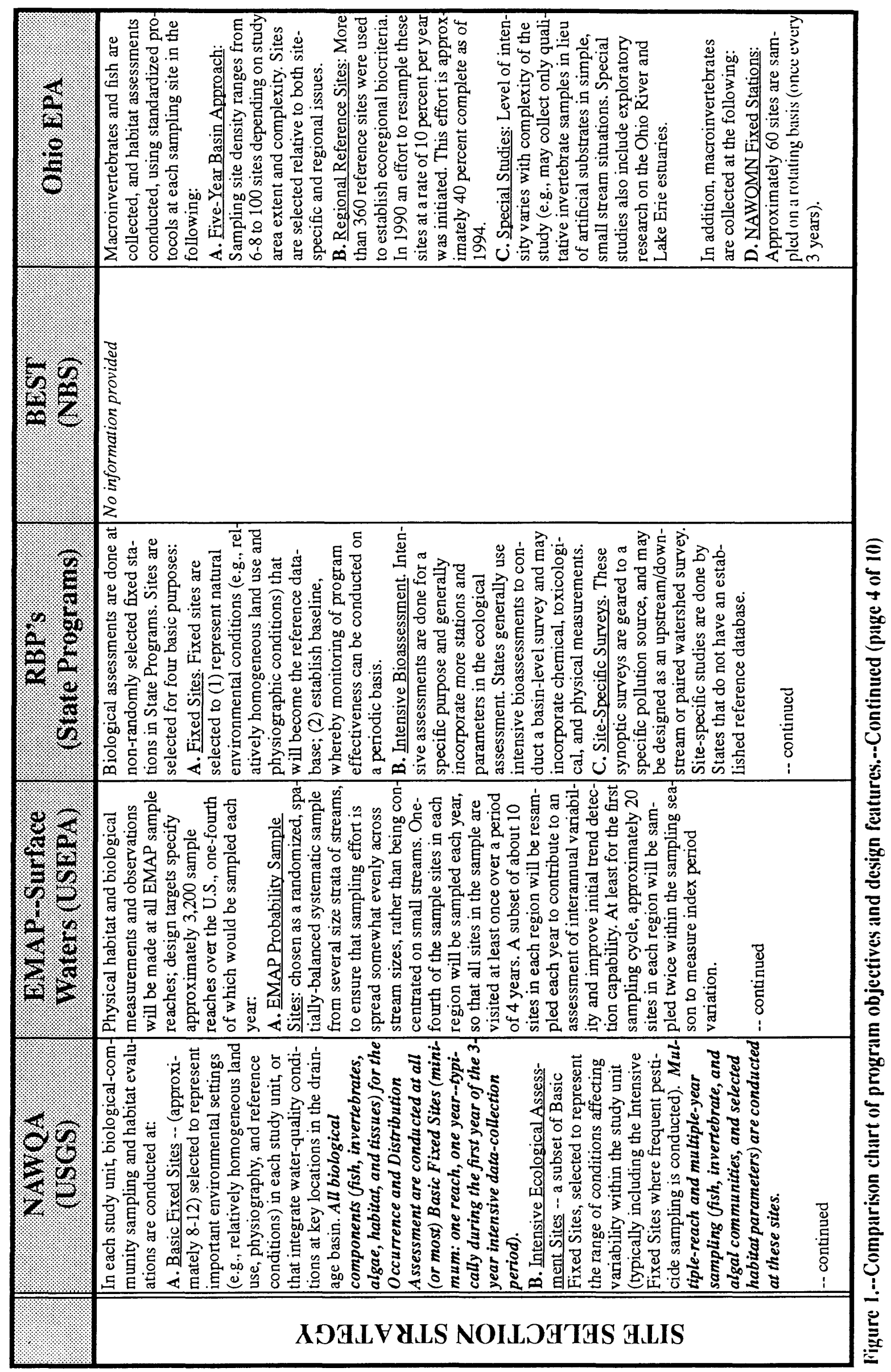




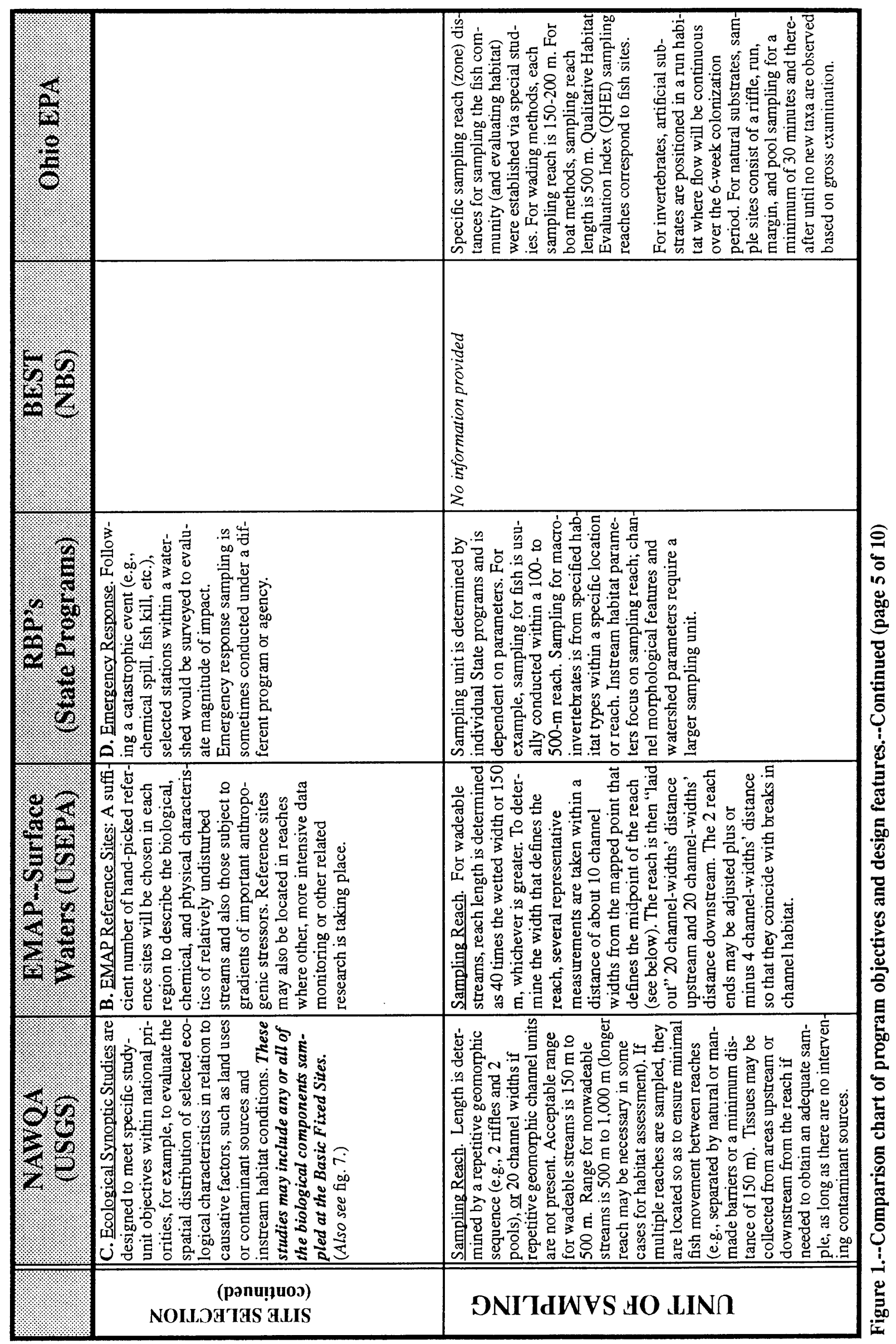




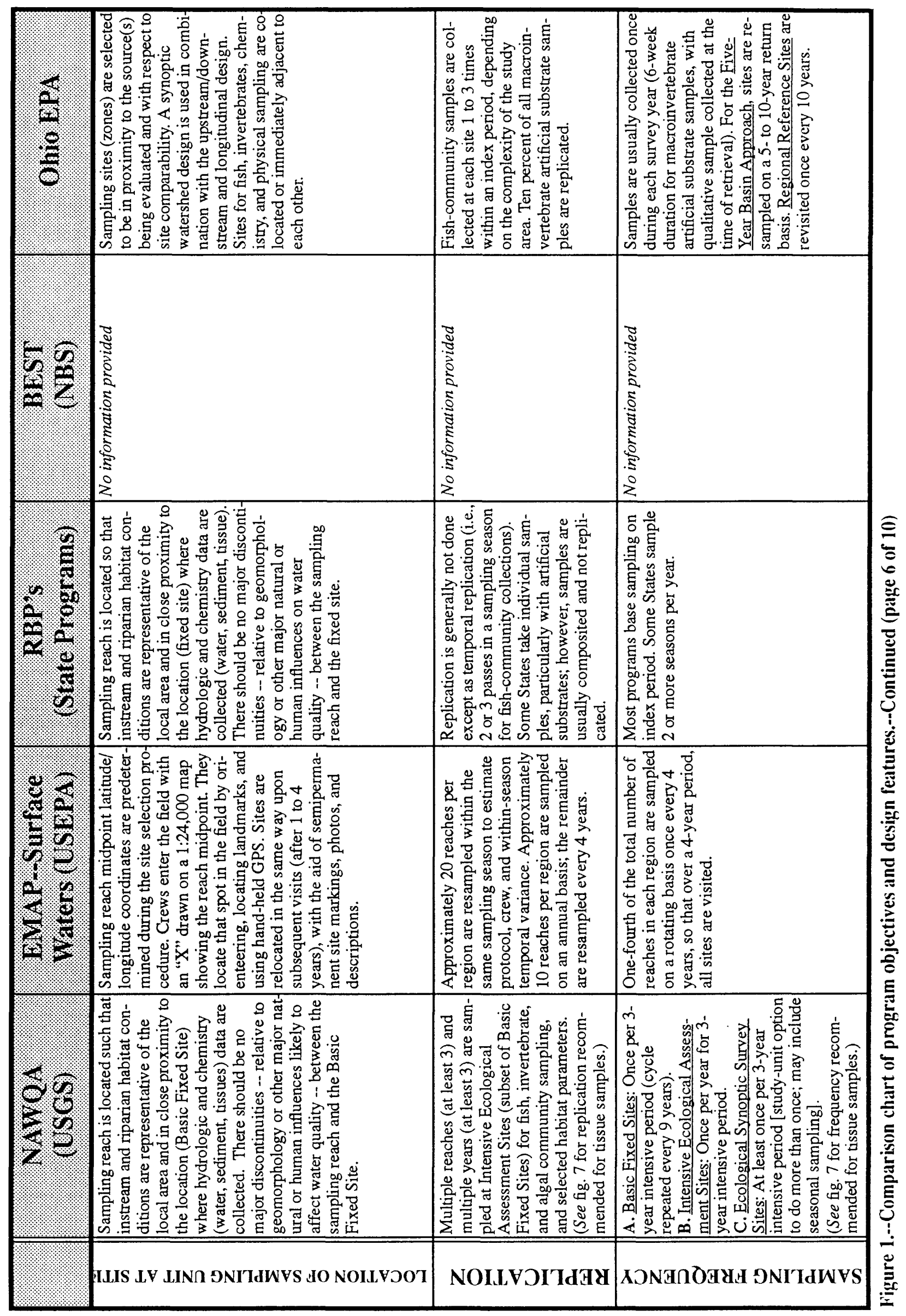




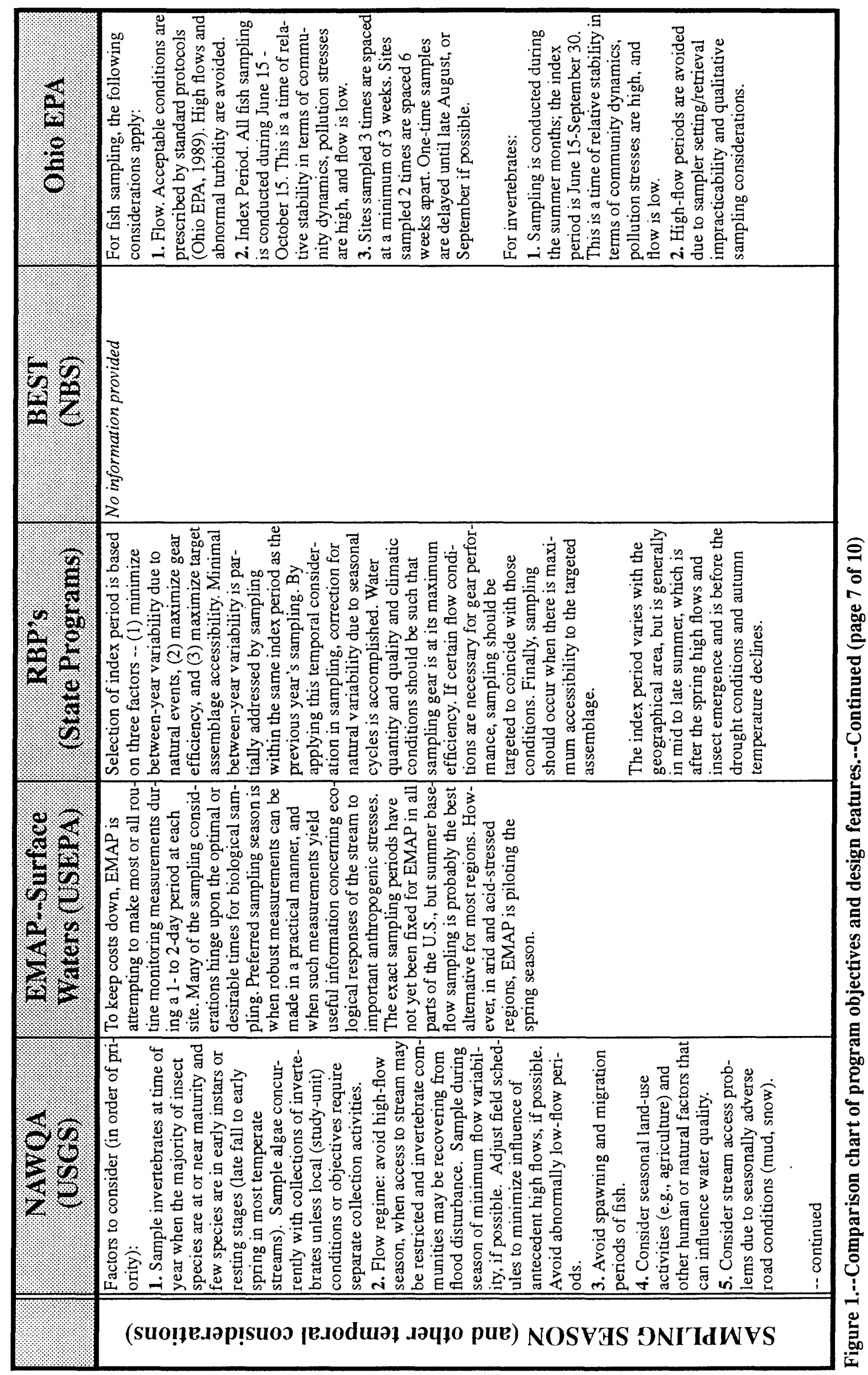




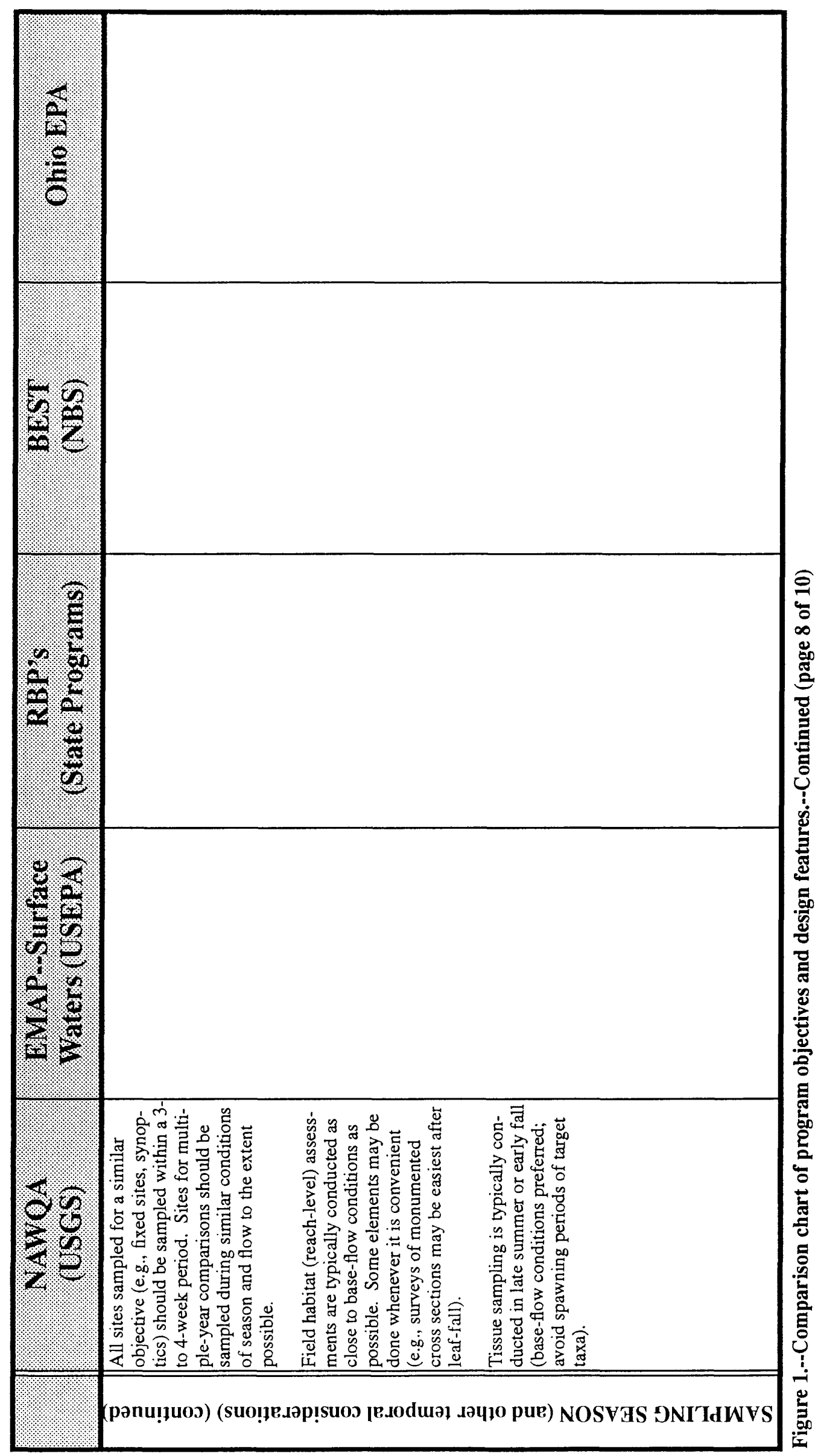




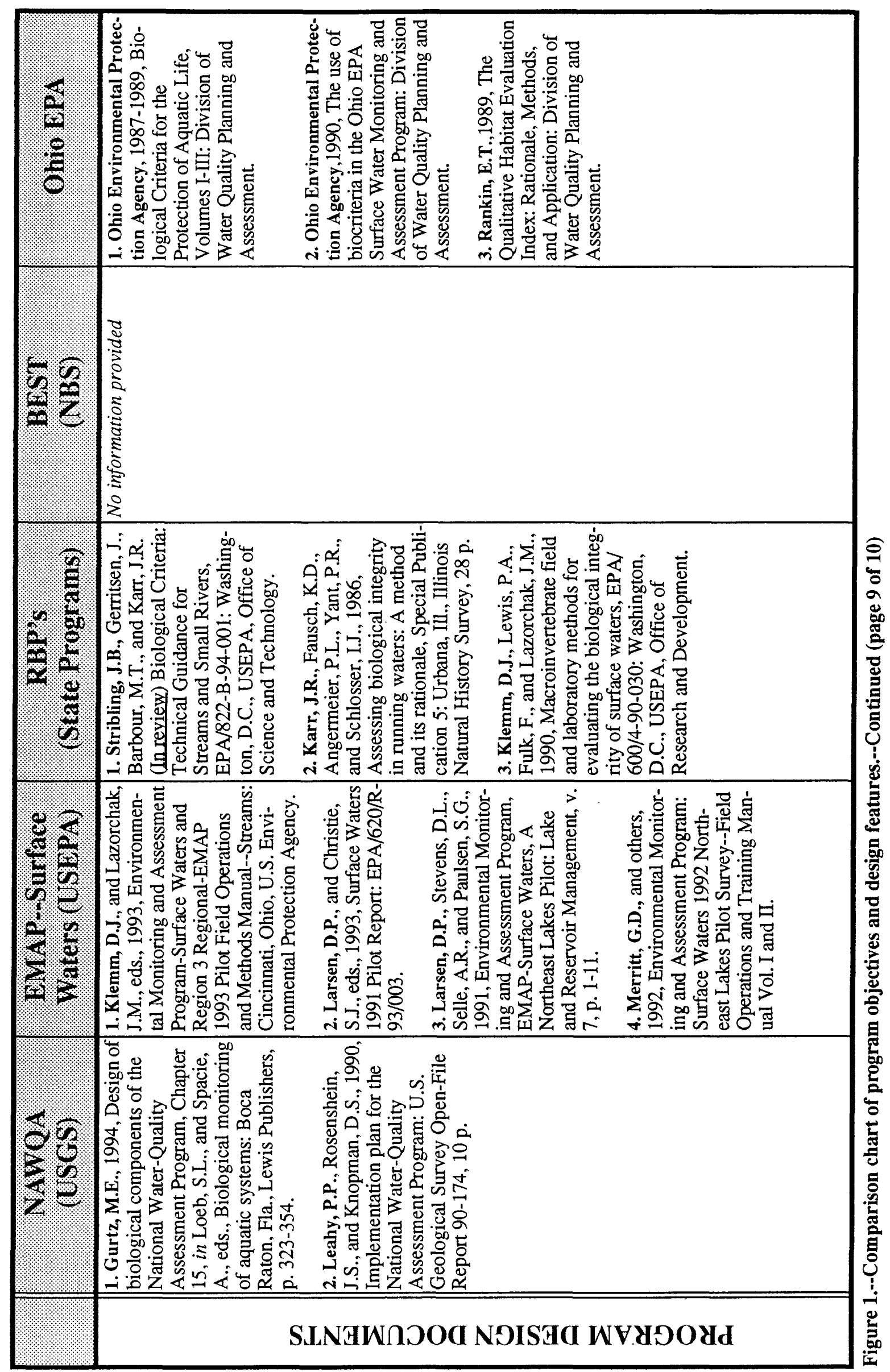




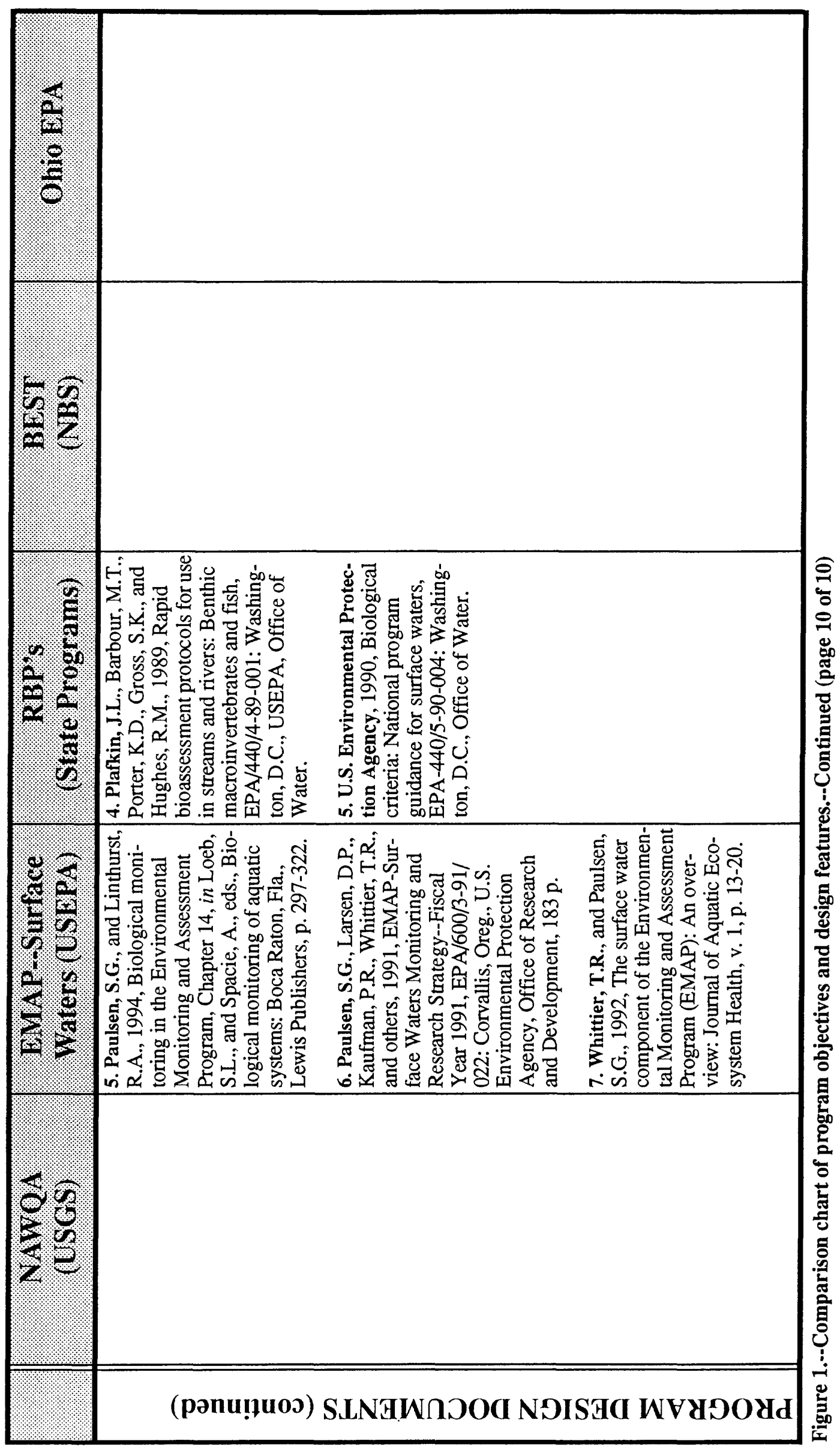




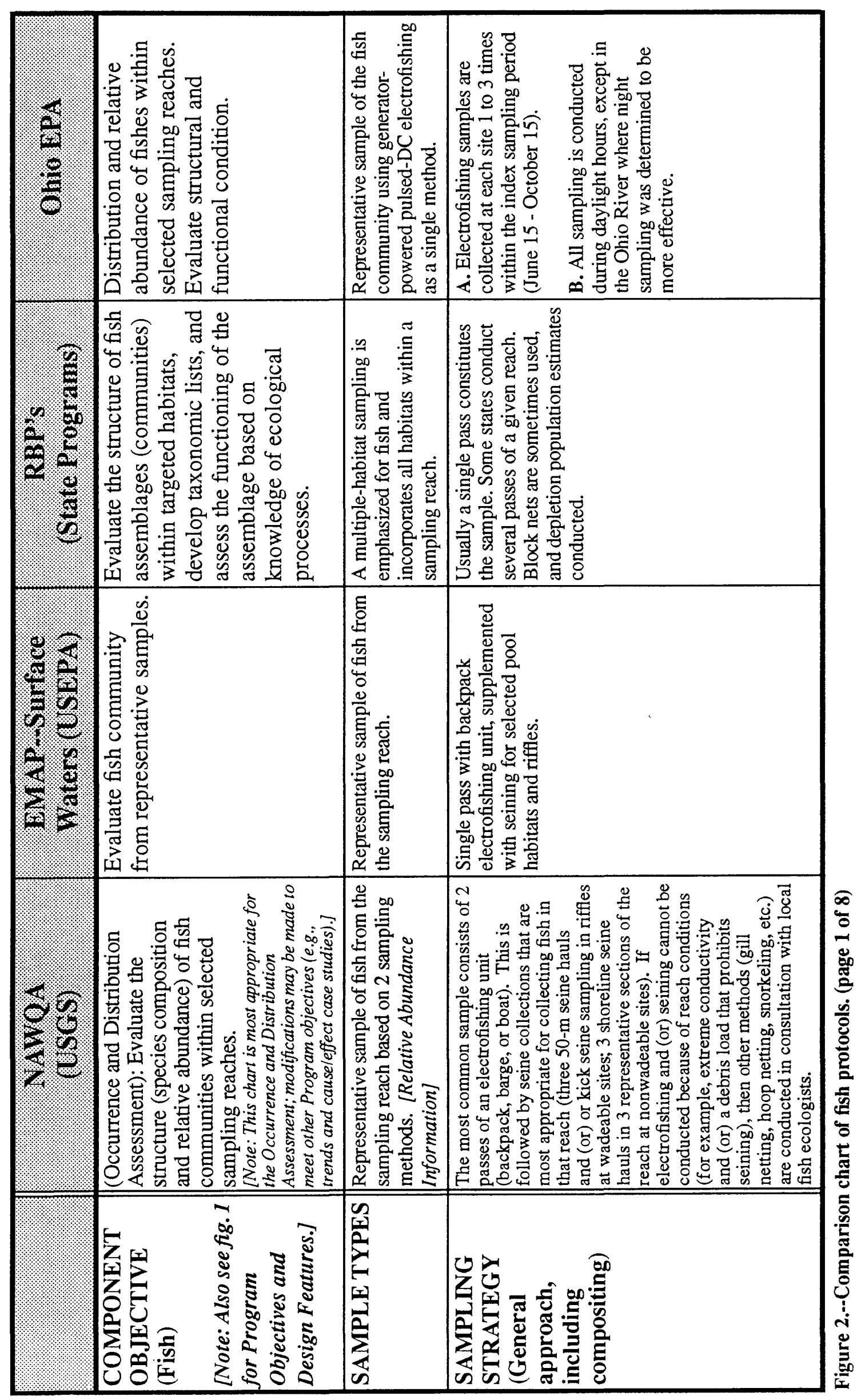




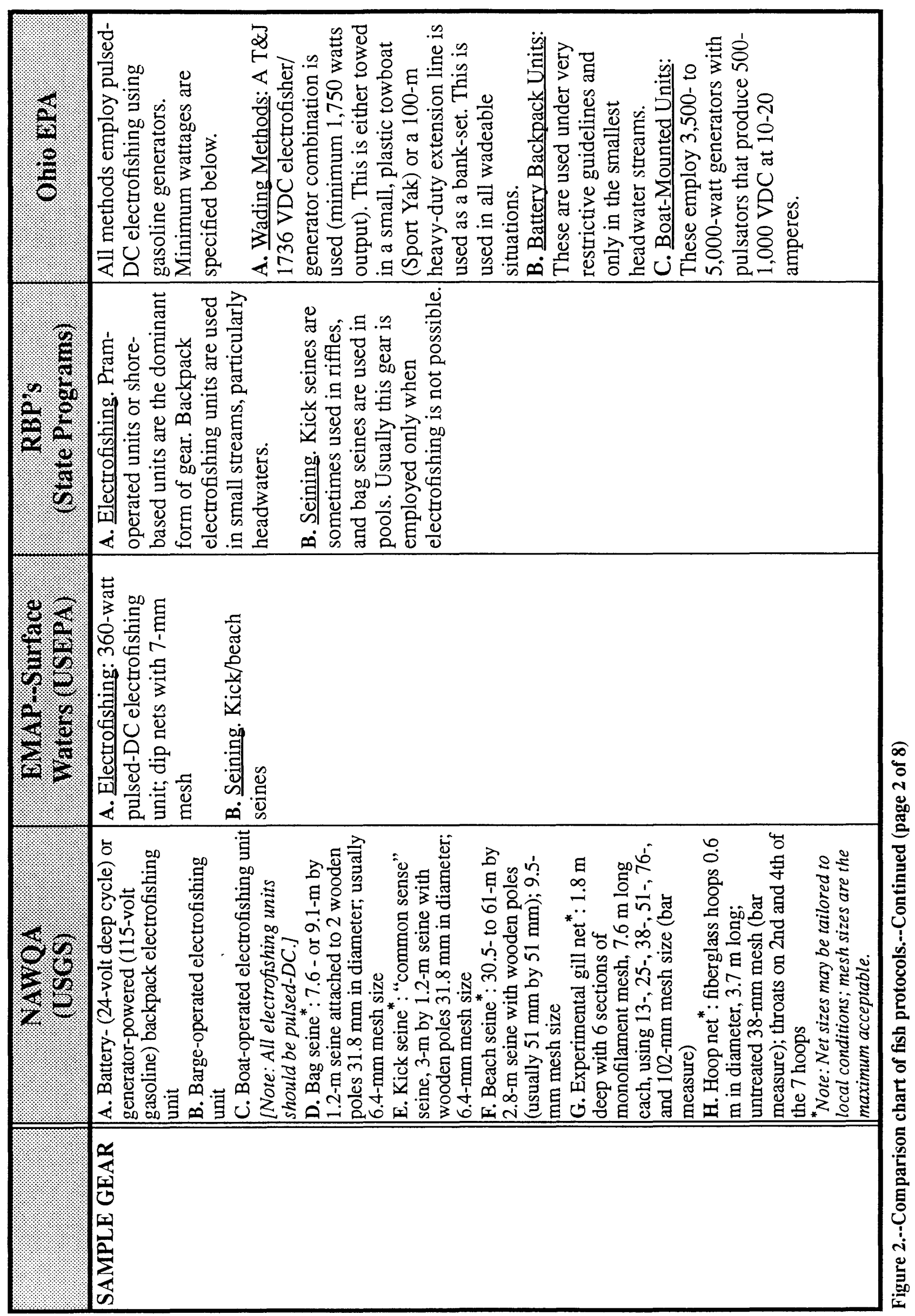




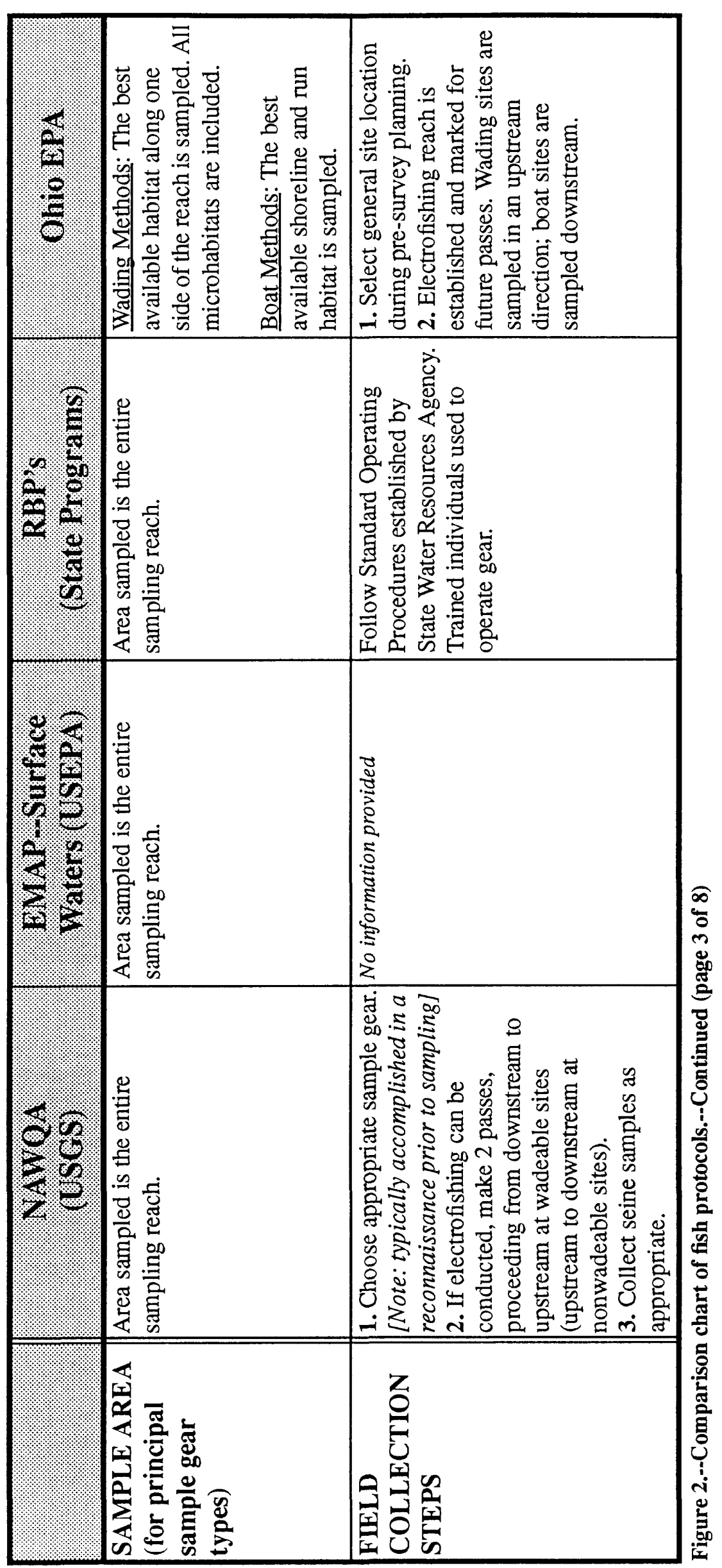




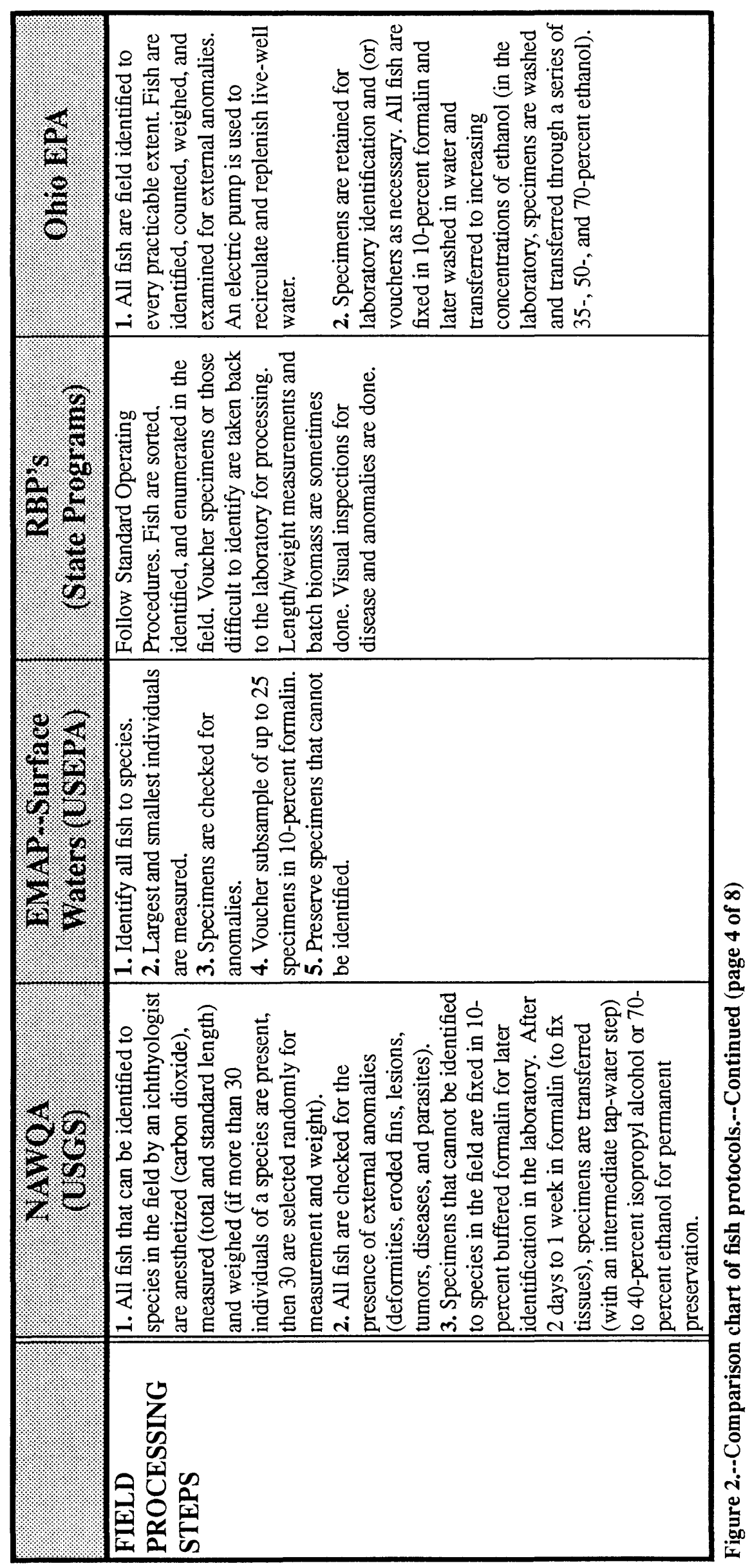




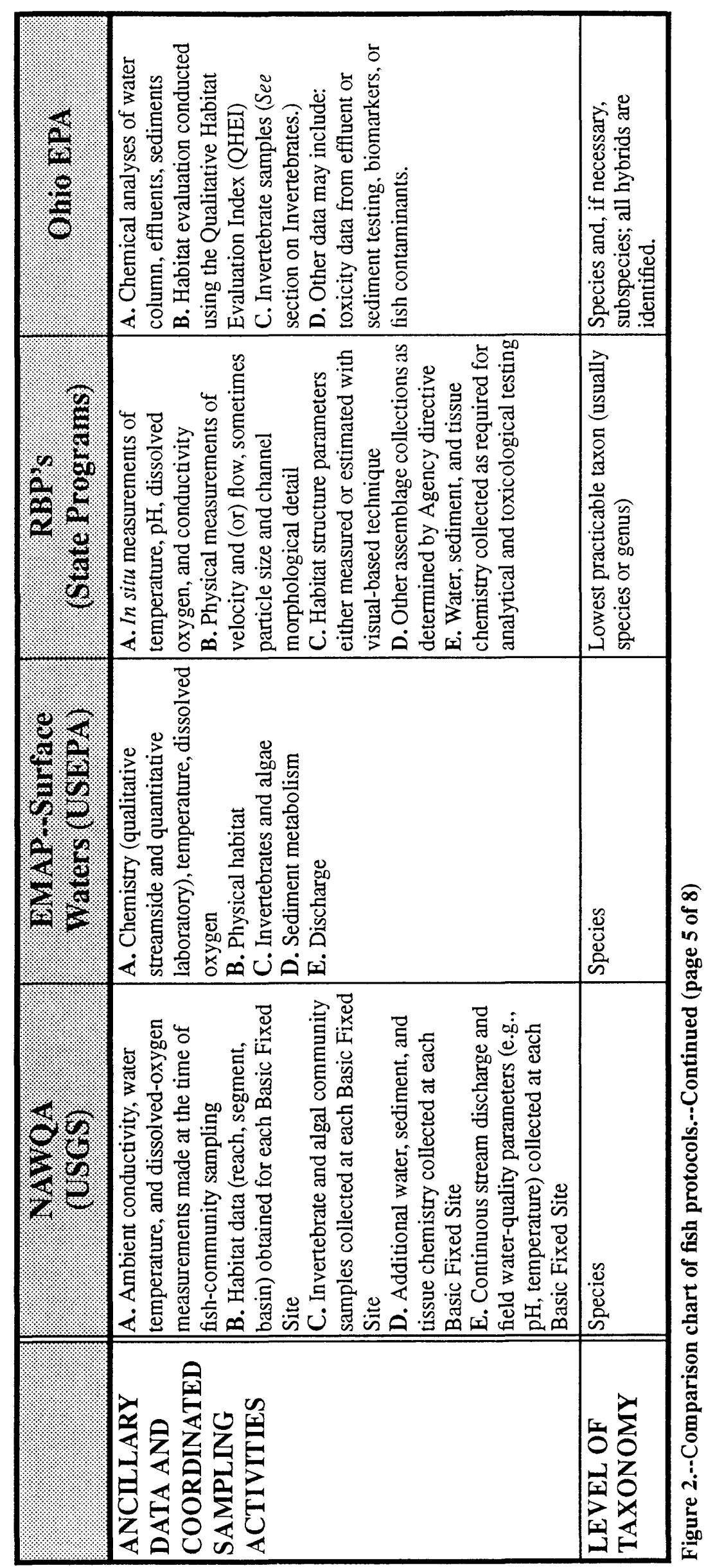




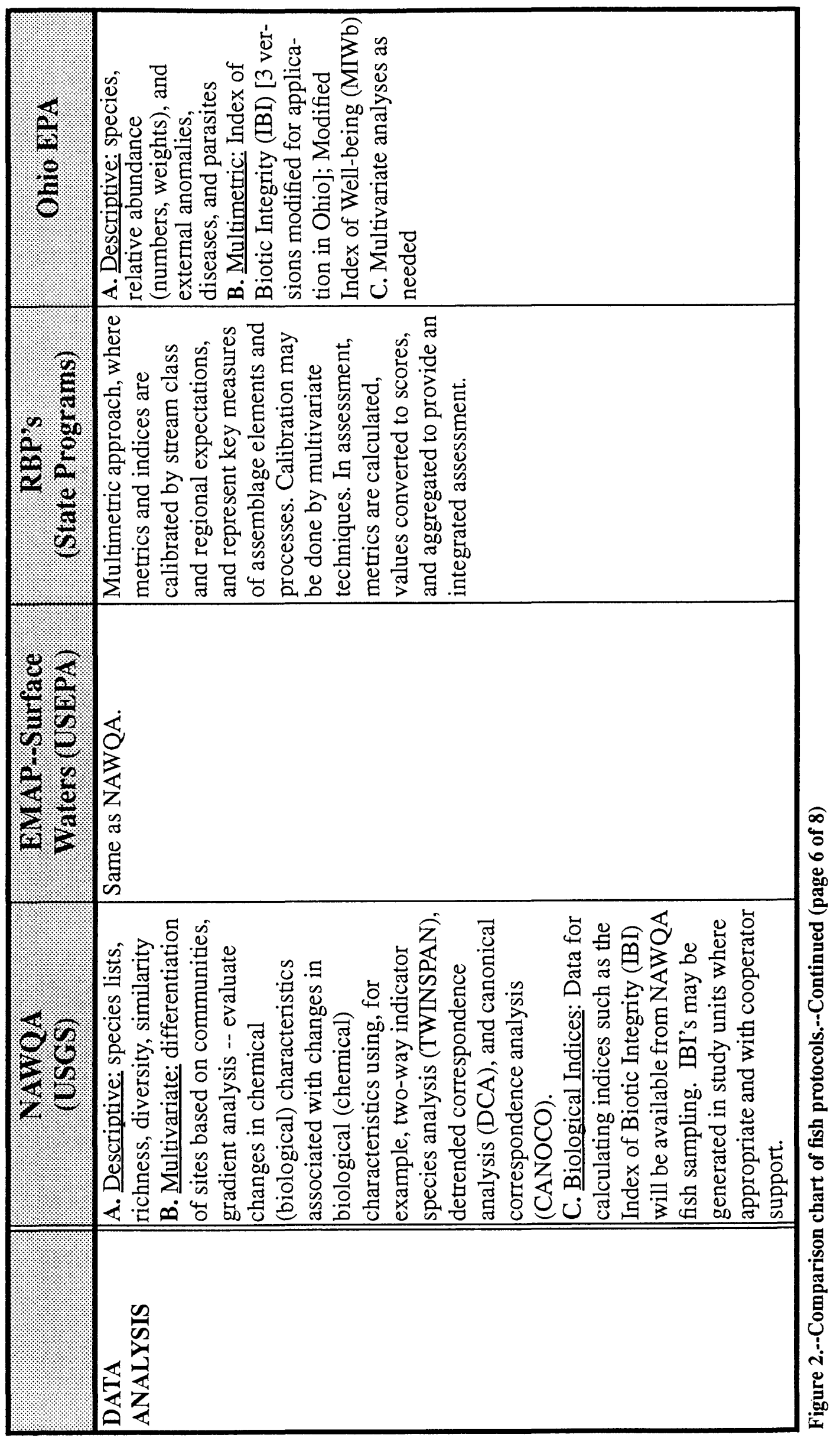




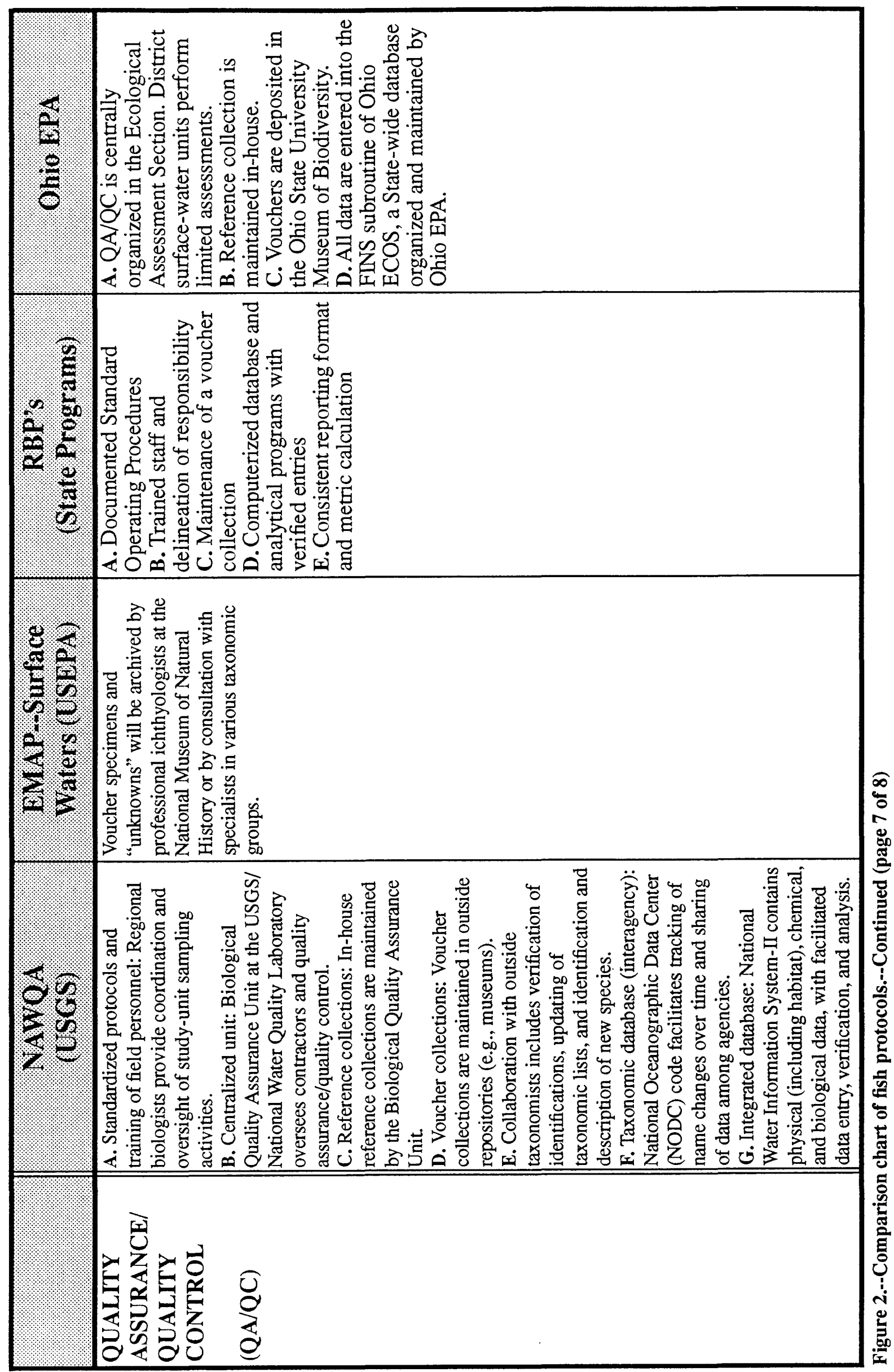




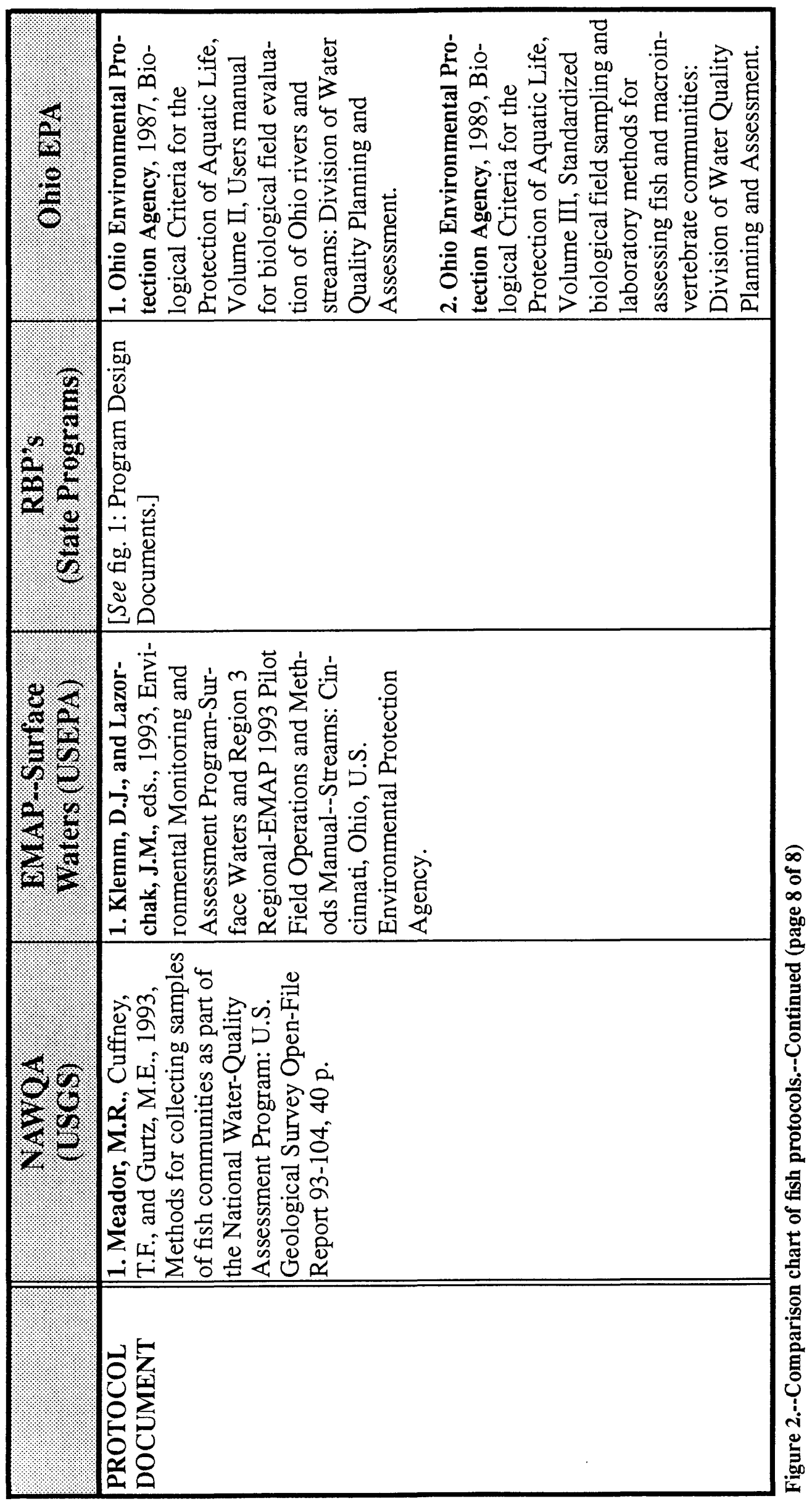




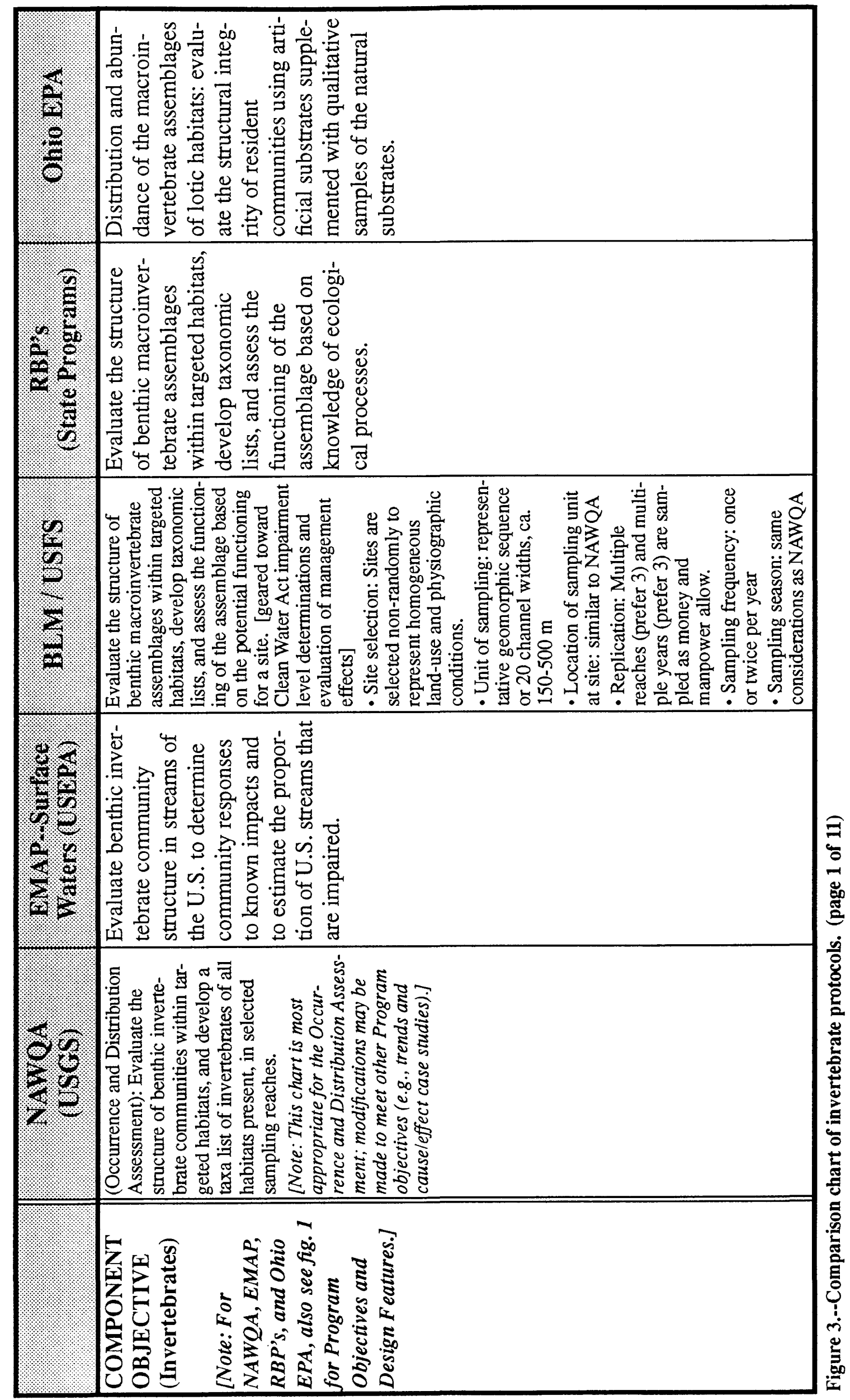




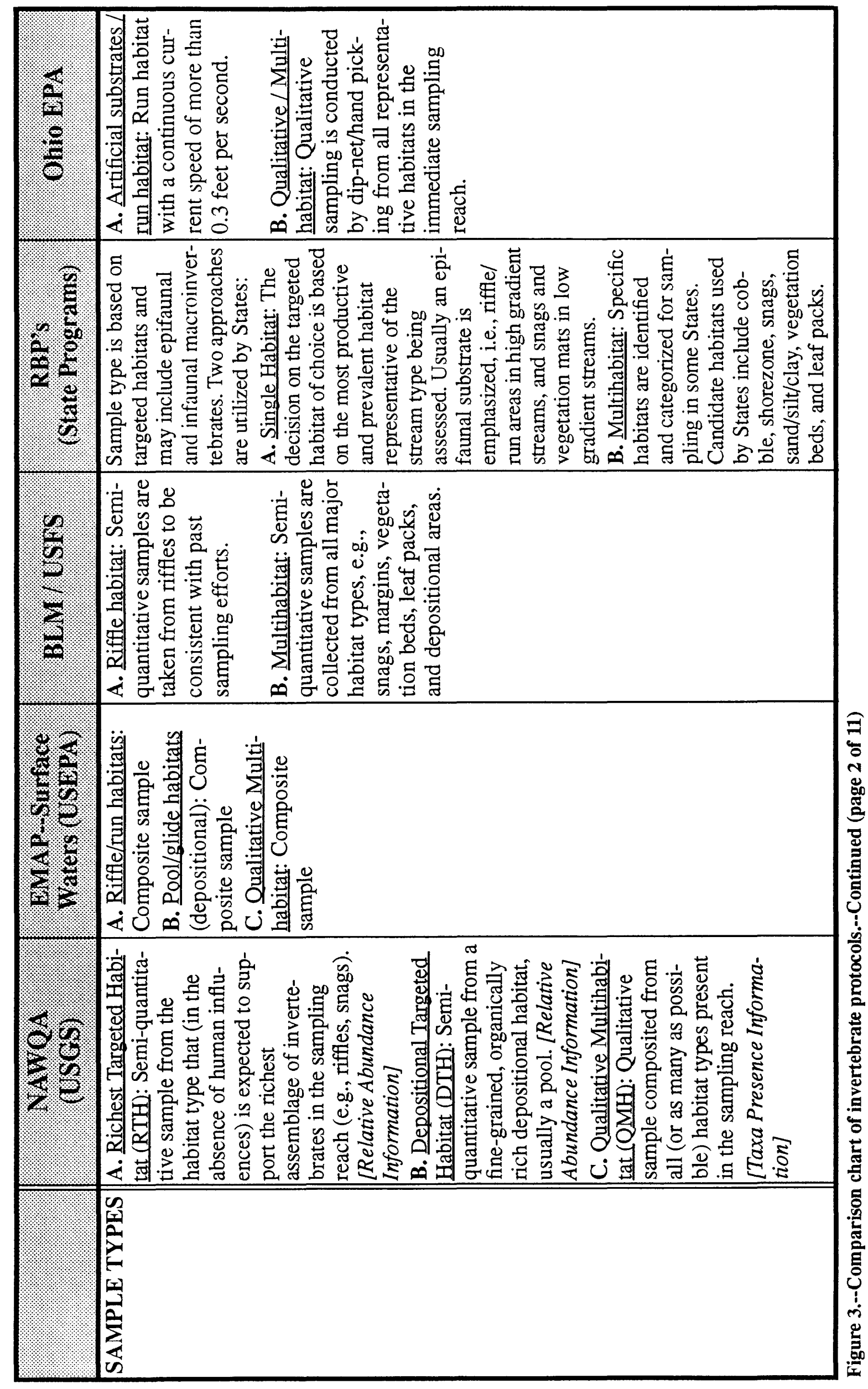




\begin{tabular}{|c|c|}
\hline$\frac{6}{48}$ & 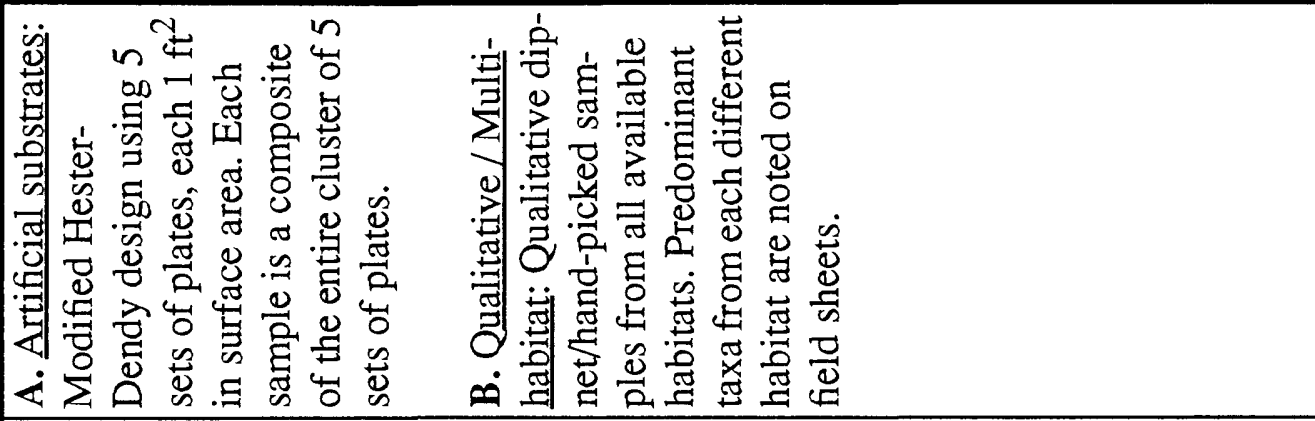 \\
\hline 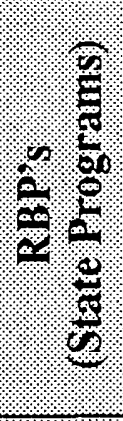 & 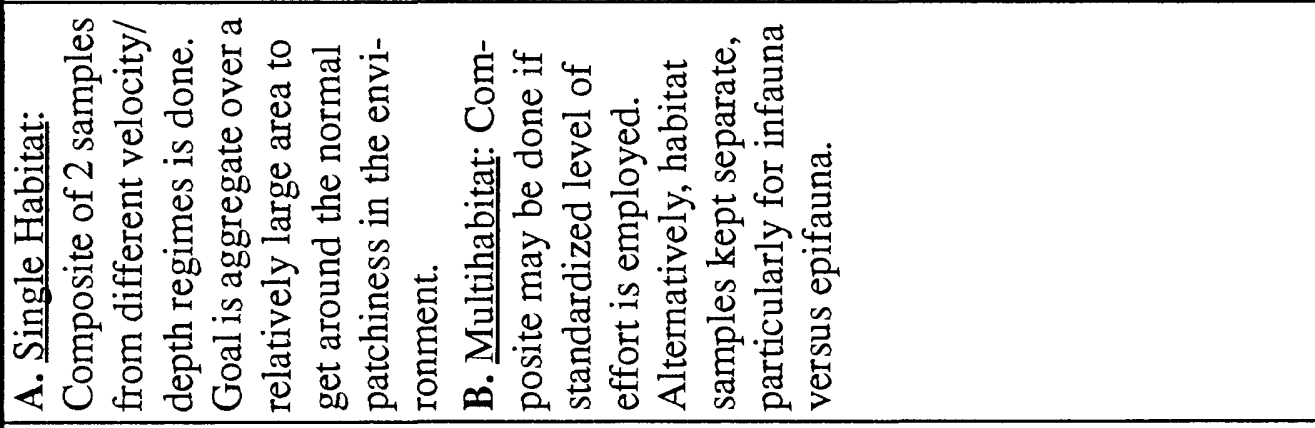 \\
\hline$\frac{69}{68}$ & 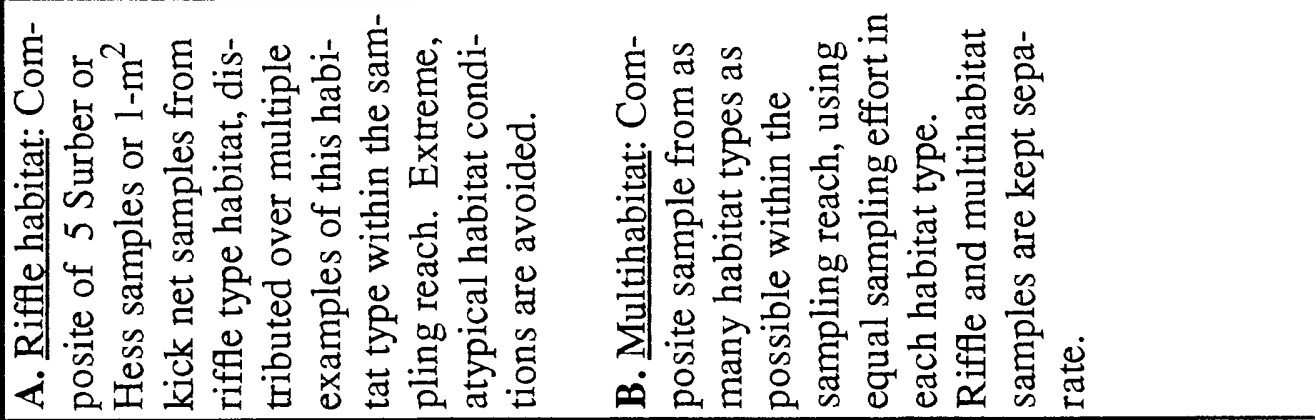 \\
\hline 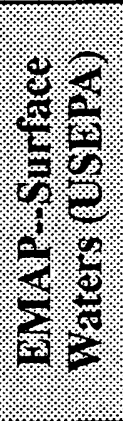 & 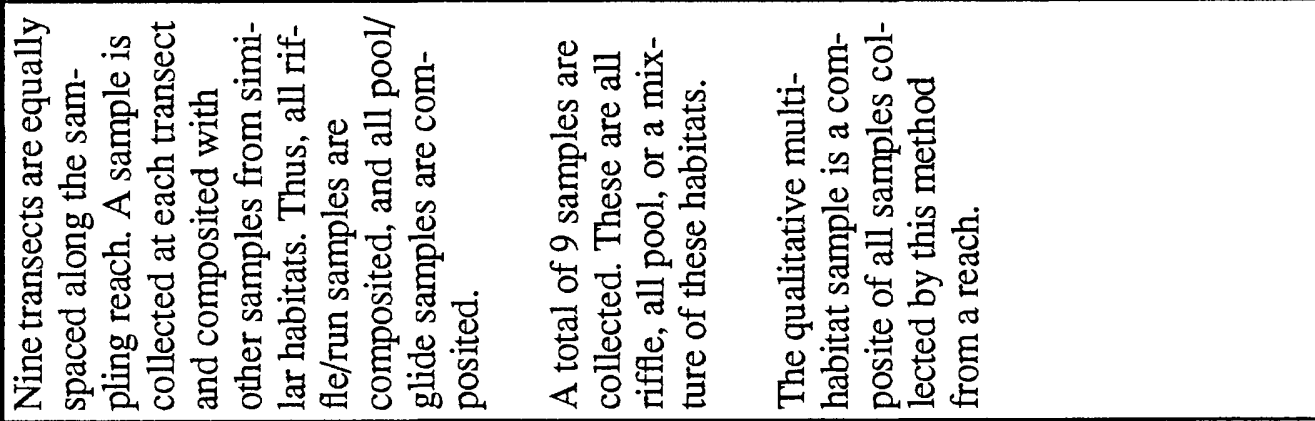 \\
\hline 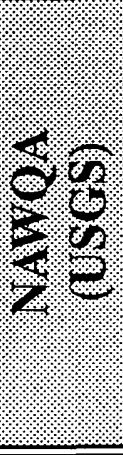 & 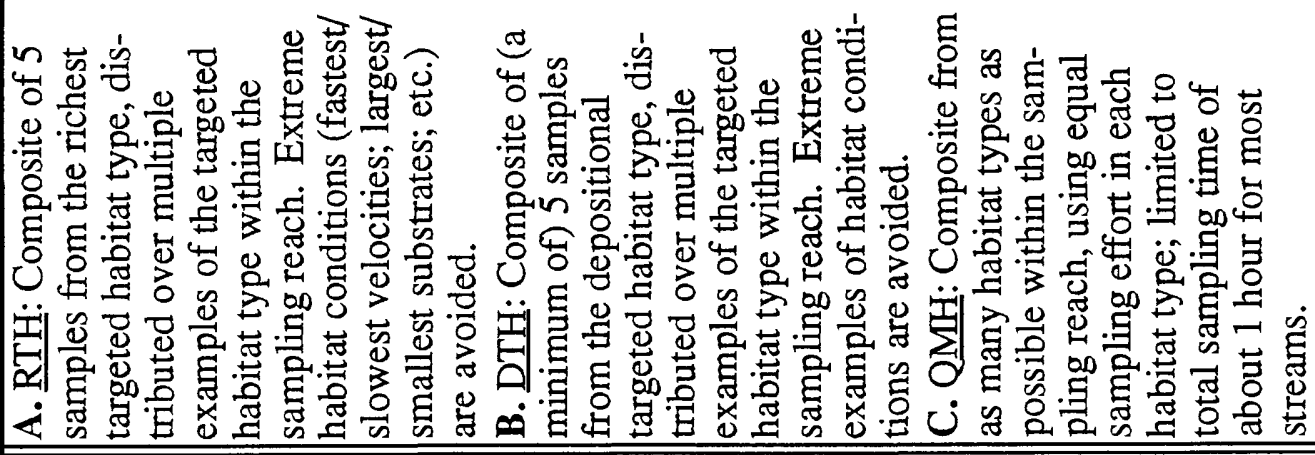 \\
\hline & 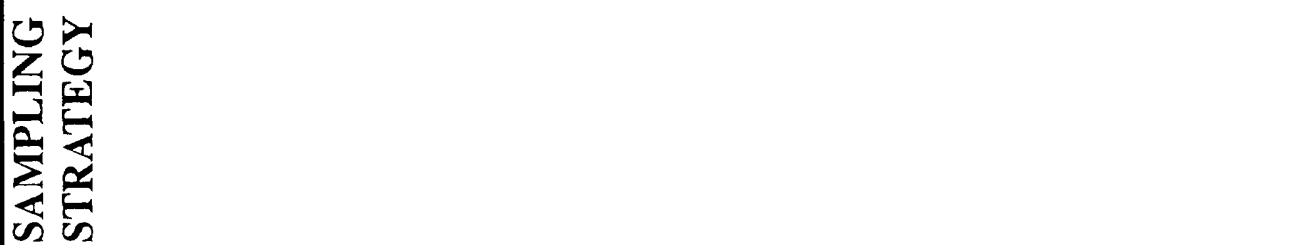 \\
\hline
\end{tabular}




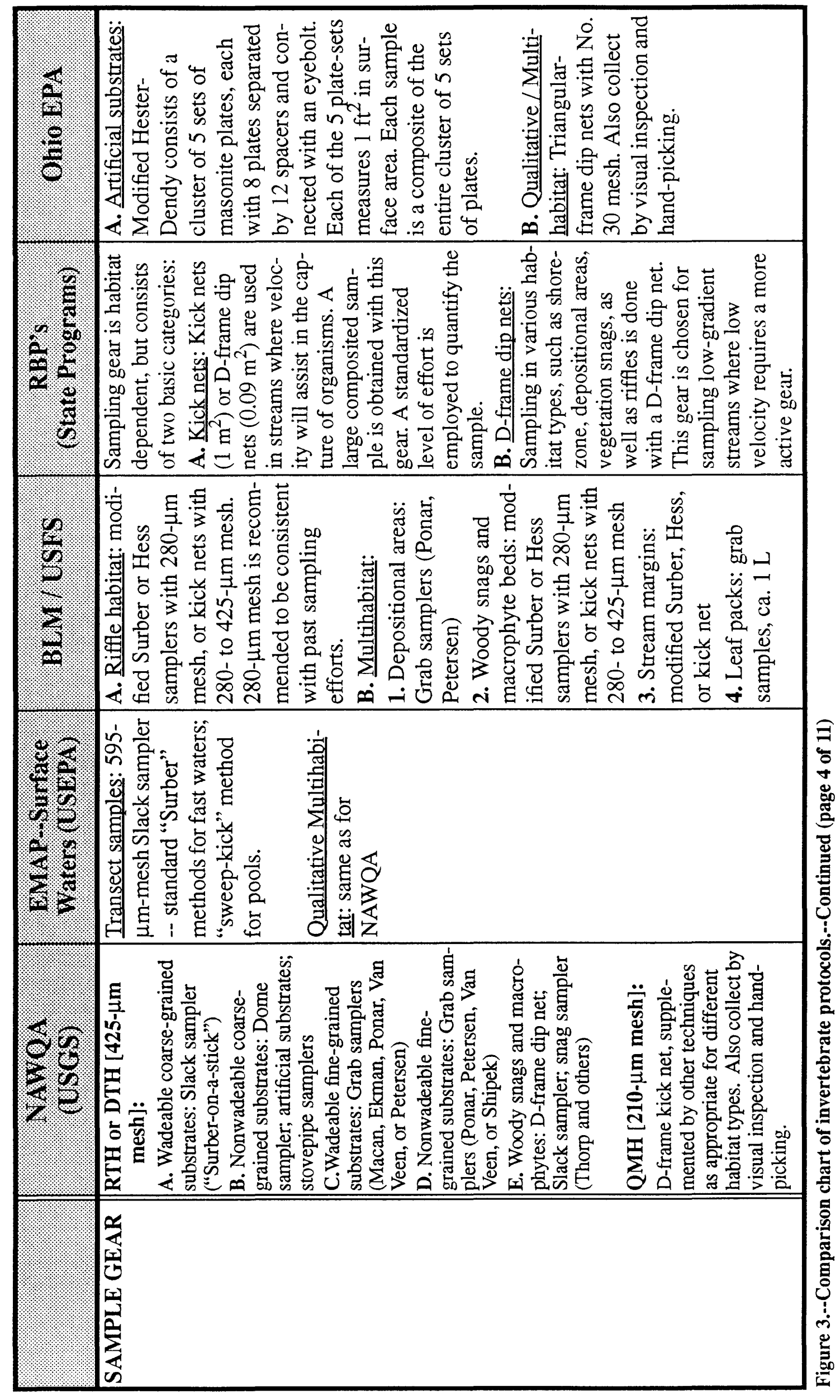




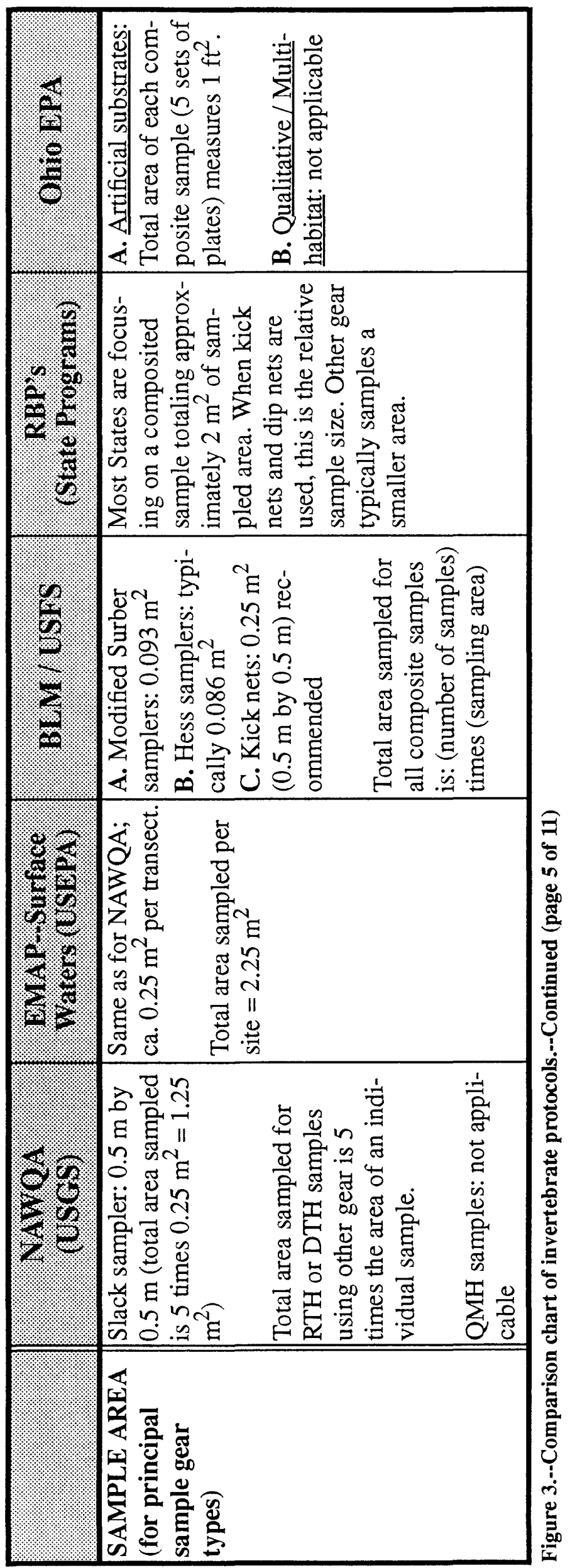




\begin{tabular}{|c|c|}
\hline$\frac{\sqrt[3]{2}}{\sqrt[3]{2}}$ & 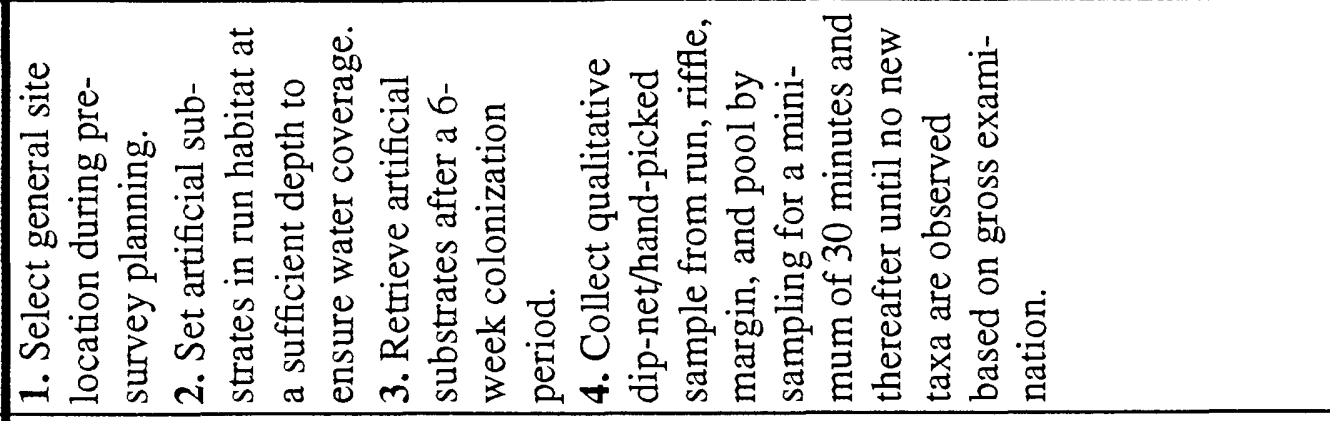 \\
\hline 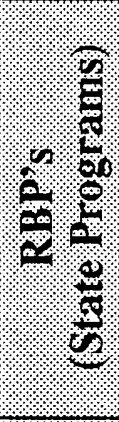 & 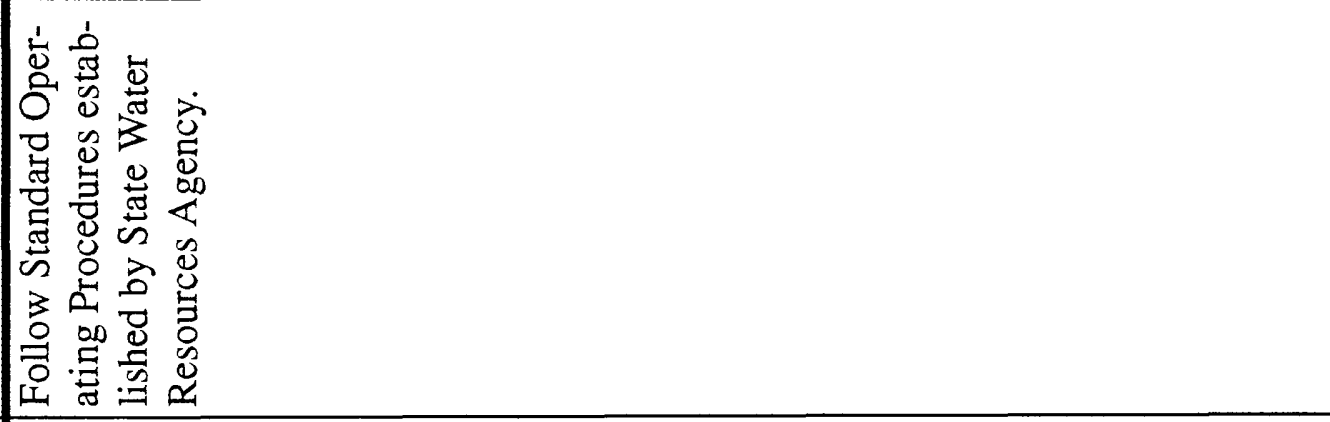 \\
\hline 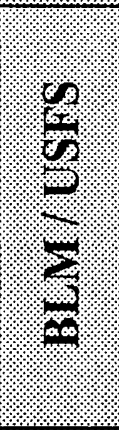 & 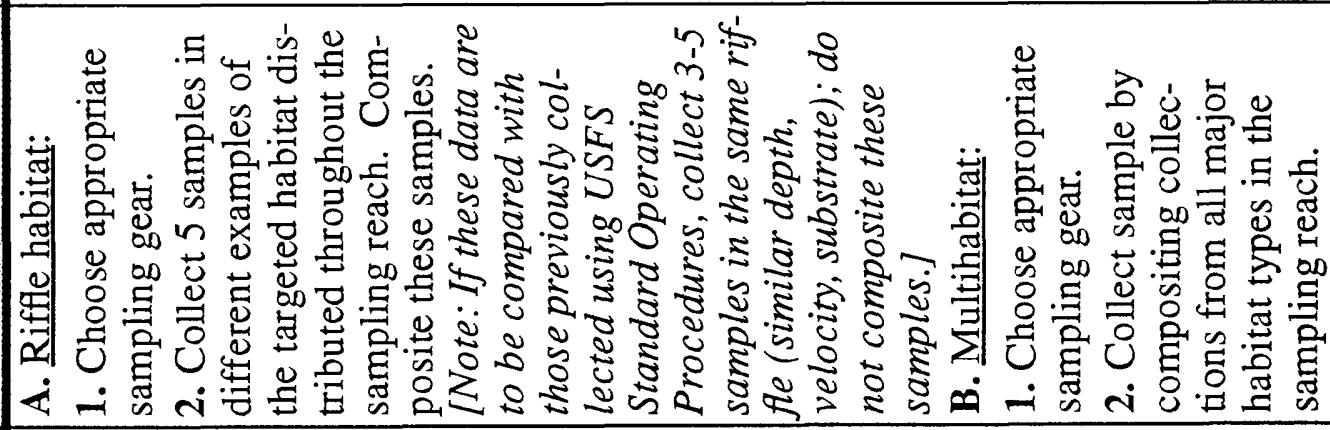 \\
\hline 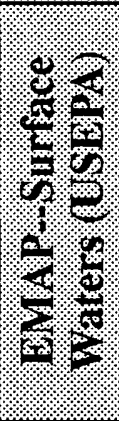 & 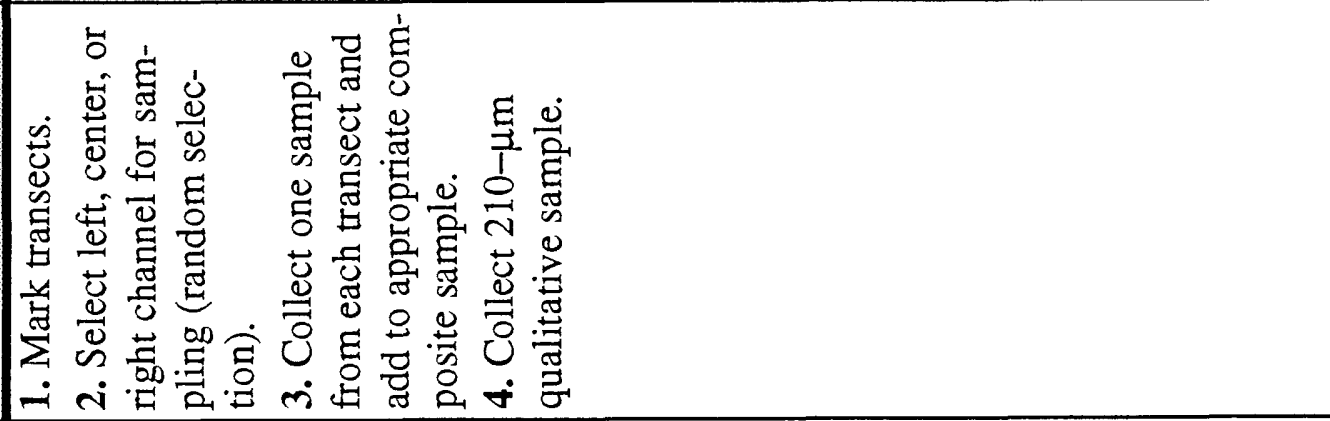 \\
\hline$\frac{5}{8}$ & 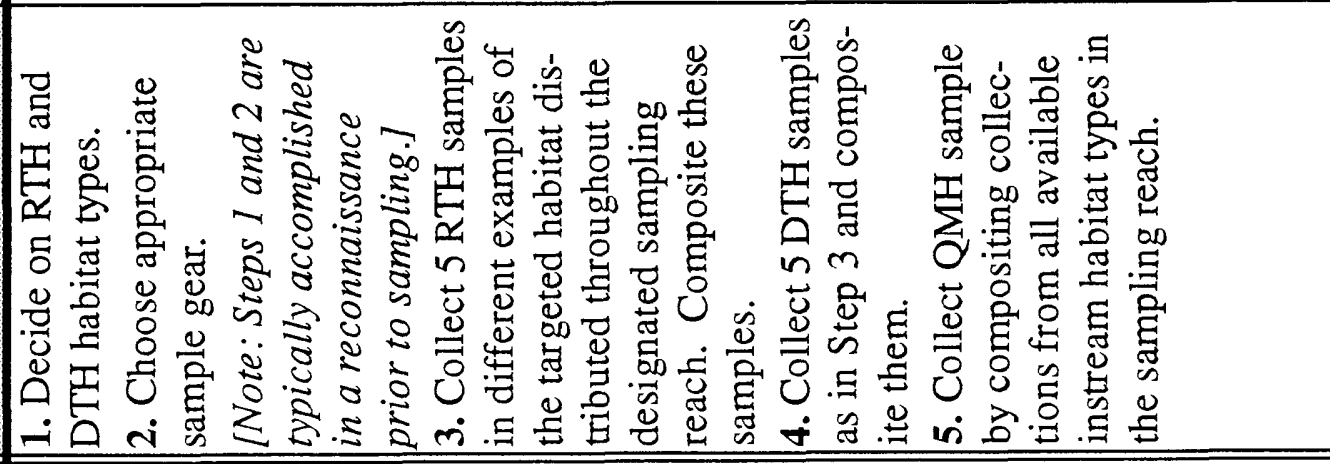 \\
\hline & 总 \\
\hline
\end{tabular}




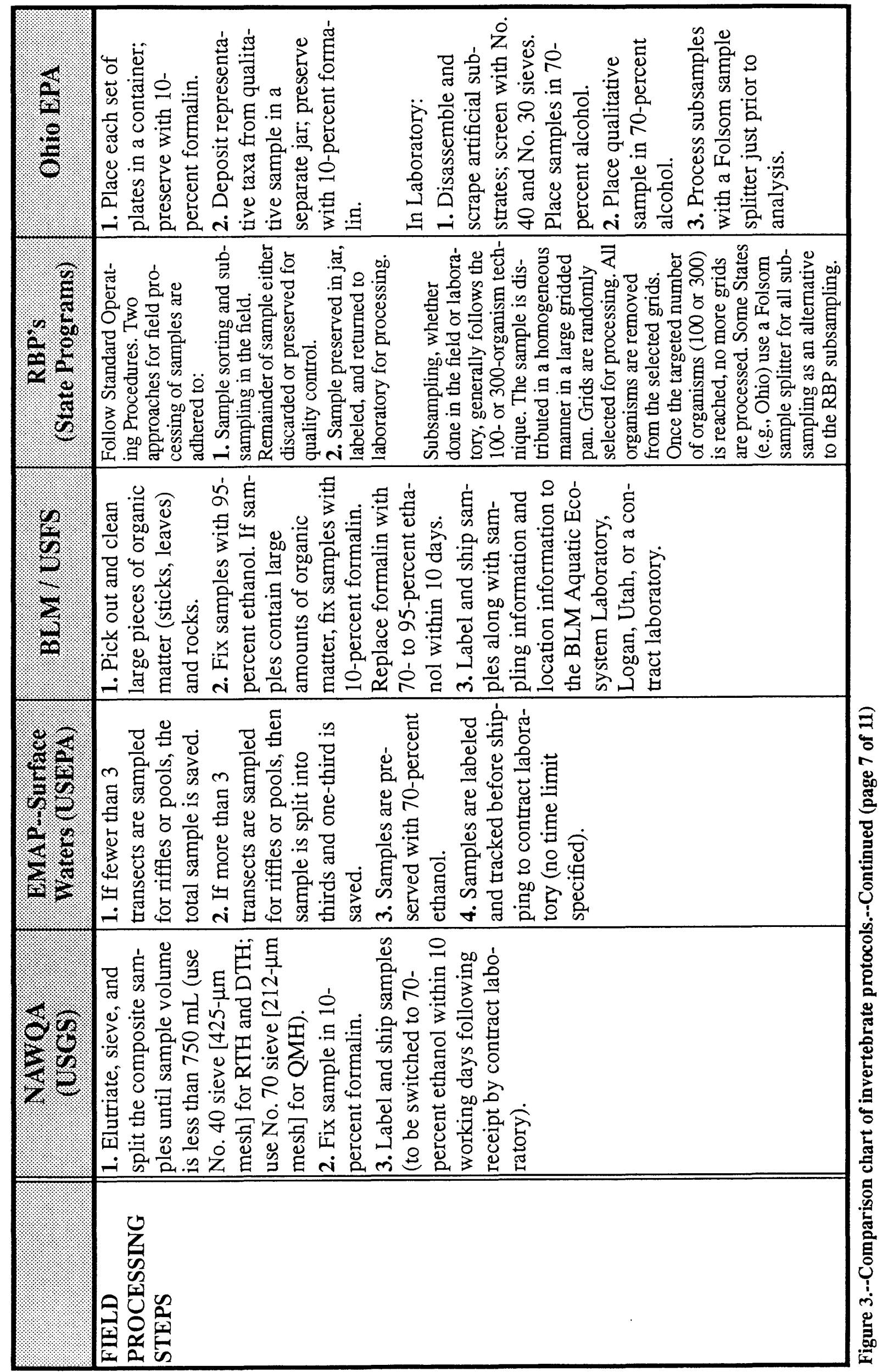




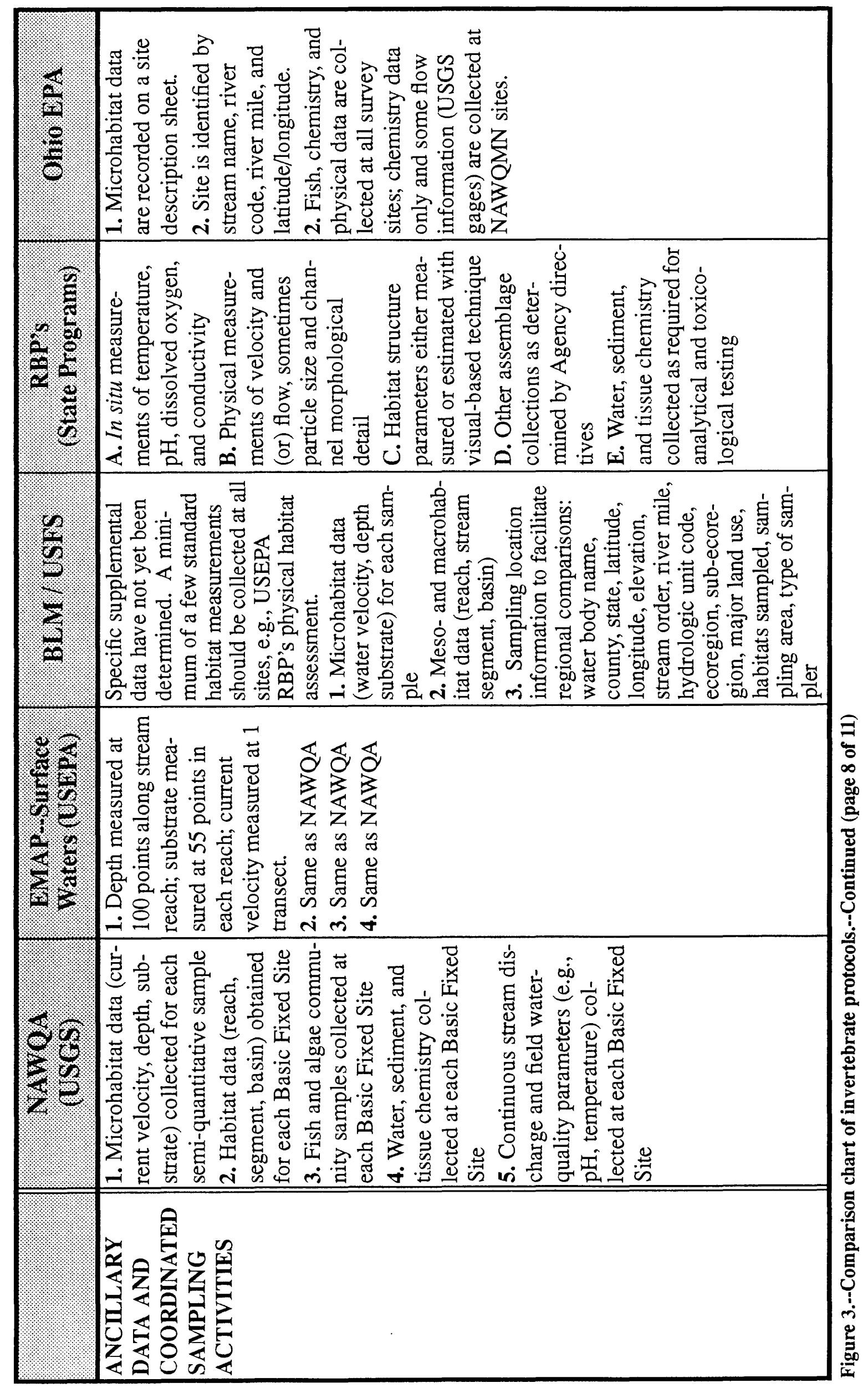




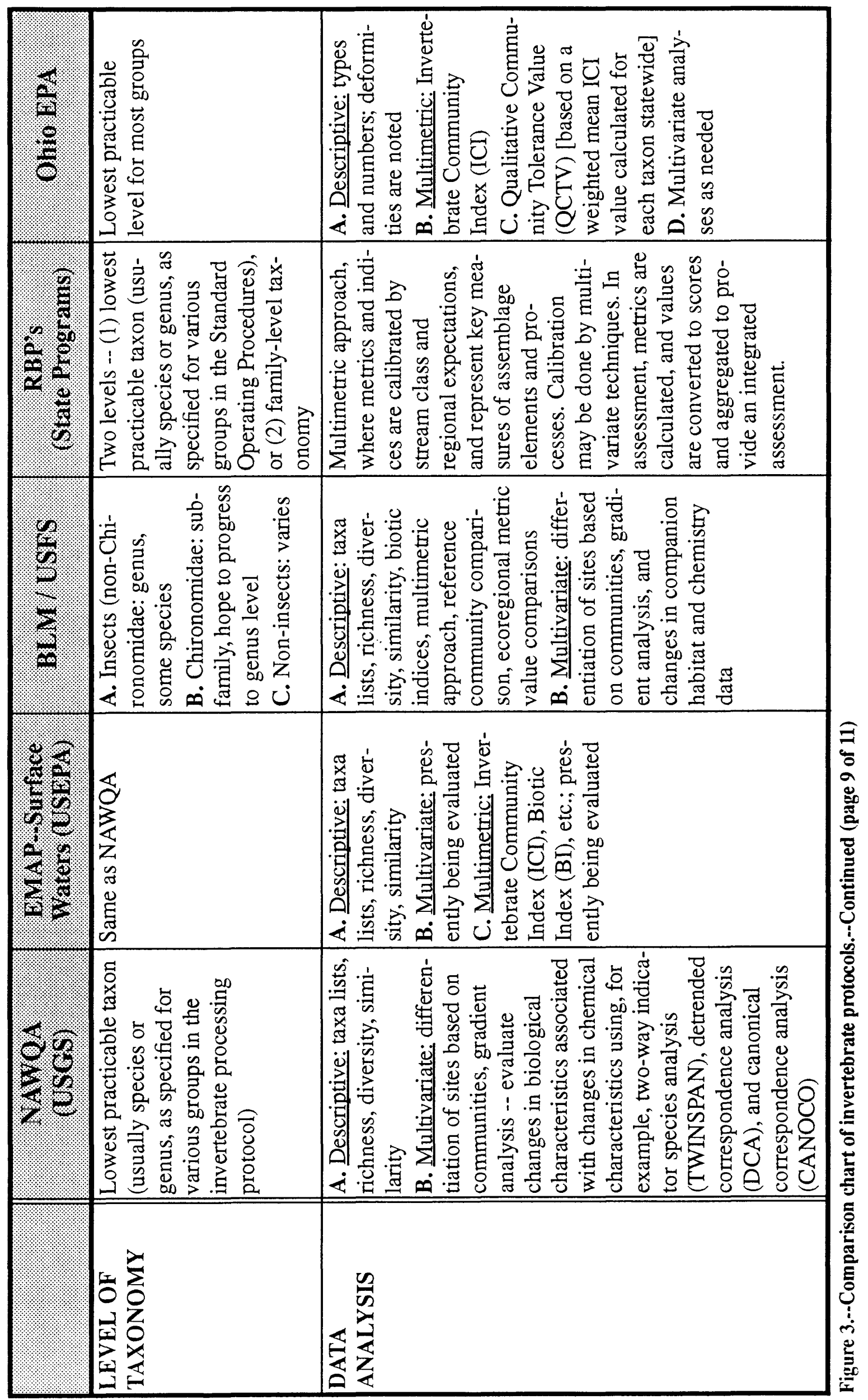




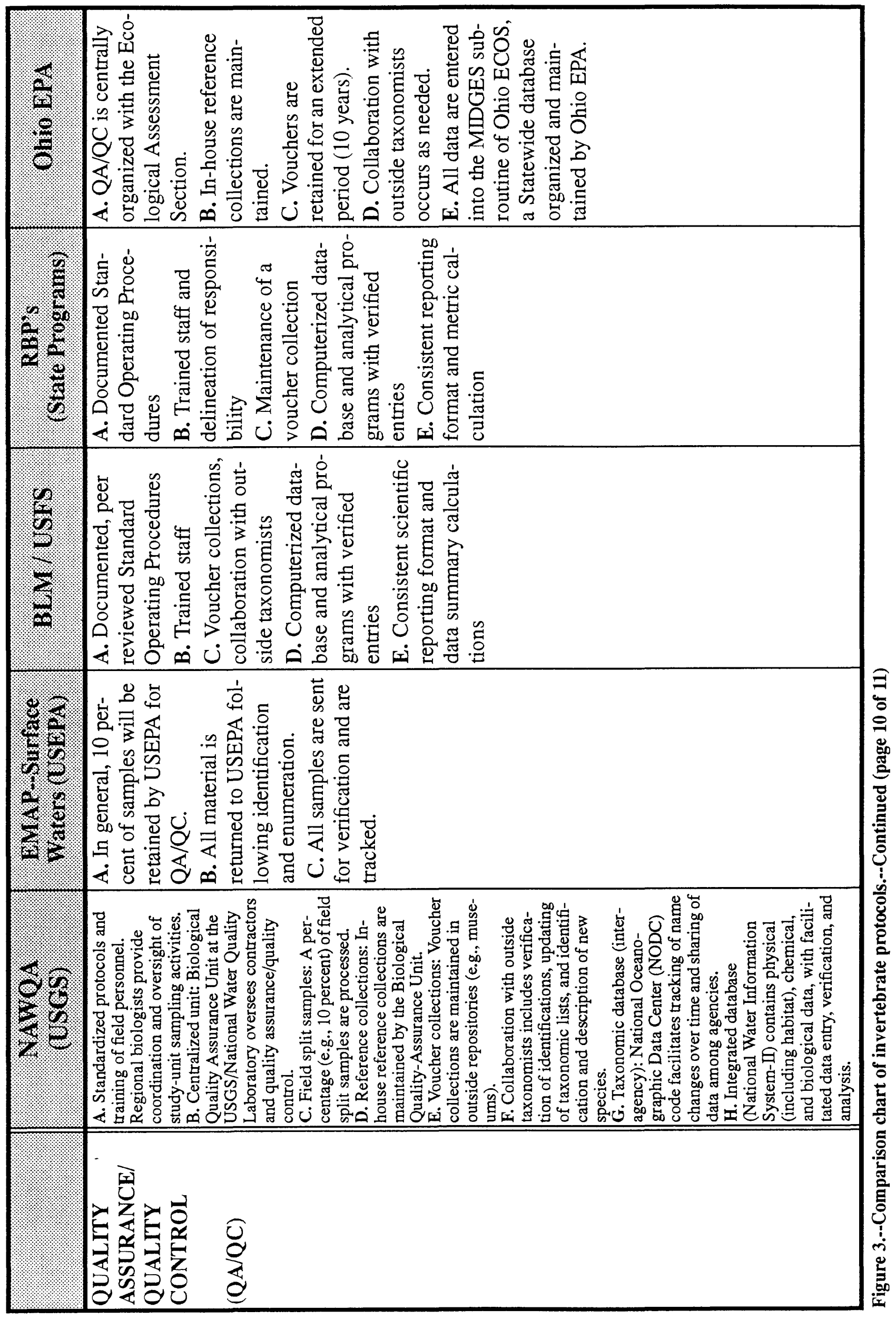




\begin{tabular}{|c|c|c|}
\hline 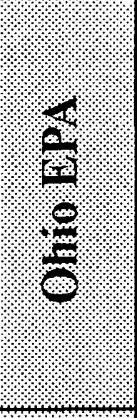 & 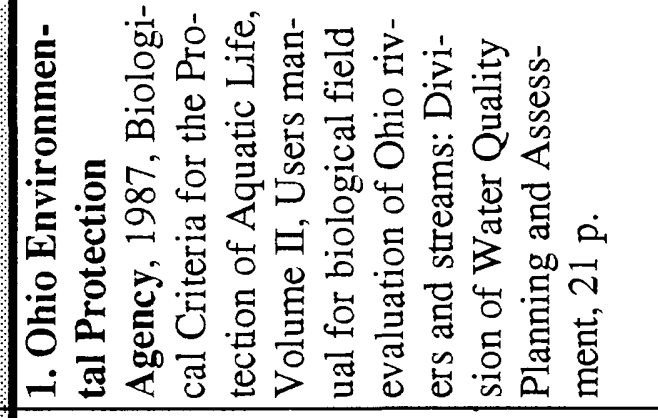 & 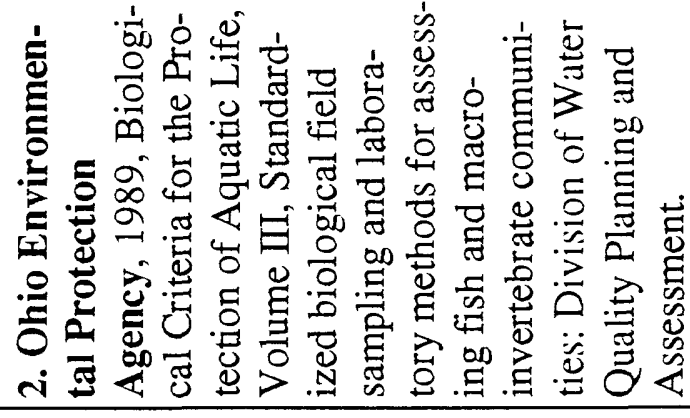 \\
\hline 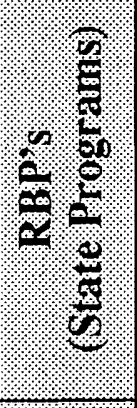 & 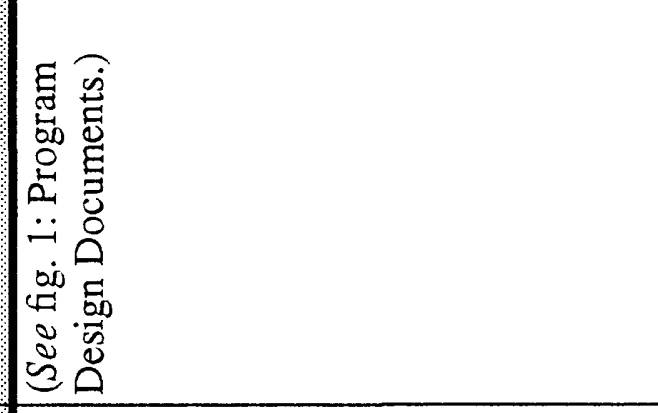 & \\
\hline$\frac{\frac{2}{2}}{\frac{2}{2}}$ & 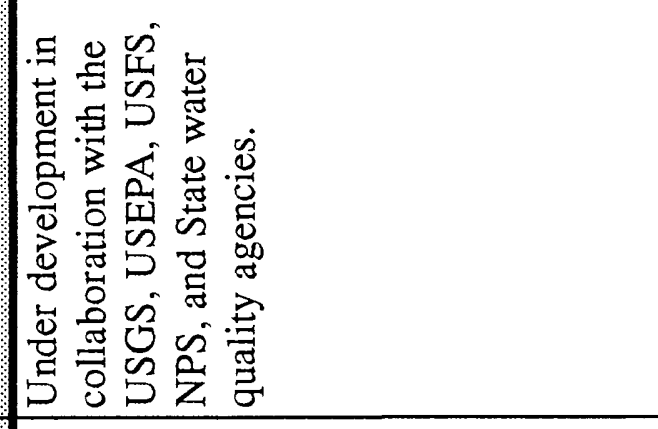 & \\
\hline 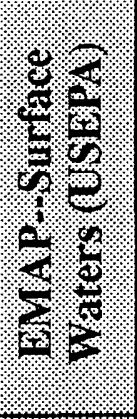 & 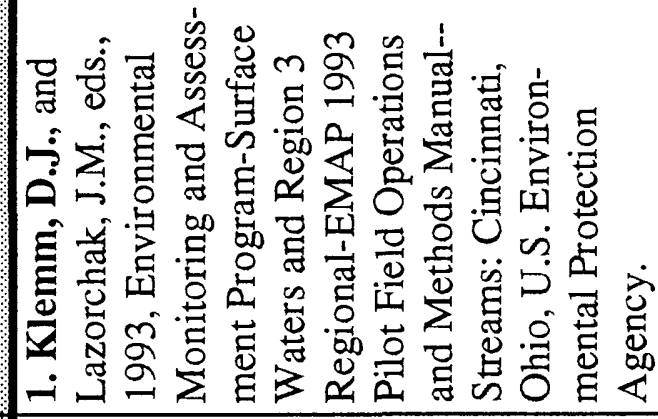 & \\
\hline $\begin{array}{l}\frac{2}{8} \\
\frac{2}{4}\end{array}$ & 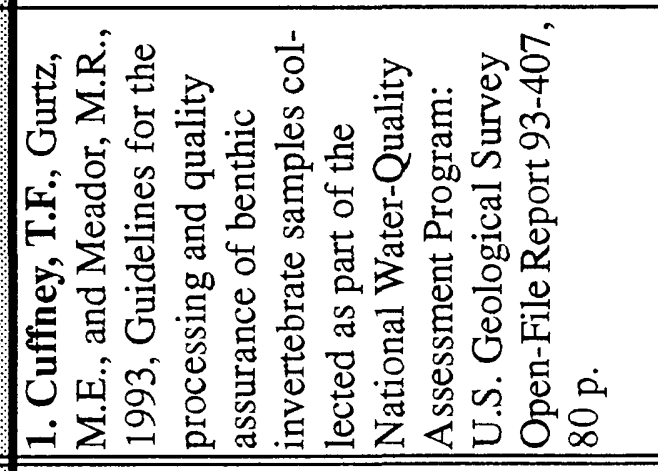 & 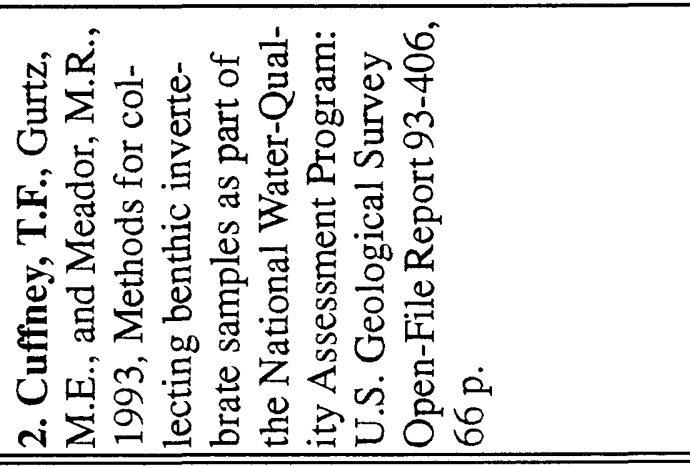 \\
\hline & 资 & \\
\hline
\end{tabular}




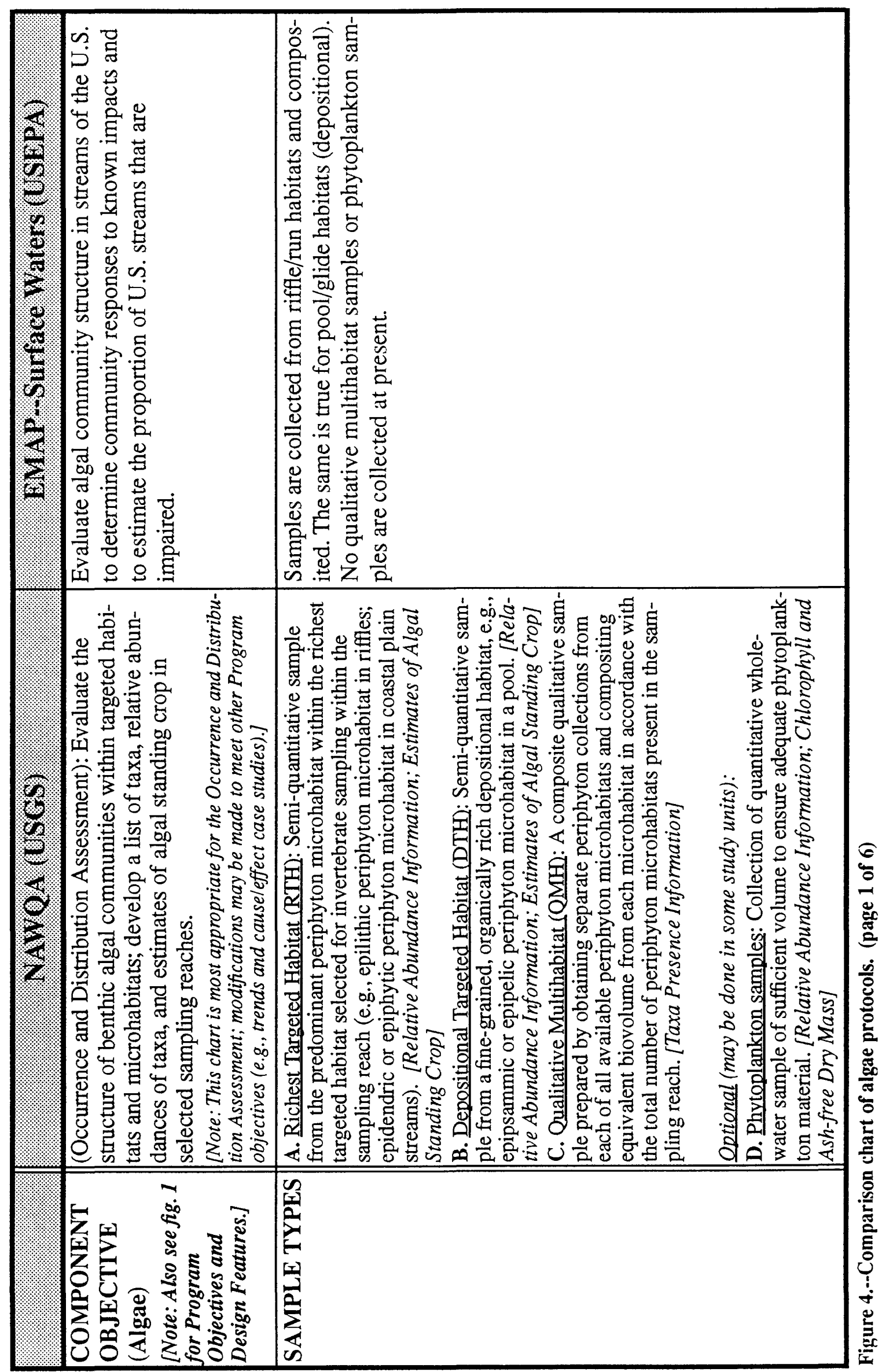




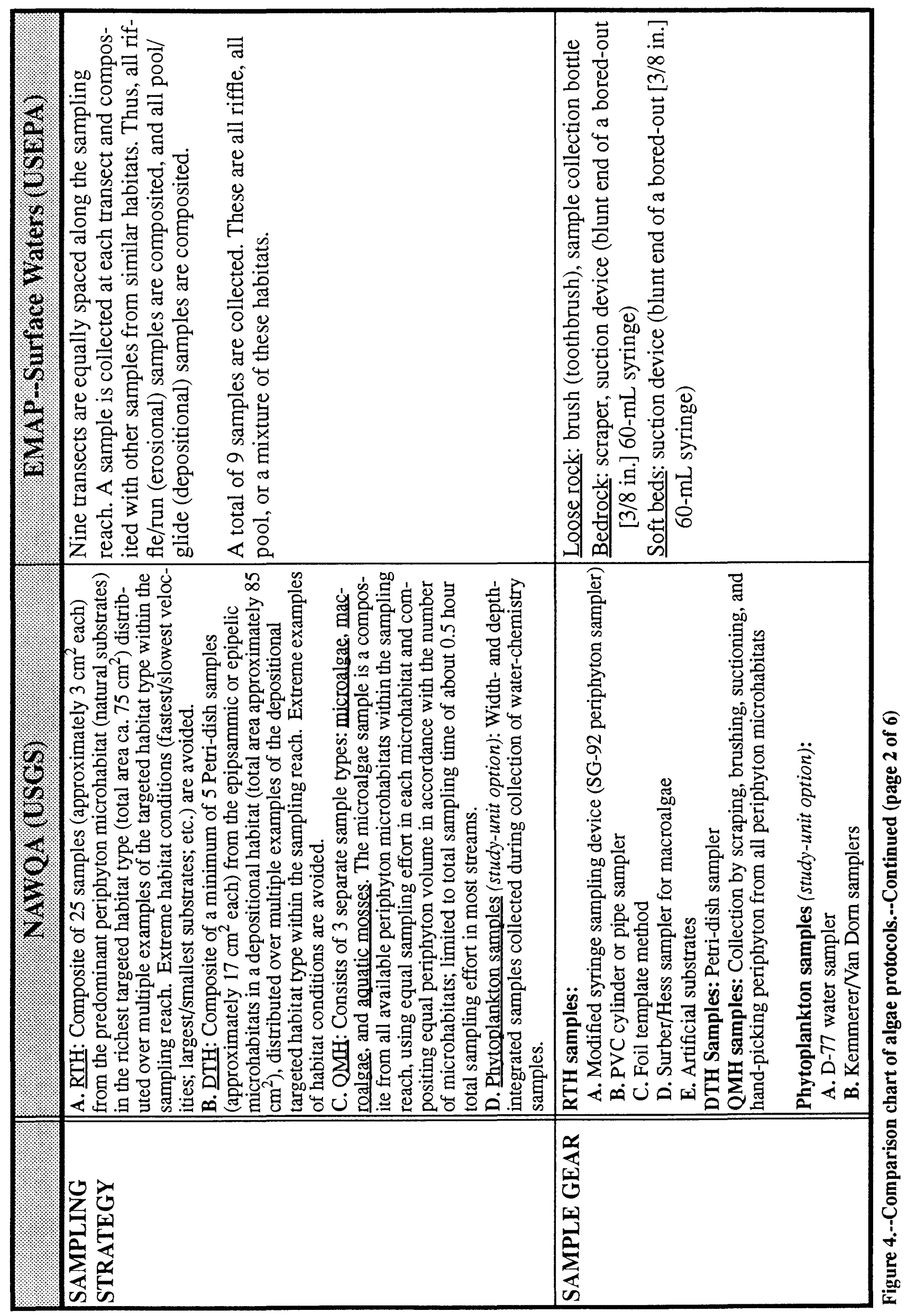




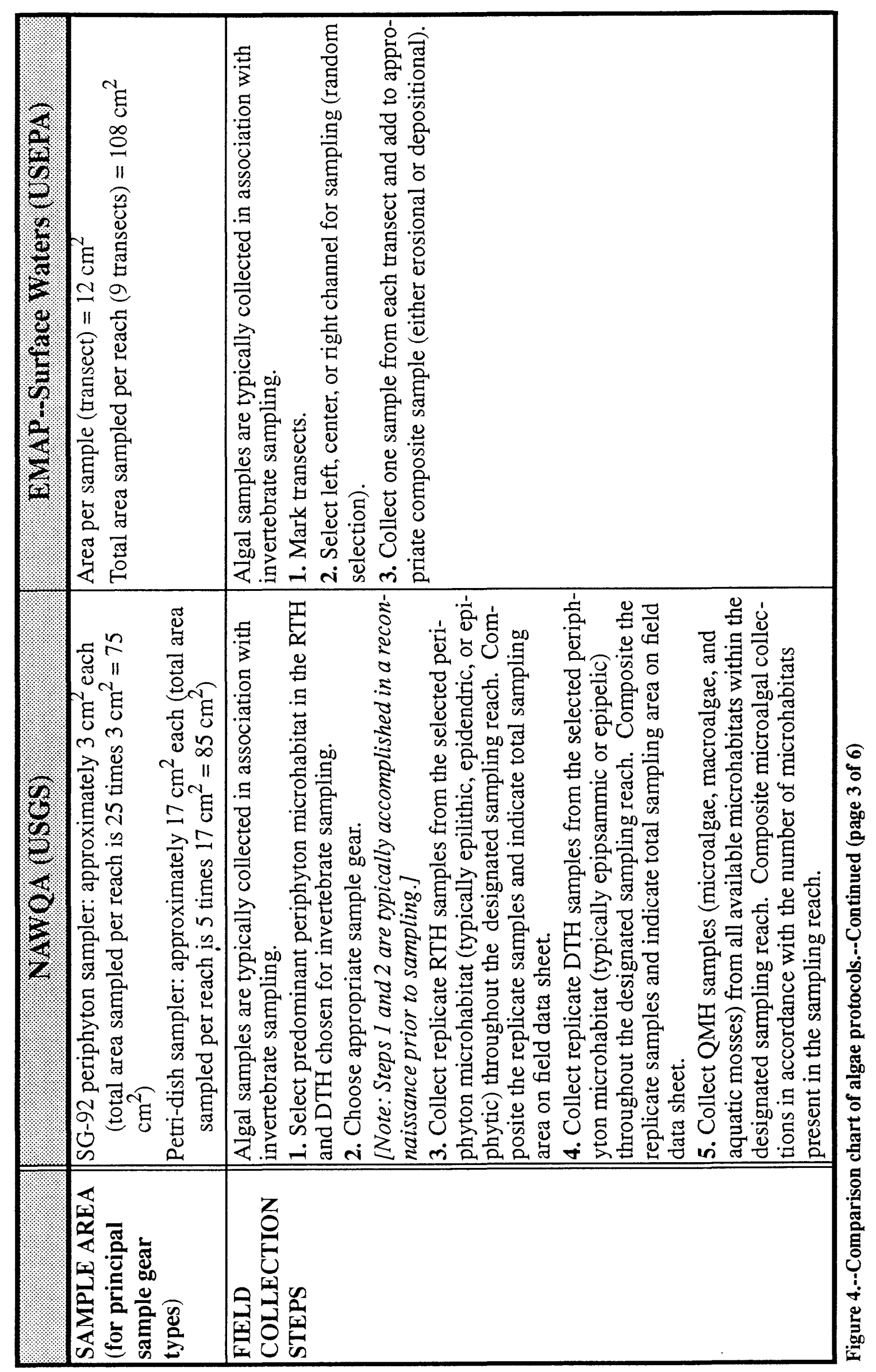




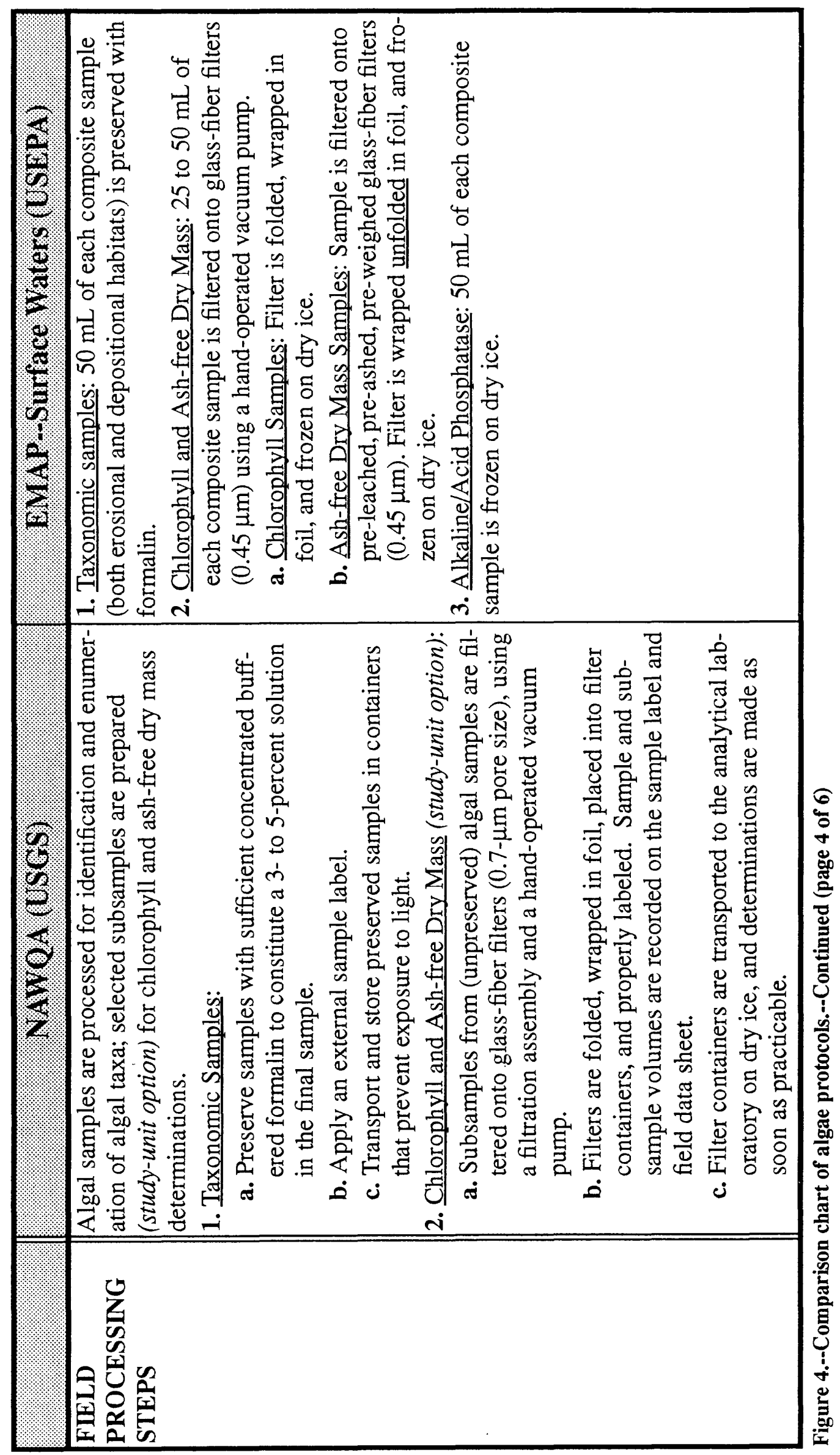




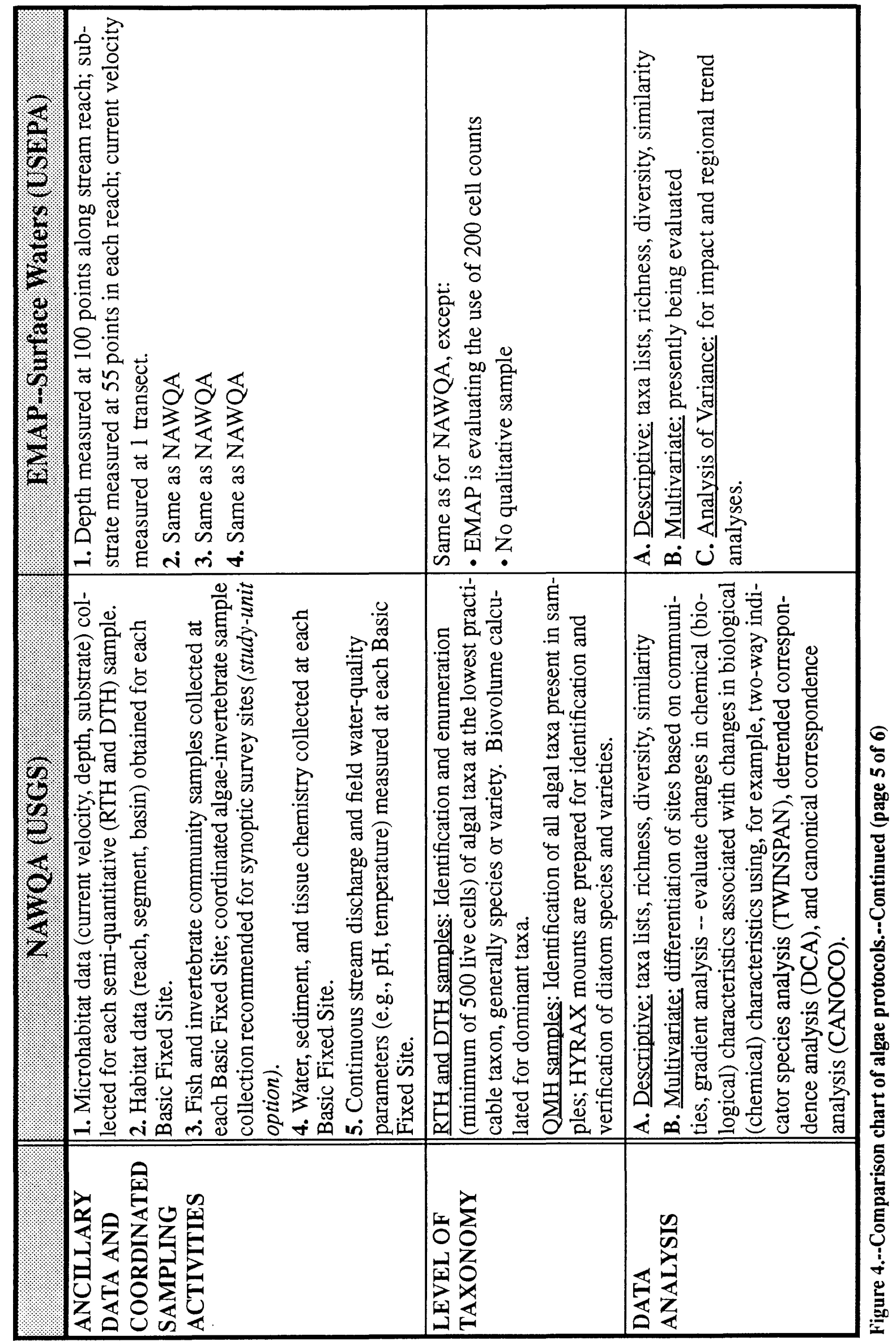




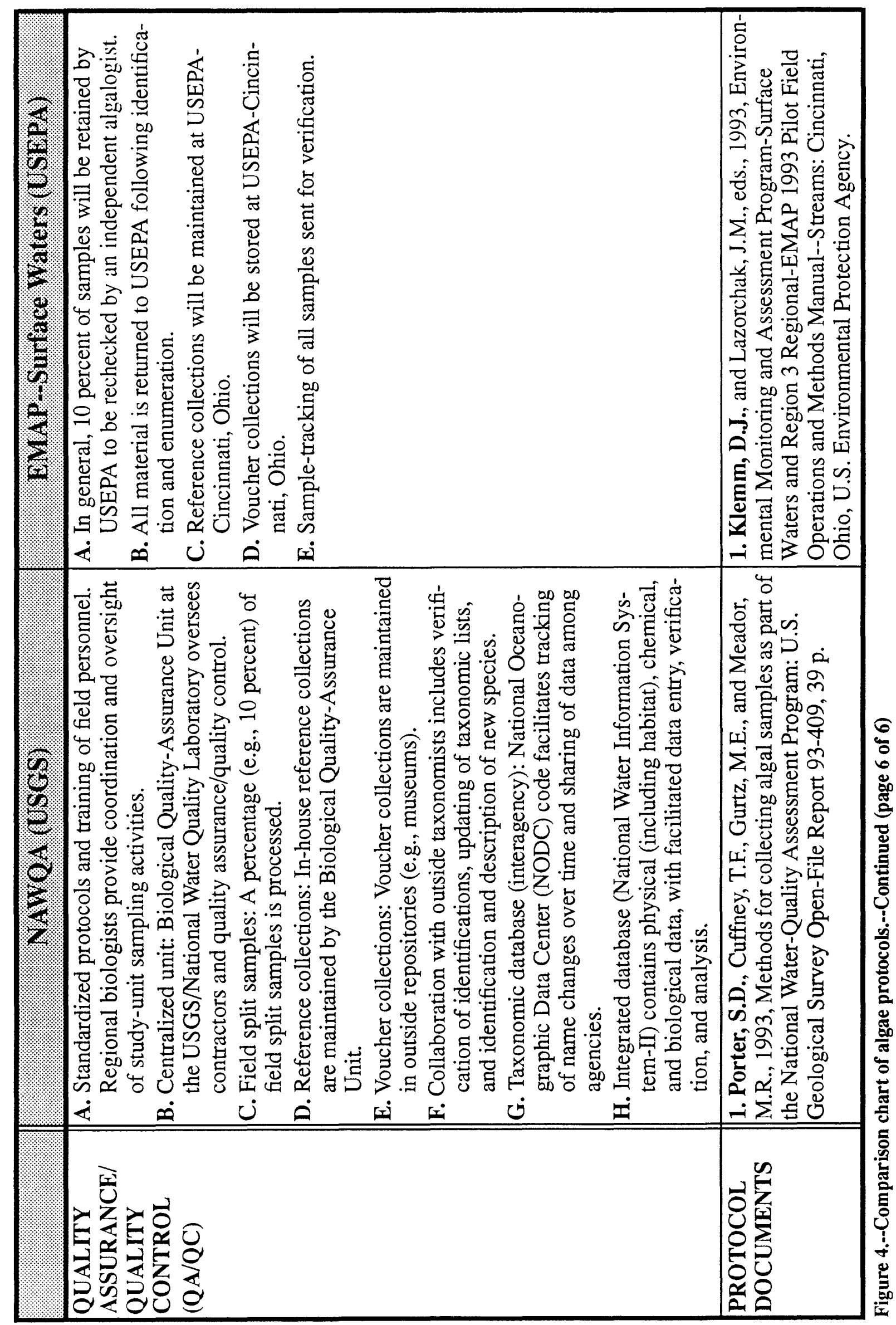




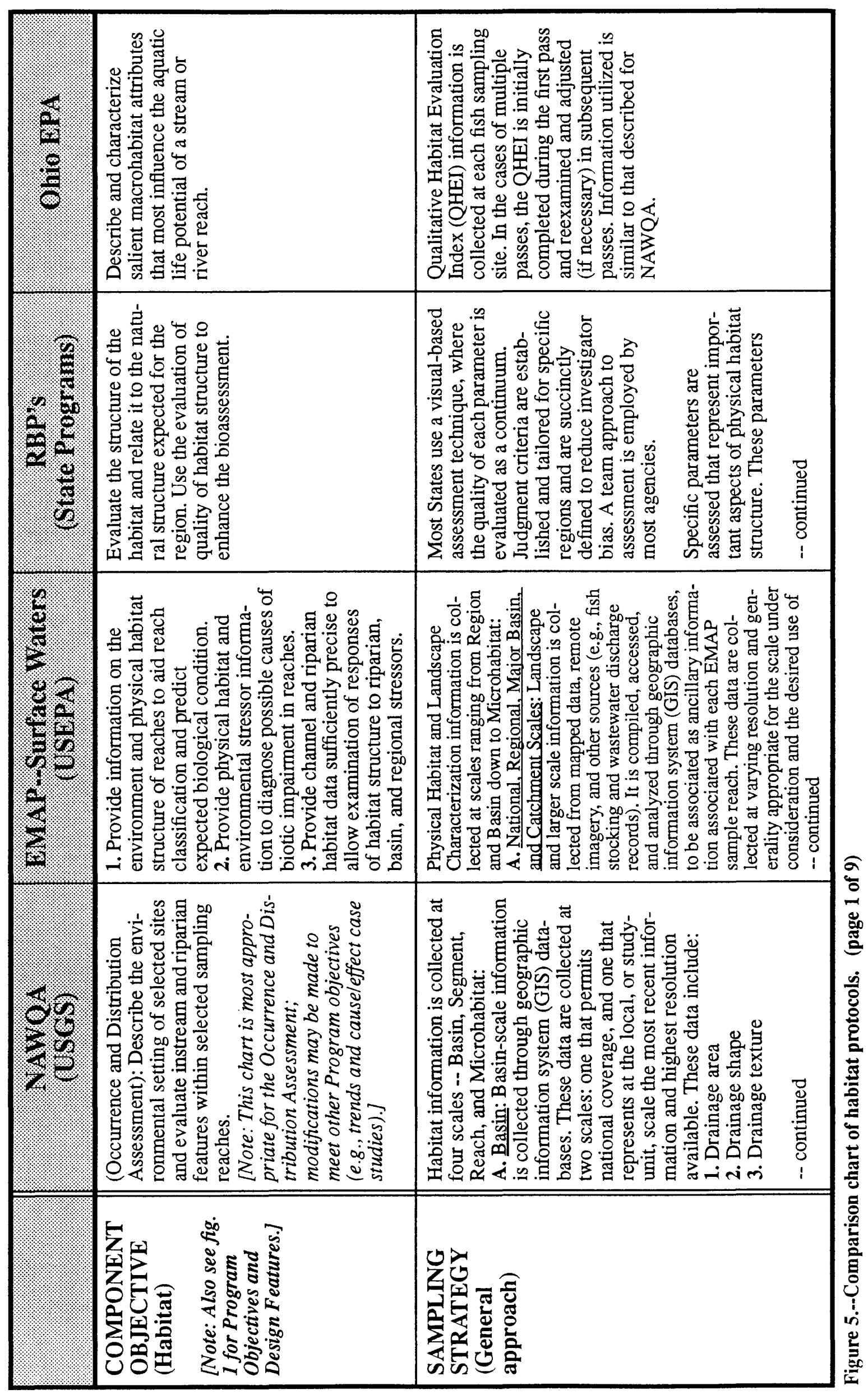




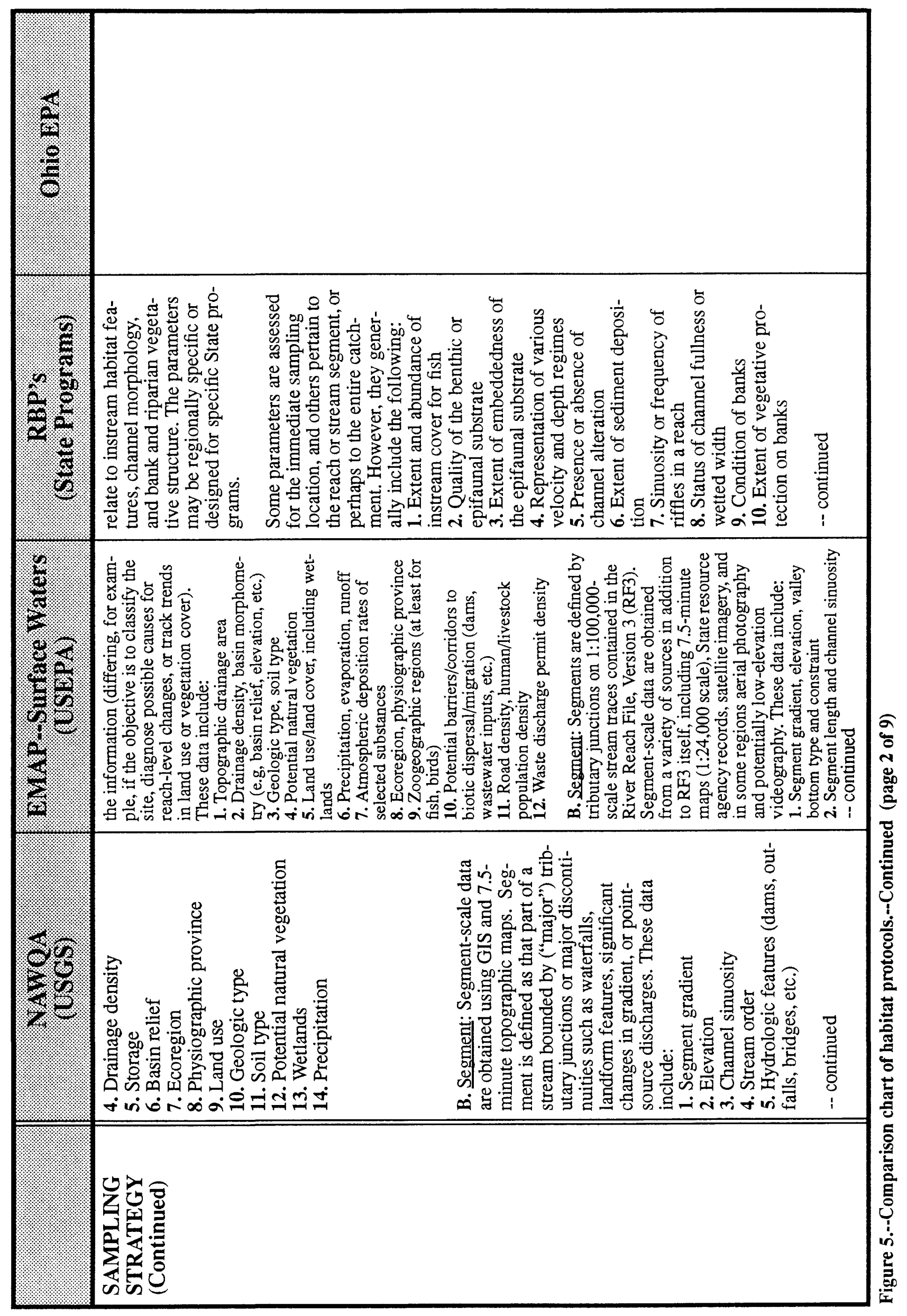




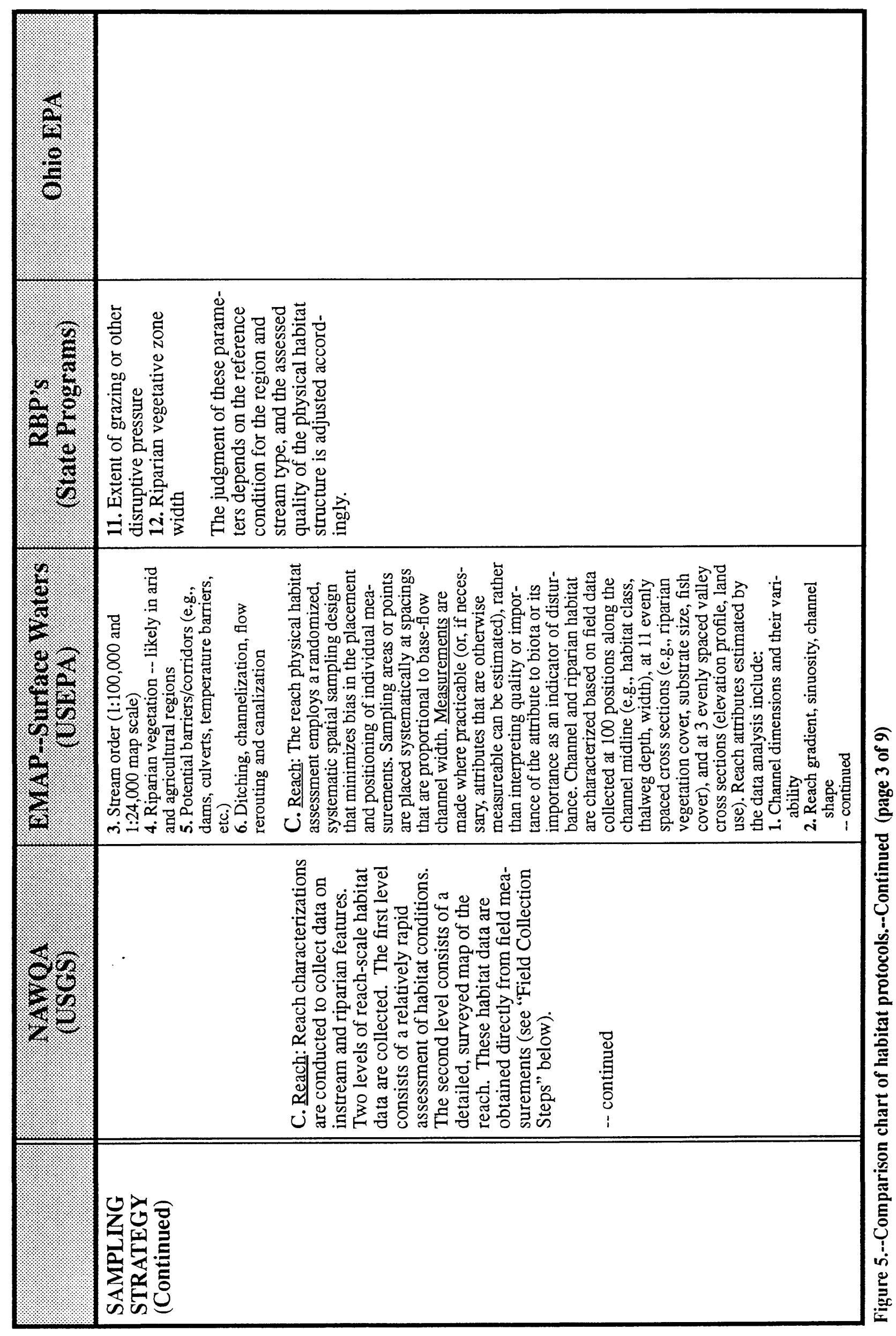




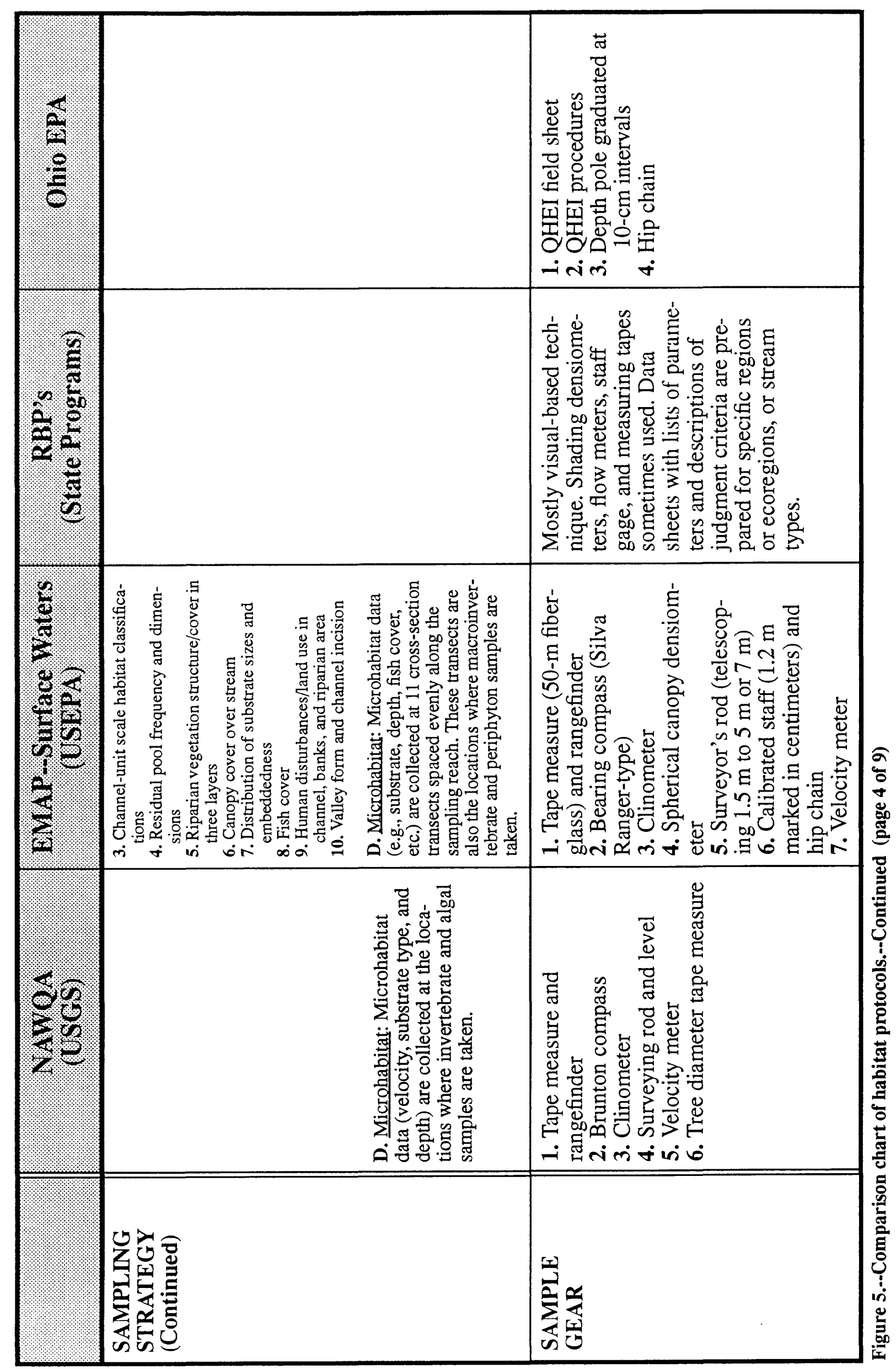




\begin{tabular}{|c|c|c|}
\hline$\frac{\pi}{8}$ & 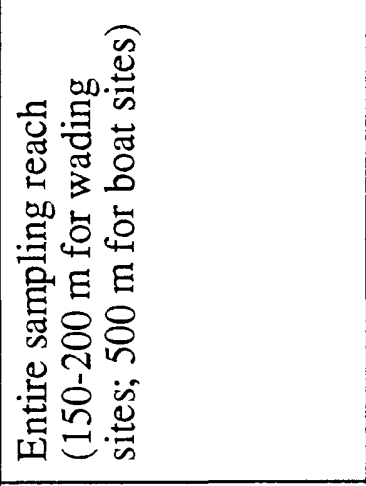 & 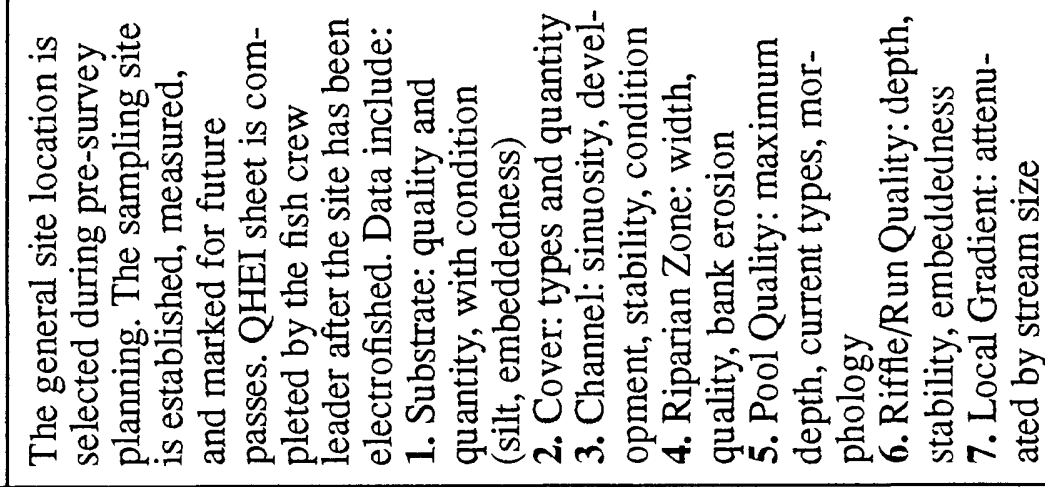 \\
\hline 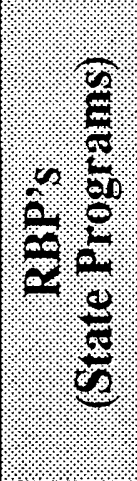 & 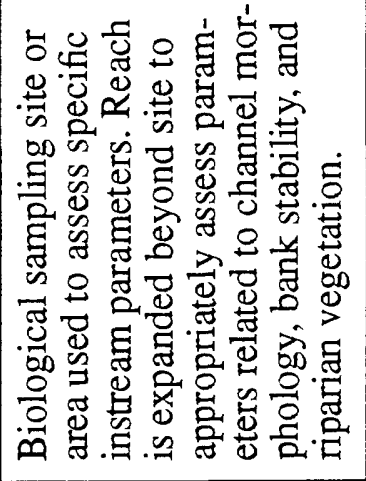 & 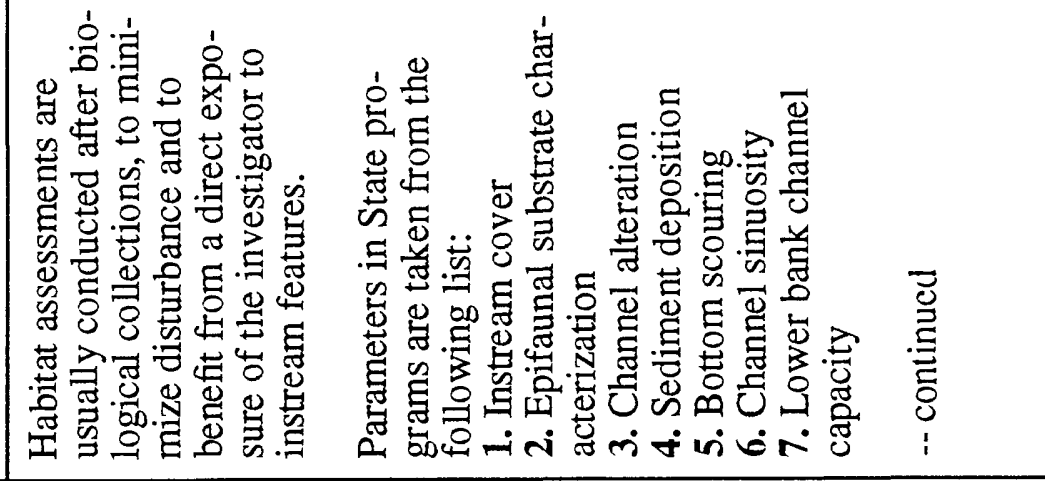 \\
\hline 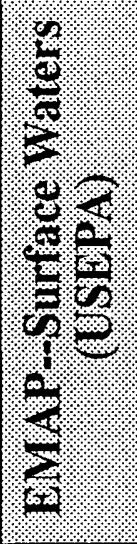 & 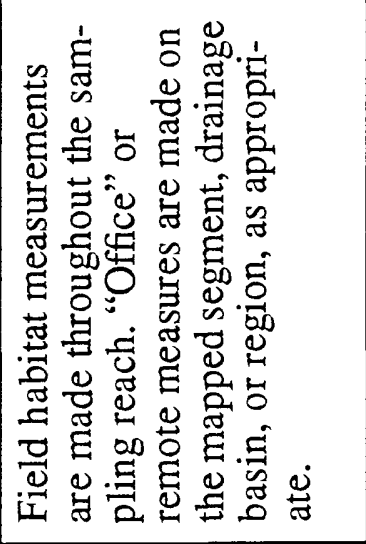 & 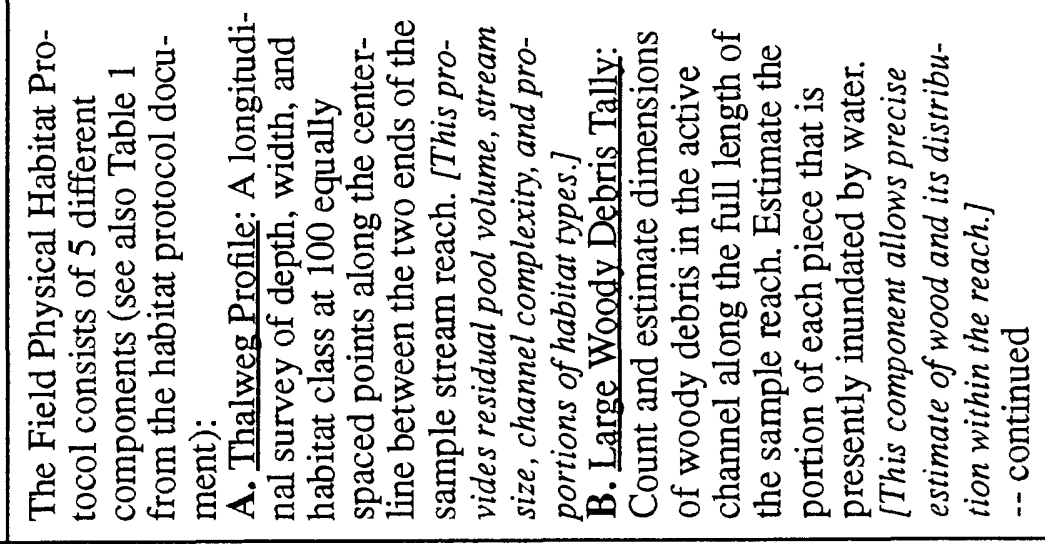 \\
\hline$\frac{3}{2}$ & 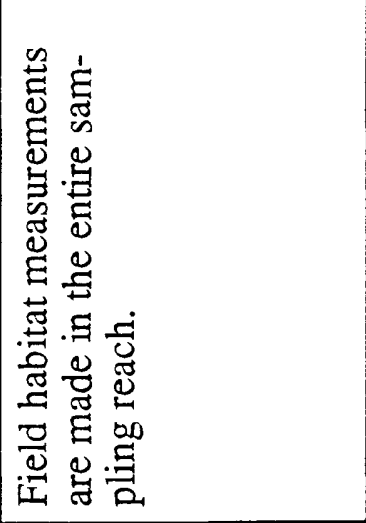 & 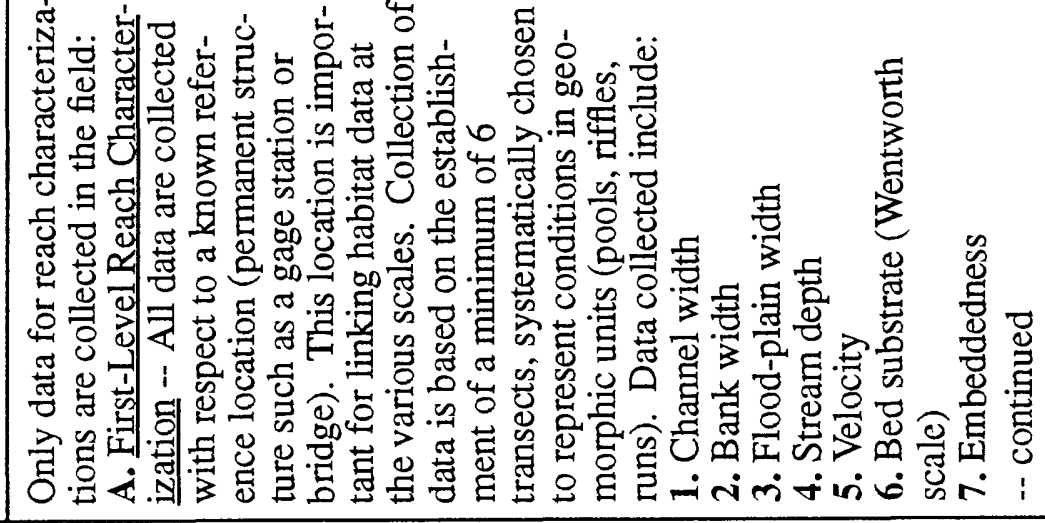 \\
\hline & 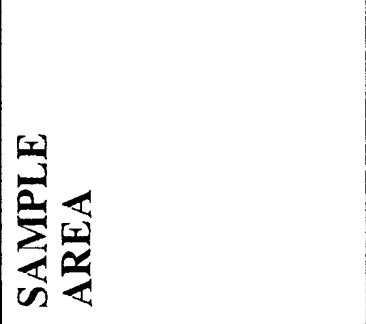 & 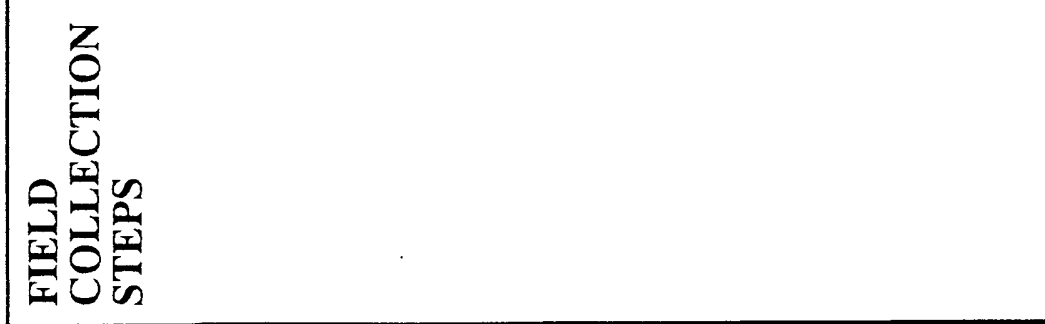 \\
\hline
\end{tabular}




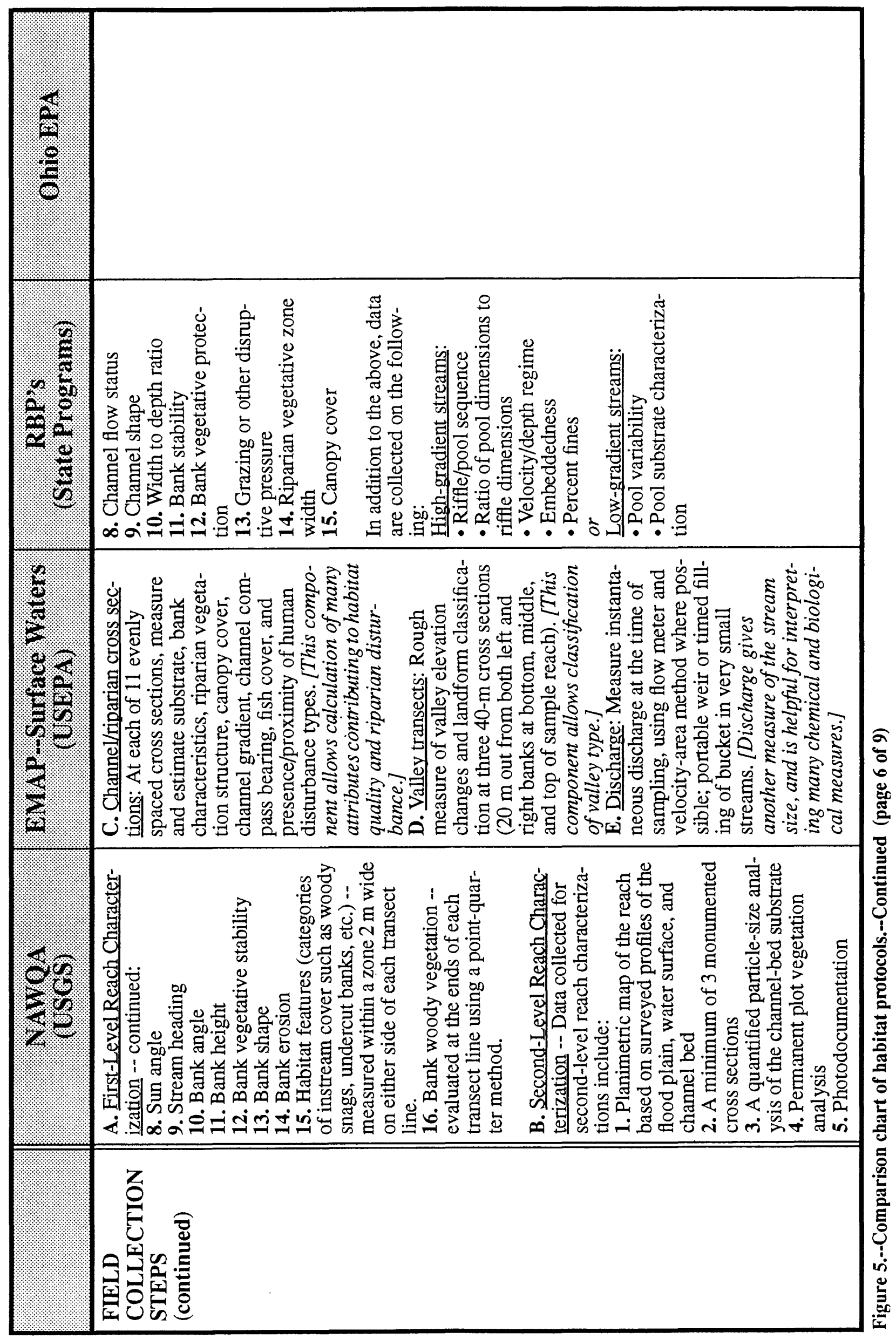




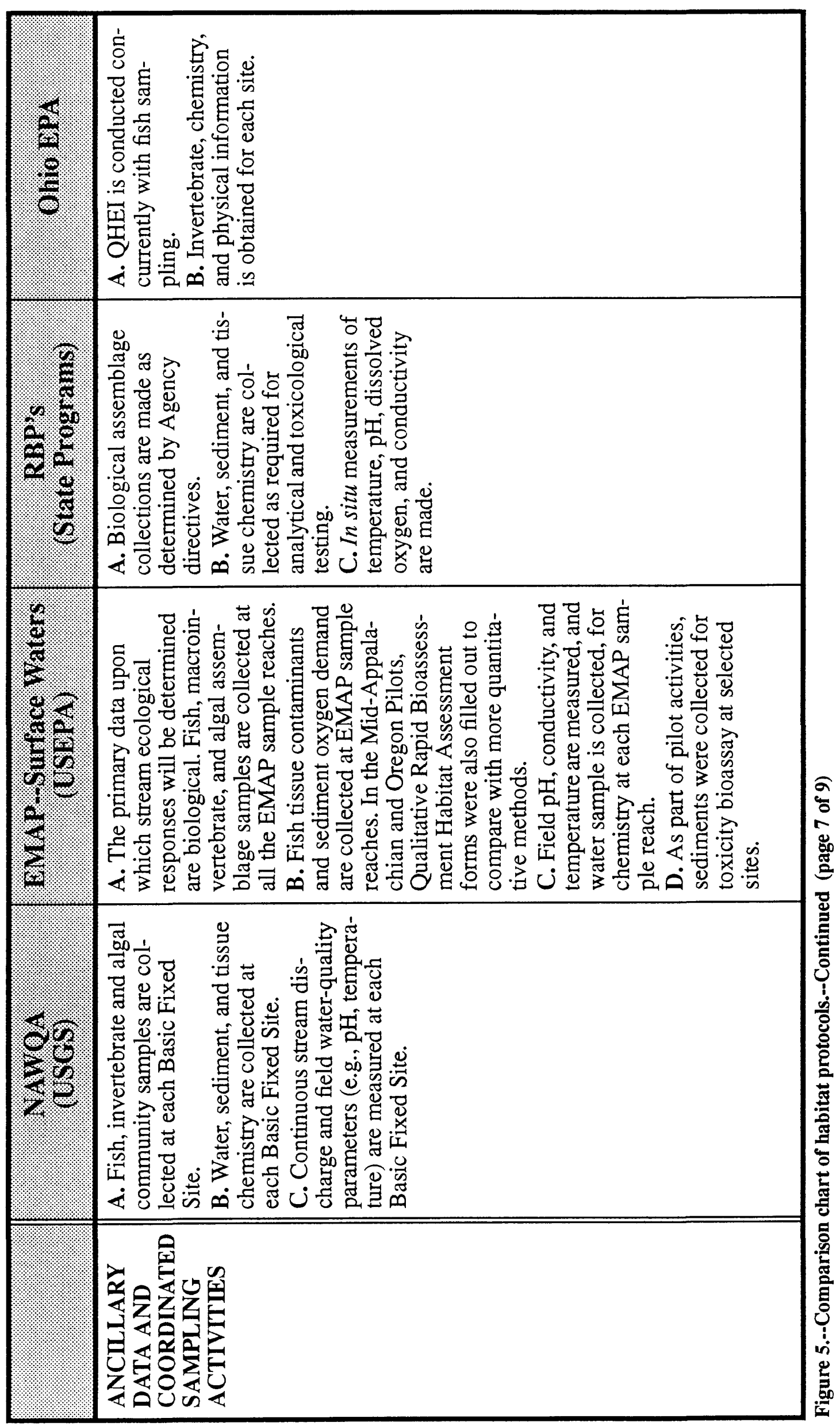




\begin{tabular}{|c|c|c|}
\hline है. & 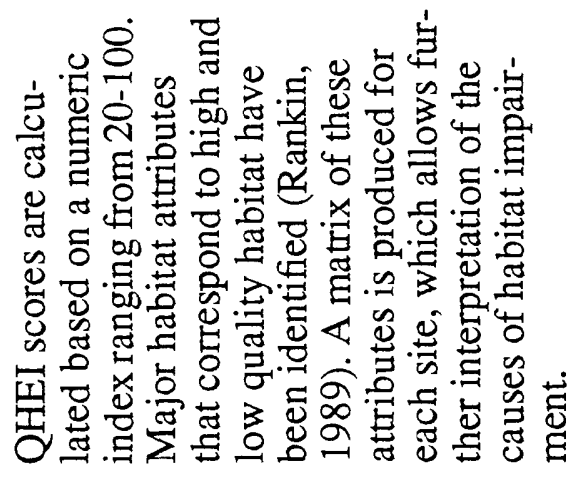 & 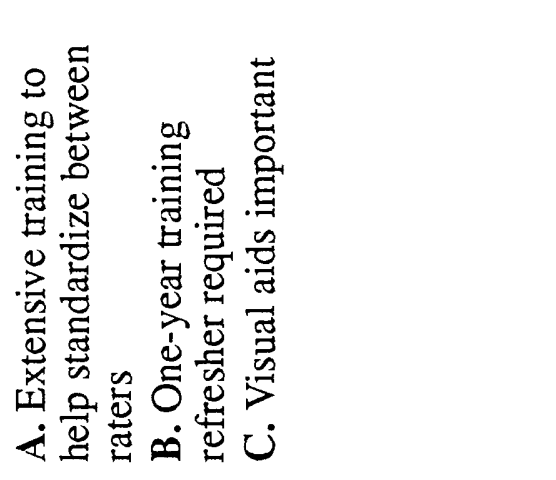 \\
\hline 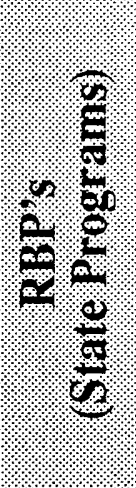 & 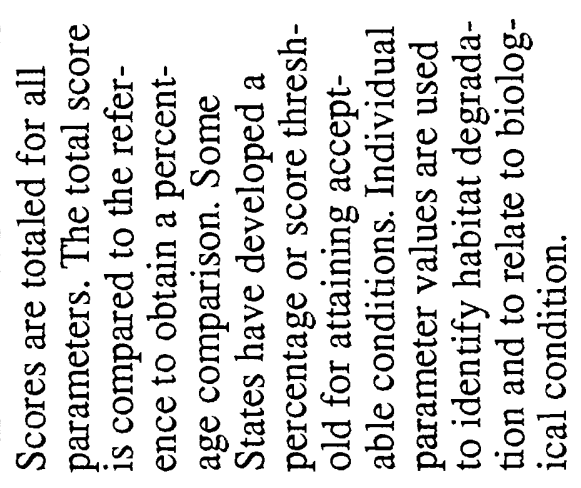 & 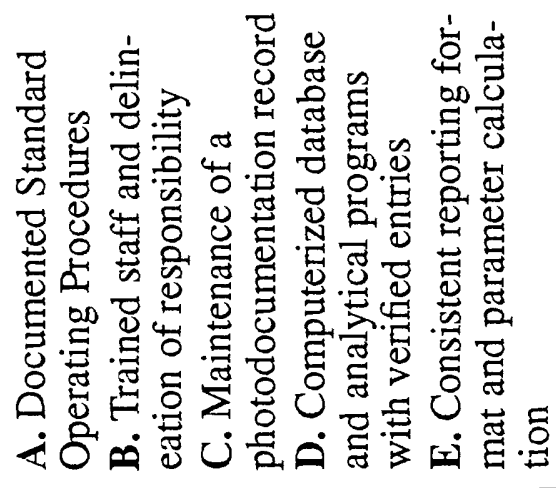 \\
\hline 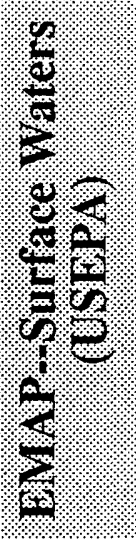 & 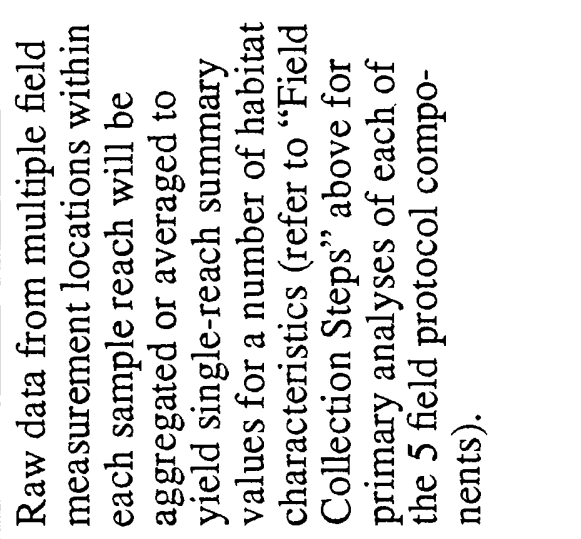 & 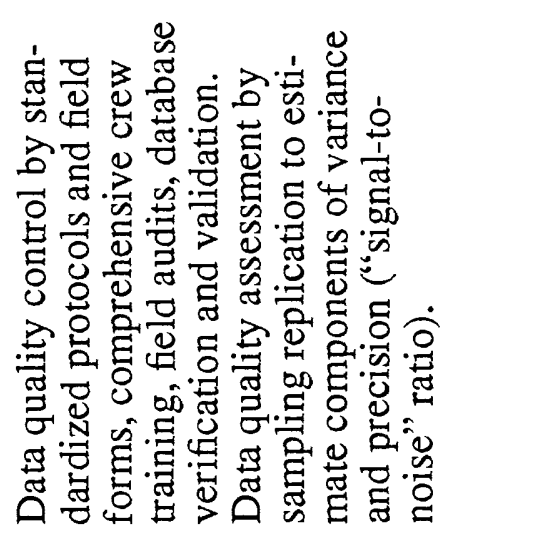 \\
\hline 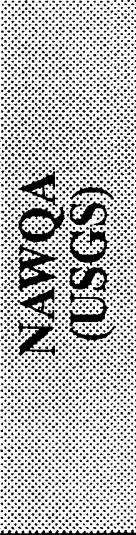 & 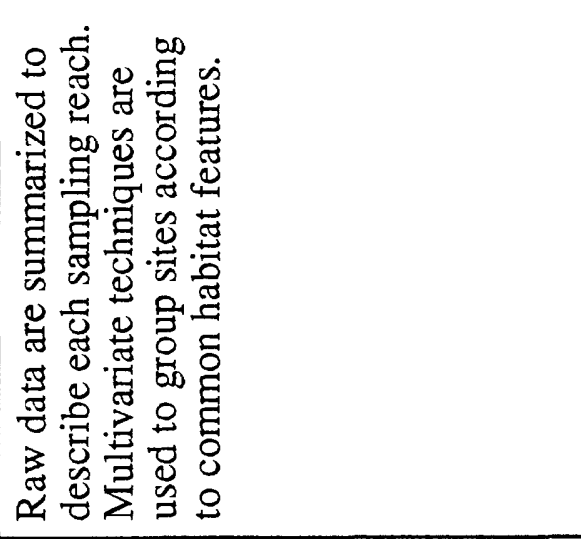 & 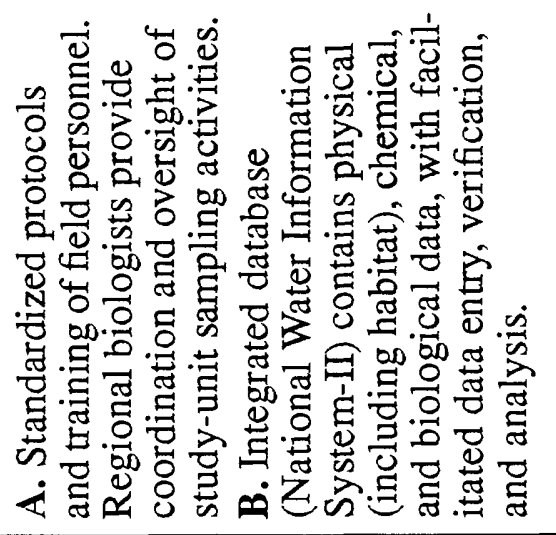 \\
\hline & 焉变 & 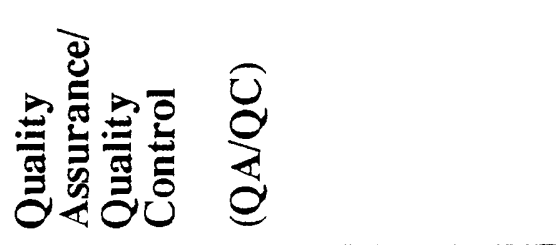 \\
\hline
\end{tabular}




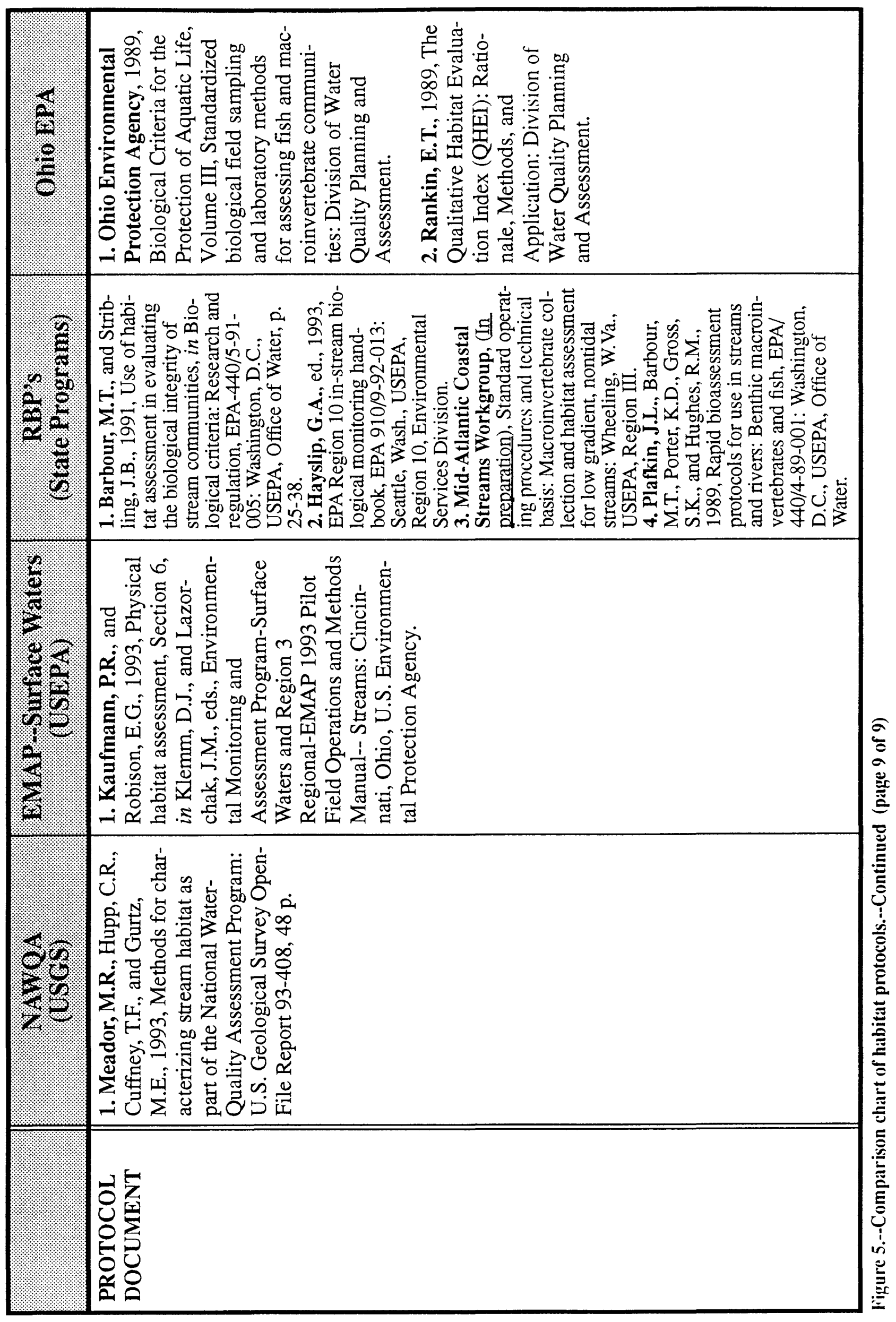




\begin{tabular}{|c|c|c|c|c|c|}
\hline Mrysical habitat characteristic & $\frac{6}{4}$ & $\frac{a^{2}}{1+1}$ & $\frac{6}{6}$ & $\sqrt{2}$ & $\frac{6}{6}$ \\
\hline $\begin{array}{l}\text { Channel Width } \\
\text { a. Wetted Width -- at several places } \\
\text { b. Wetted Width -- one estimate } \\
\text { Channel Depth } \\
\text { a. Via Transect } \\
\text { b. Via Habitat } \\
\text { c. Thalweg Depth } \\
\text { Channel Gradient }\end{array}$ & $\begin{array}{l}\mathbf{X} \\
\mathbf{X} \\
\mathbf{X}\end{array}$ & $\begin{array}{l}\mathbf{X} \\
\mathbf{X} \\
\mathbf{X} \\
\mathbf{X}\end{array}$ & $\mathbf{x}$ & $\begin{array}{l}\mathbf{X} \\
\mathbf{X}\end{array}$ & $\begin{array}{l}\mathbf{x} \\
\mathbf{X}\end{array}$ \\
\hline $\begin{array}{l}\text { Bed Substrate (Visual) } \\
\text { a. Pebble Counts } \\
\text { b. Surface Fines (P/A=Presence/Absence) } \\
\text { Embeddedness }\end{array}$ & $\begin{array}{c}\mathbf{X} \\
\mathbf{X} \\
\mathbf{P} / \mathbf{A} \\
\mathbf{X}\end{array}$ & $\begin{array}{l}\mathbf{X} \\
\mathbf{X} \\
\mathbf{X} \\
\mathbf{X}\end{array}$ & $\mathbf{X}$ & $\begin{array}{l}\mathbf{X} \\
\mathbf{X} \\
\mathbf{X} \\
\mathbf{X}\end{array}$ & $\begin{array}{l}\mathbf{X} \\
\mathbf{X} \\
\mathbf{X} \\
\mathbf{X}\end{array}$ \\
\hline $\begin{array}{l}\text { Habitat Features / Cover (Instream; e.g., snags, } \\
\text { boulders, cobble, pools, etc.) } \\
\text { Large Woody Debris }\end{array}$ & $\begin{array}{c}\mathrm{X} \\
\text { Indirect }\end{array}$ & $\begin{array}{l}x \\
x\end{array}$ & $\begin{array}{c}\mathrm{X} \\
\text { Indirect }\end{array}$ & $\begin{array}{l}\mathrm{x} \\
\mathrm{x}\end{array}$ & $\begin{array}{l}\mathbf{x} \\
\mathbf{x}\end{array}$ \\
\hline $\begin{array}{l}\text { Sun Angle } \\
\text { Shading (Canopy Cover) } \\
\text { Stream Heading (Aspect) } \\
\text { Channel Shape }\end{array}$ & $\begin{array}{c}\mathrm{X} \\
\mathrm{X} \\
\text { Indirect }\end{array}$ & $\begin{array}{c}\mathbf{X} \\
\mathbf{X} \\
\text { Indirect }\end{array}$ & $\begin{array}{c}\mathrm{X} \\
\text { Indirect } \\
\text { Indirect }\end{array}$ & $\begin{array}{c}\mathrm{X} \\
\text { Indirect }\end{array}$ & $\begin{array}{l}\text { Indirect } \\
\text { Optional }\end{array}$ \\
\hline $\begin{array}{l}\text { Velocity } \\
\text { Discharge (Flow) }\end{array}$ & $\begin{array}{l}\mathbf{X} \\
\mathbf{X}\end{array}$ & $\begin{array}{l}\mathbf{X} \\
\mathbf{X}\end{array}$ & $\begin{array}{c}\mathrm{X} \\
\text { Indirect }\end{array}$ & $\begin{array}{c}\mathrm{X} \\
\text { Indirect }\end{array}$ & $\begin{array}{c}\mathrm{X} \\
\text { Indirect }\end{array}$ \\
\hline $\begin{array}{l}\text { Bank Angle (Hor=Horizontal, Ver=Vertical) } \\
\text { Bank Height } \\
\text { Bank Vegetative Stability (Platts) } \\
\text { Bank Shape } \\
\text { Bank Erosion }\end{array}$ & $\begin{array}{l}\text { X(Ver) } \\
\mathbf{X} \\
\mathbf{X} \\
\mathbf{X} \\
\mathbf{X}\end{array}$ & $\begin{array}{l}\mathbf{X}(\text { Ver }) \\
\quad \mathbf{X} \\
\mathbf{X} \\
\text { Indirect } \\
\quad \mathbf{X}\end{array}$ & $\begin{array}{c}\mathrm{X} \\
\text { Indirect } \\
\mathbf{X}\end{array}$ & $\begin{array}{c}\mathbf{X}(\text { Hor }) \\
\mathbf{X} \\
\mathbf{X}\end{array}$ & $\begin{array}{l}\text { X(Hor) } \\
\text { Optional } \\
\text { X }\end{array}$ \\
\hline $\begin{array}{l}\text { Bank Width } \\
\text { Bankfull Width } \\
\text { Flood-plain Width }\end{array}$ & $\begin{array}{c}X \\
\text { Indirect } \\
X\end{array}$ & $\mathbf{x}$ & Indirect & $\begin{array}{c}\text { Indirect } \\
\mathbf{X} \\
\text { Indirect }\end{array}$ & $\begin{array}{c}\text { Indirect } \\
\mathbf{X} \\
\text { Indirect }\end{array}$ \\
\hline $\begin{array}{l}\text { Riparian Zone } \\
\text { a. Vegetation Type } \\
\text { b. Density } \\
\text { c. Dominance } \\
\text { d. Vigor / Biomass } \\
\text { e. Areal Extent / Width } \\
\text { f. Successional Stage (Size Class) }\end{array}$ & $\begin{array}{c}\mathbf{X} \\
\mathbf{X} \\
\text { Indirect } \\
\mathbf{X} \\
\text { Indirect } \\
\text { Indirect }\end{array}$ & $\begin{array}{c}X \\
\text { Indirect } \\
X \\
\text { Indirect } \\
X \\
\text { Indirect }\end{array}$ & $\begin{array}{l}\text { Indirect } \\
\text { Indirect } \\
\mathbf{X} \\
\mathrm{X}\end{array}$ & $\begin{array}{l}\mathbf{X} \\
\mathbf{X} \\
\mathbf{X} \\
\mathbf{X}\end{array}$ & $\begin{array}{c}\quad \text { X } \\
\text { Indirect } \\
\text { Indirect } \\
\text { Indirect } \\
\text { Indirect } \\
\text { Indirect }\end{array}$ \\
\hline Human Disturbance & & $\mathbf{x}$ & $\mathbf{x}$ & & \\
\hline
\end{tabular}

Figure 6.--Comparison chart of physical and vegetative habitat characteristics. 


\begin{tabular}{|c|c|}
\hline 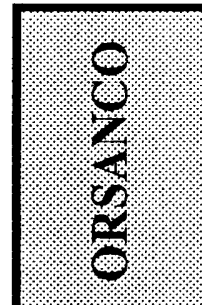 & 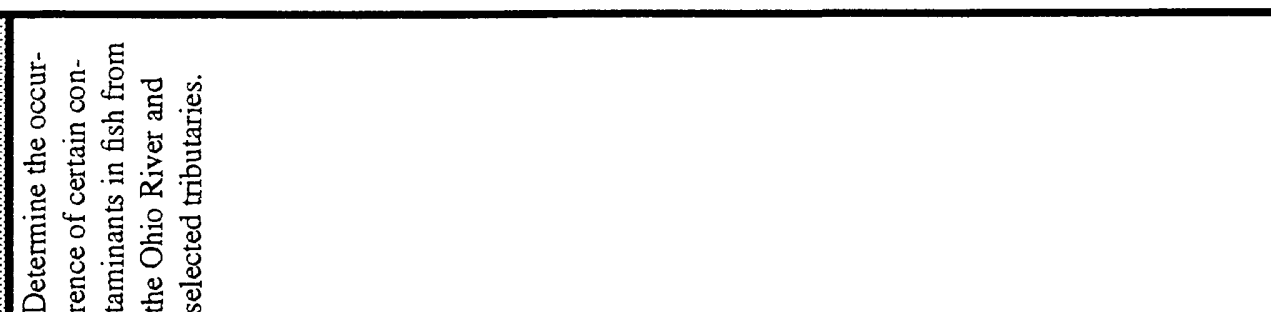 \\
\hline 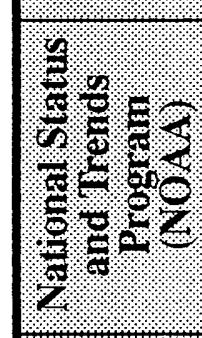 & 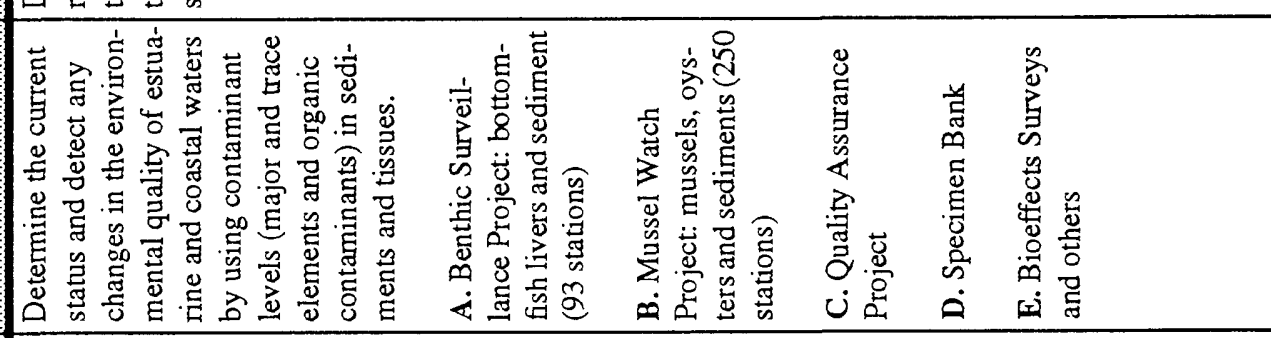 \\
\hline 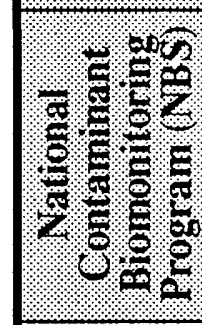 & 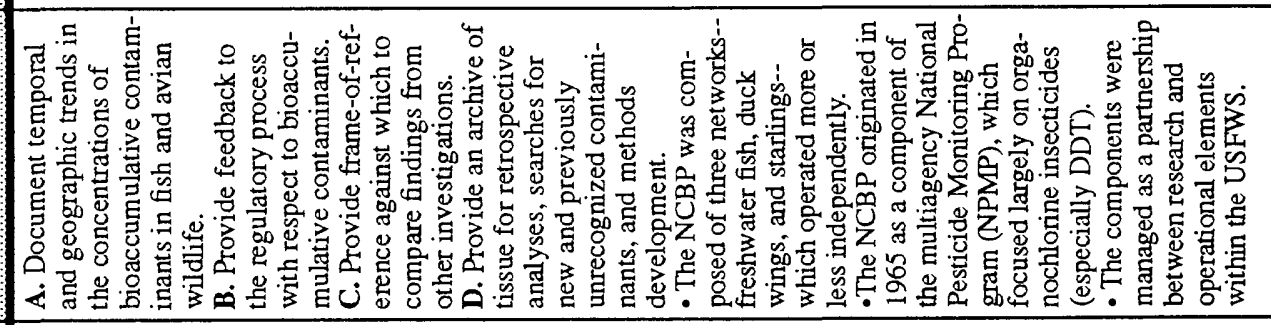 \\
\hline 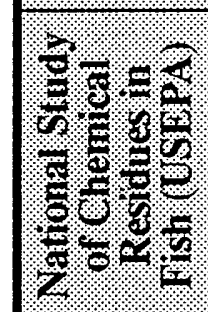 & 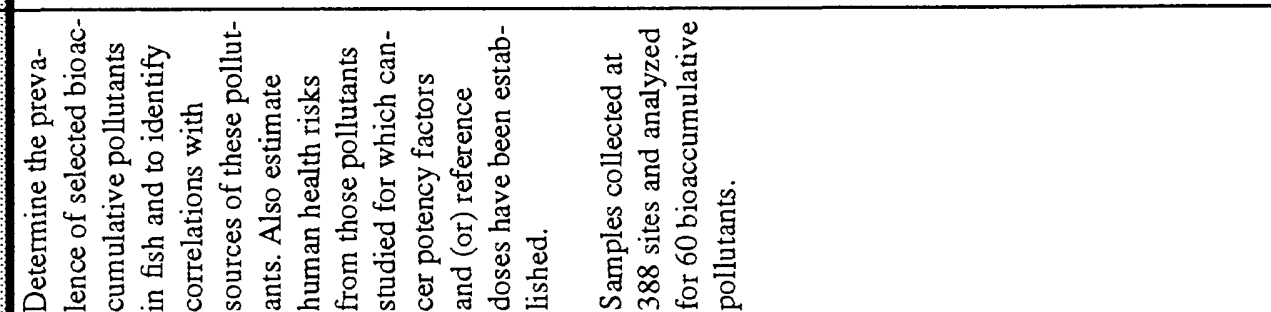 \\
\hline 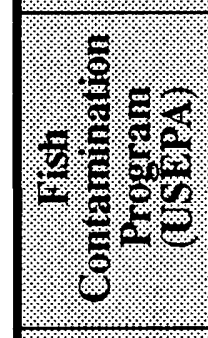 & 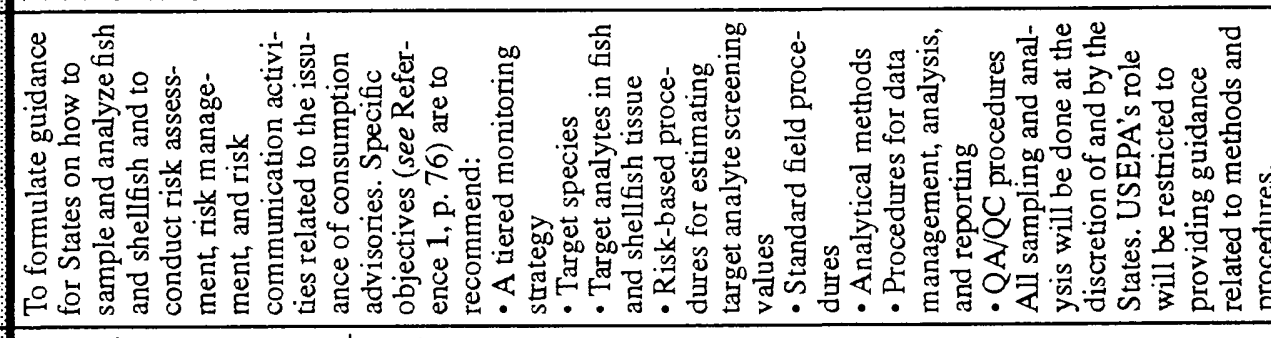 \\
\hline 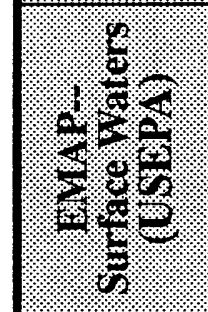 & 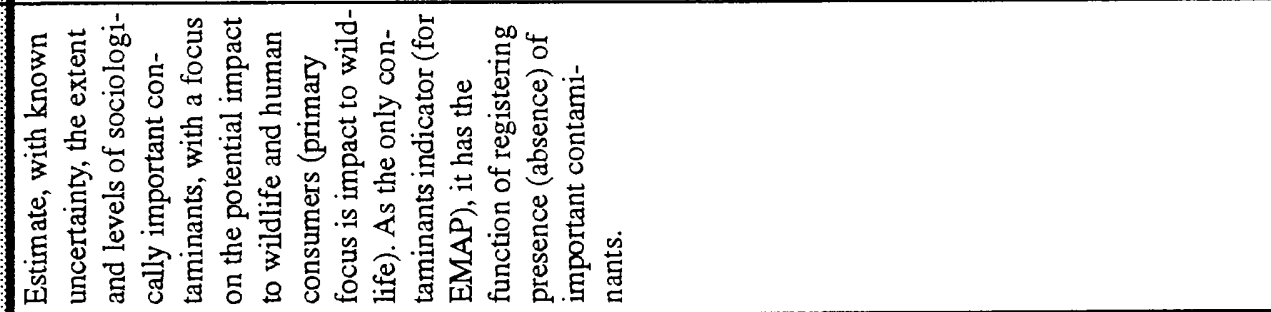 \\
\hline $\begin{array}{l}\frac{1}{2} \mathscr{b} \\
\frac{3}{2}\end{array}$ & 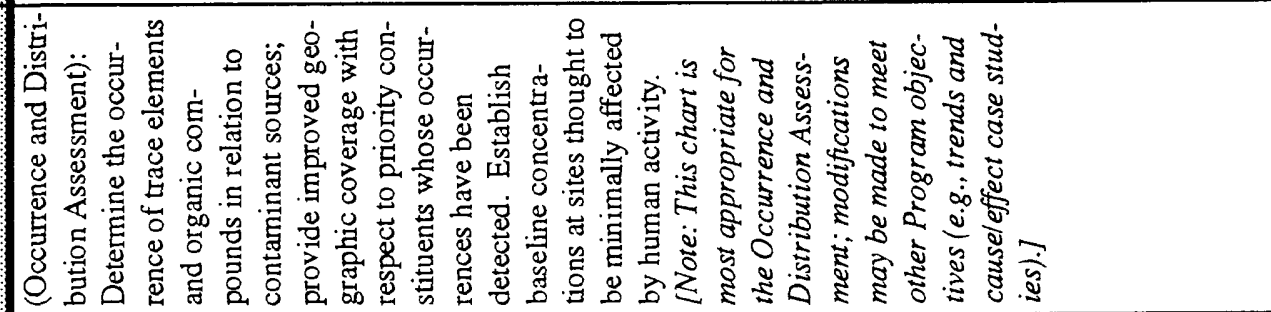 \\
\hline & 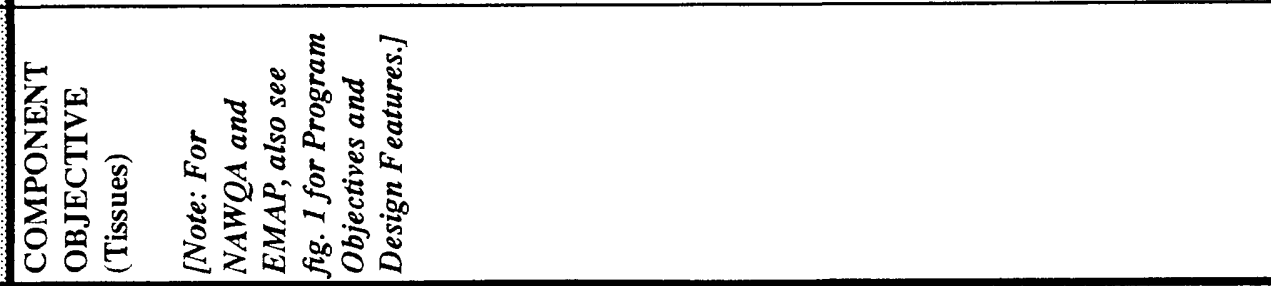 \\
\hline
\end{tabular}




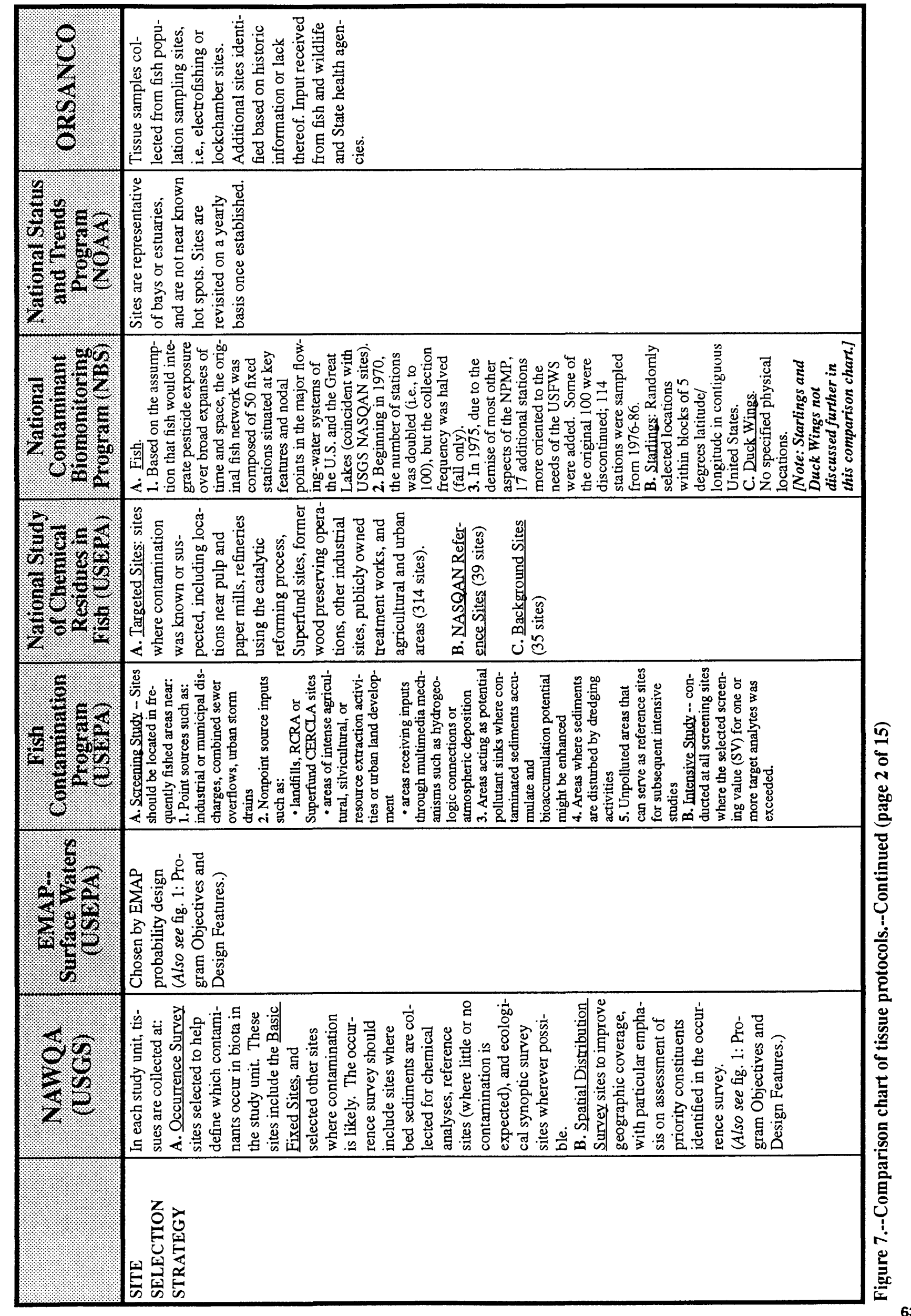




\begin{tabular}{|c|c|c|}
\hline$\frac{8}{\frac{8}{2}}$ & 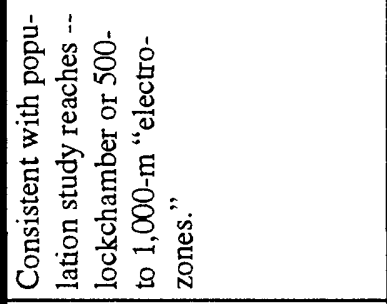 & 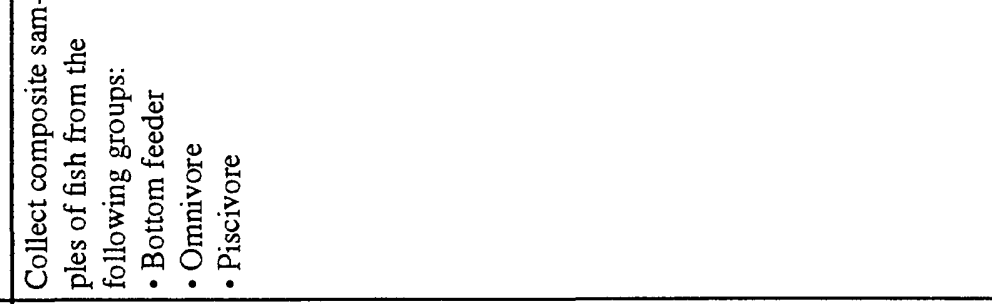 \\
\hline 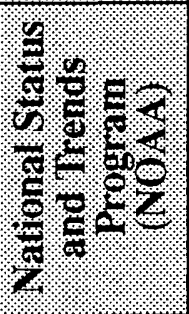 & & 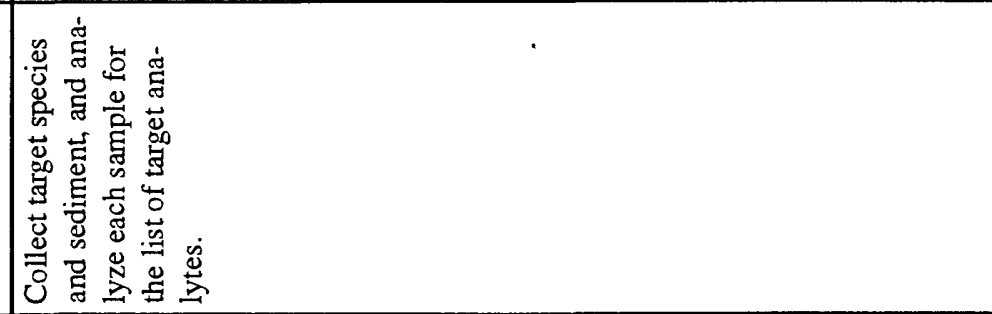 \\
\hline 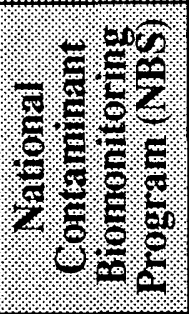 & 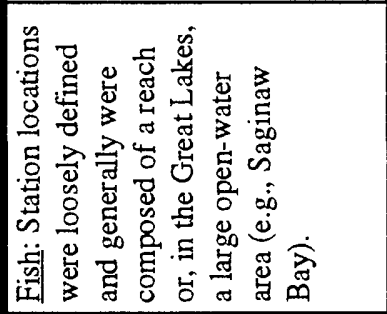 & 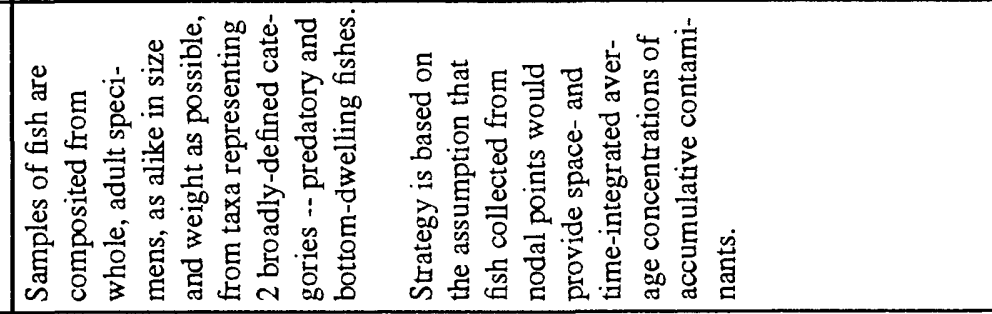 \\
\hline 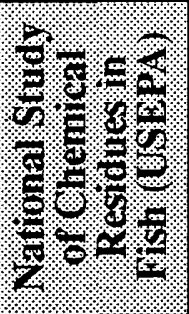 & & 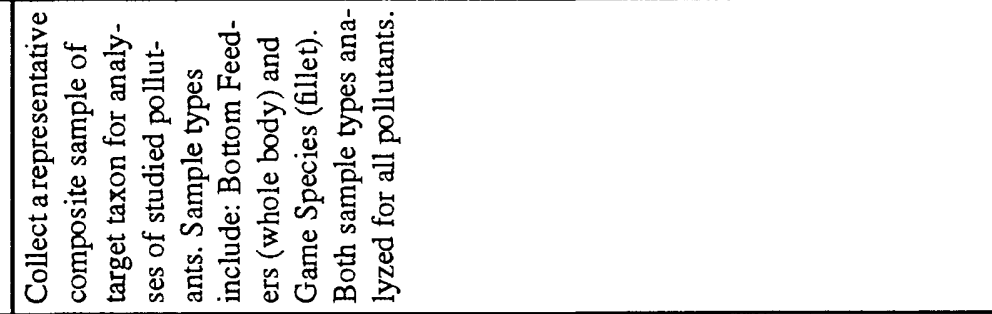 \\
\hline 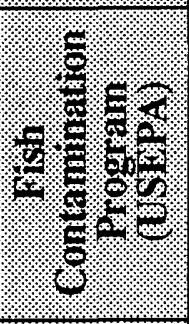 & 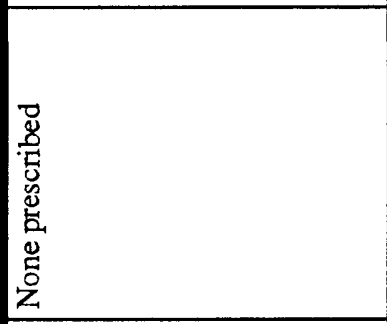 & 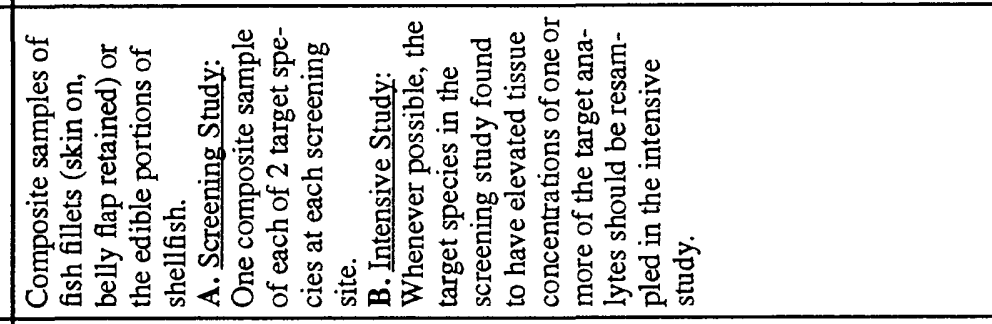 \\
\hline 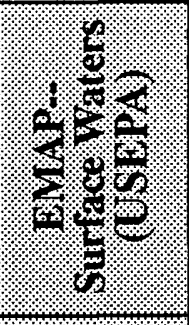 & 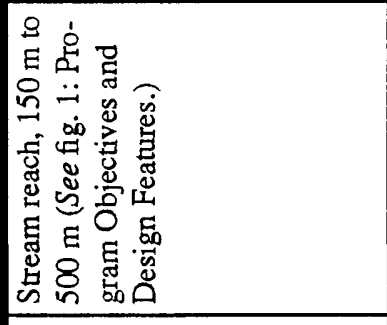 & 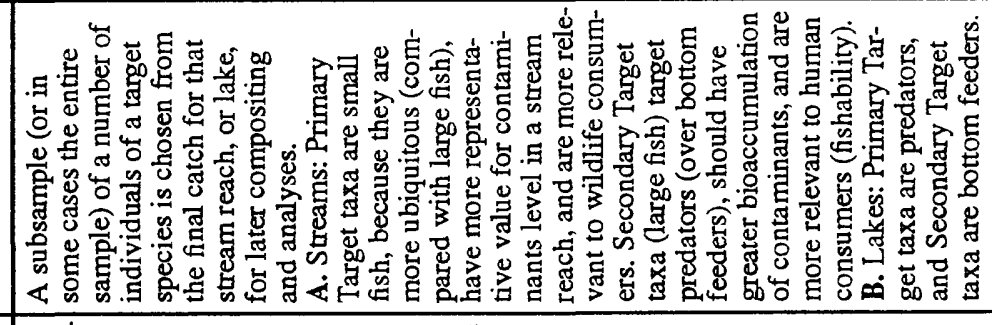 \\
\hline 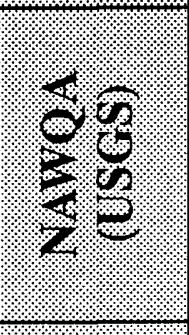 & 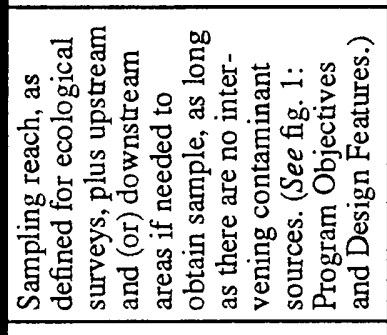 & 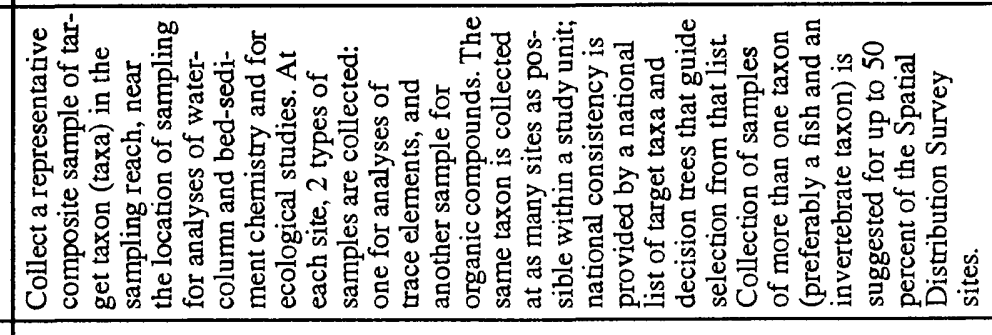 \\
\hline & 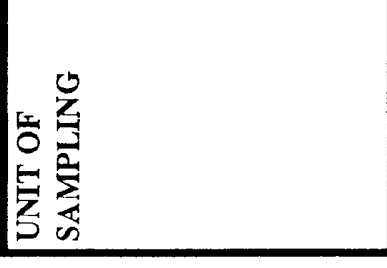 & 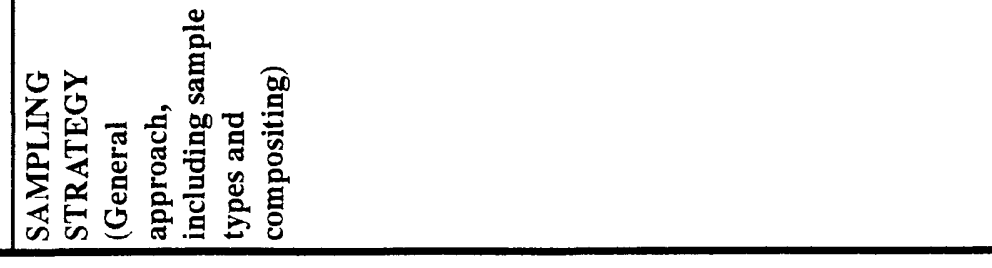 \\
\hline
\end{tabular}




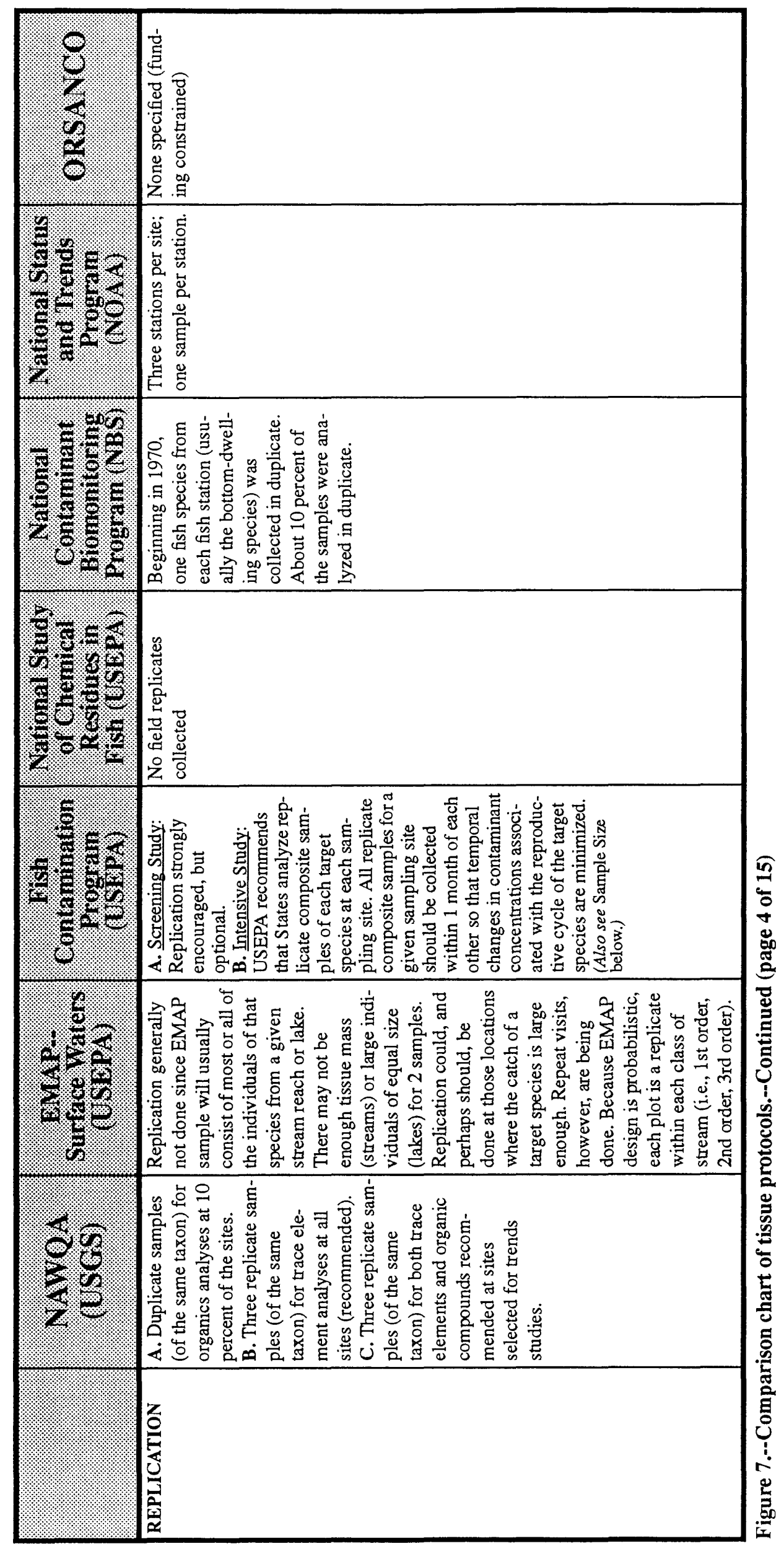




\begin{tabular}{|c|c|c|}
\hline 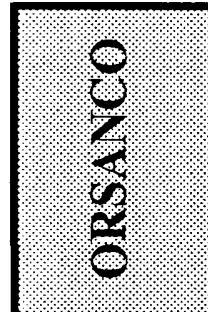 & 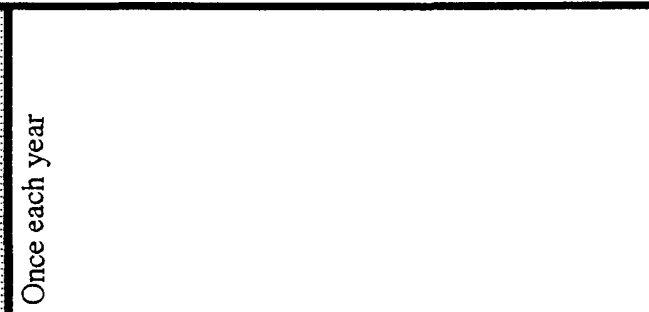 & \\
\hline 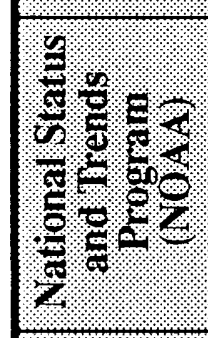 & 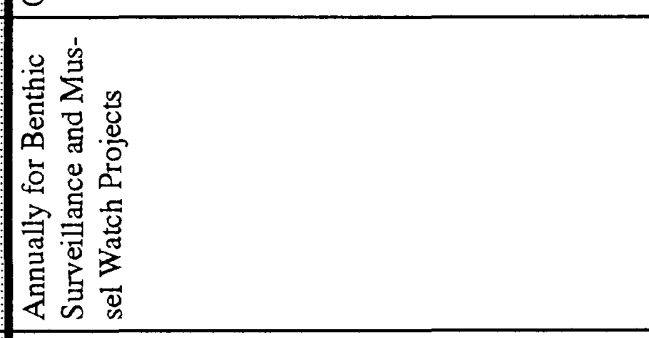 & 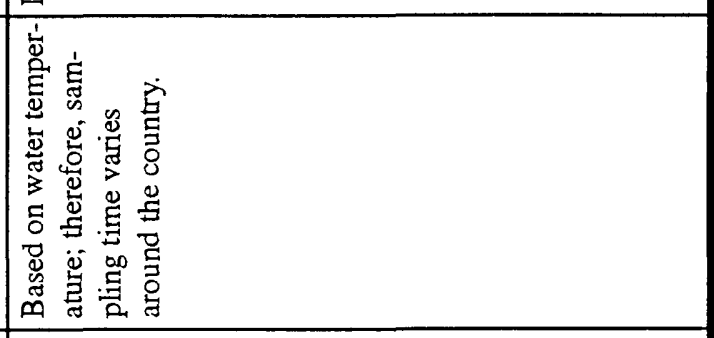 \\
\hline 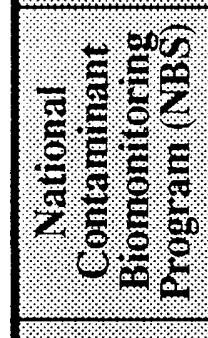 & 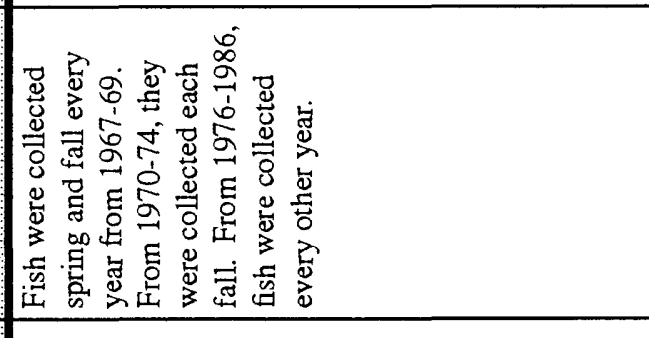 & 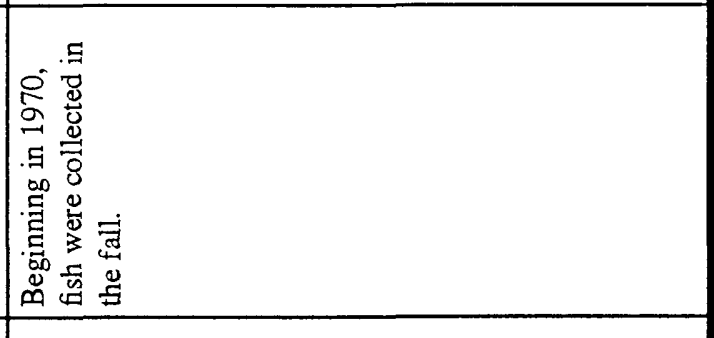 \\
\hline 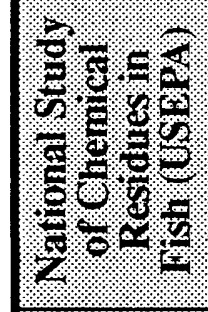 & 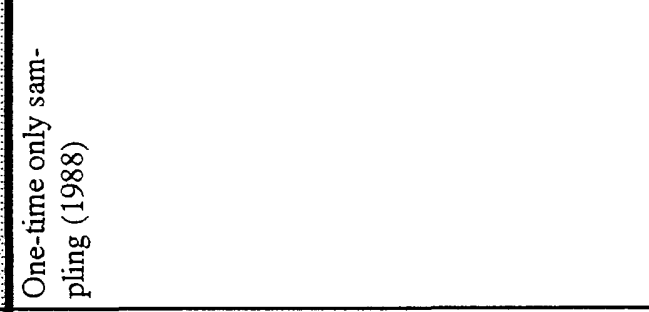 & 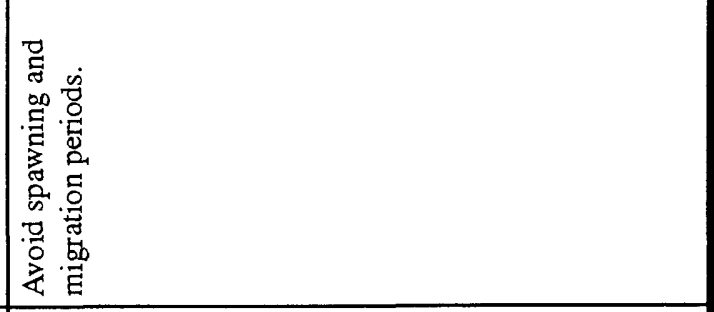 \\
\hline 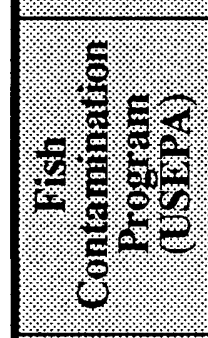 & 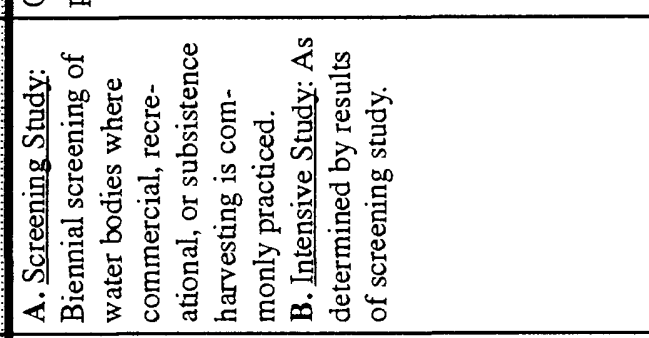 & 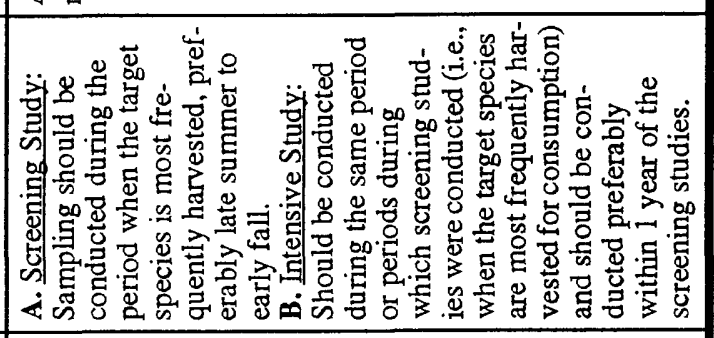 \\
\hline 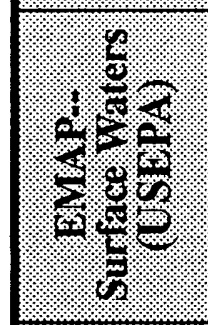 & 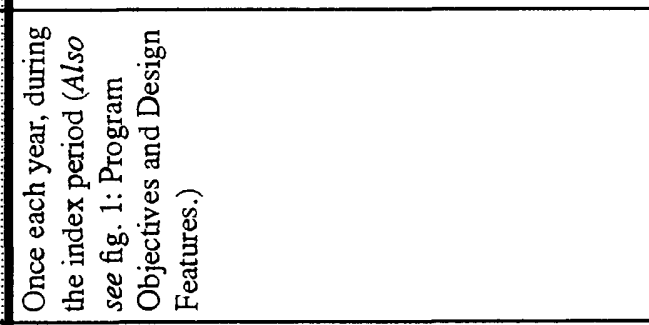 & 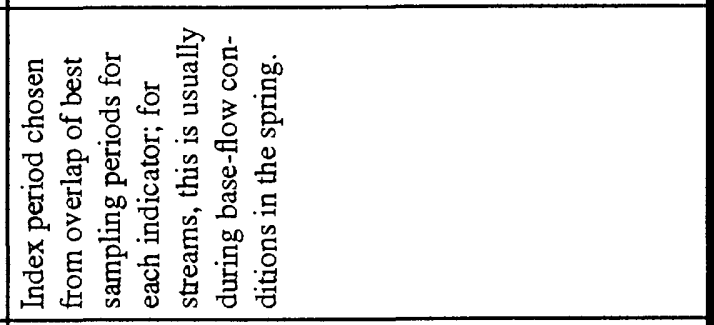 \\
\hline $\begin{array}{l}\frac{2}{2} \delta \\
\frac{3}{2}\end{array}$ & 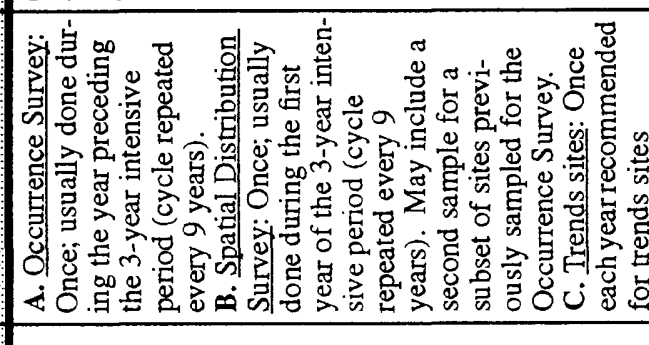 & 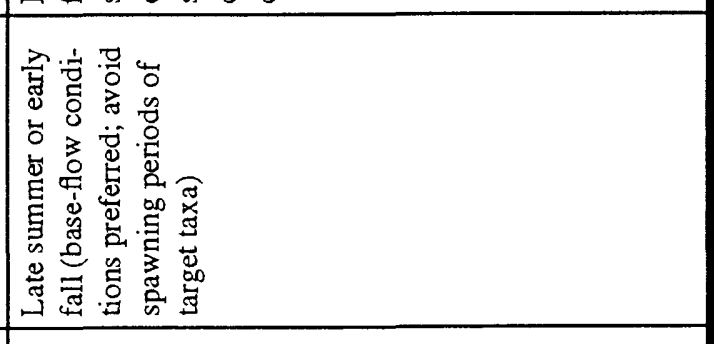 \\
\hline & 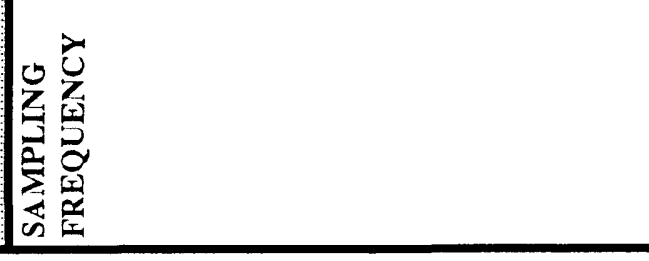 & 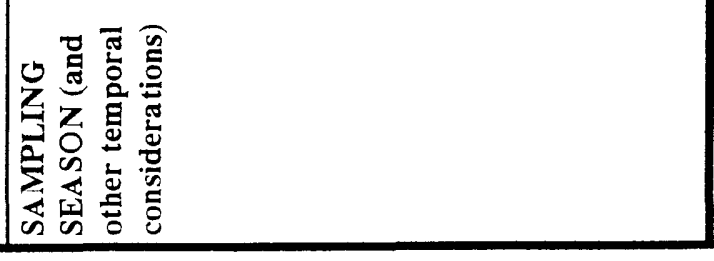 \\
\hline
\end{tabular}




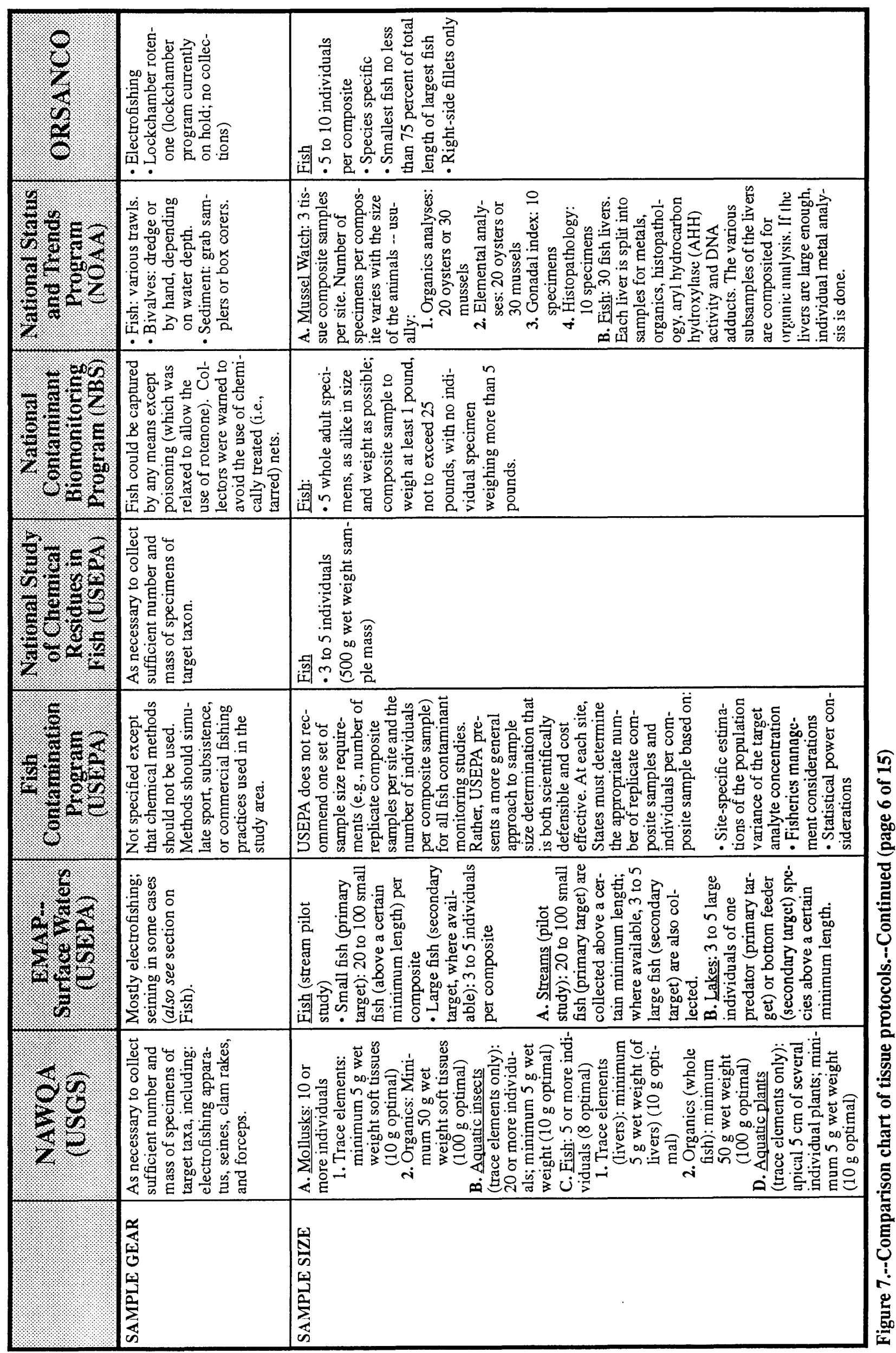




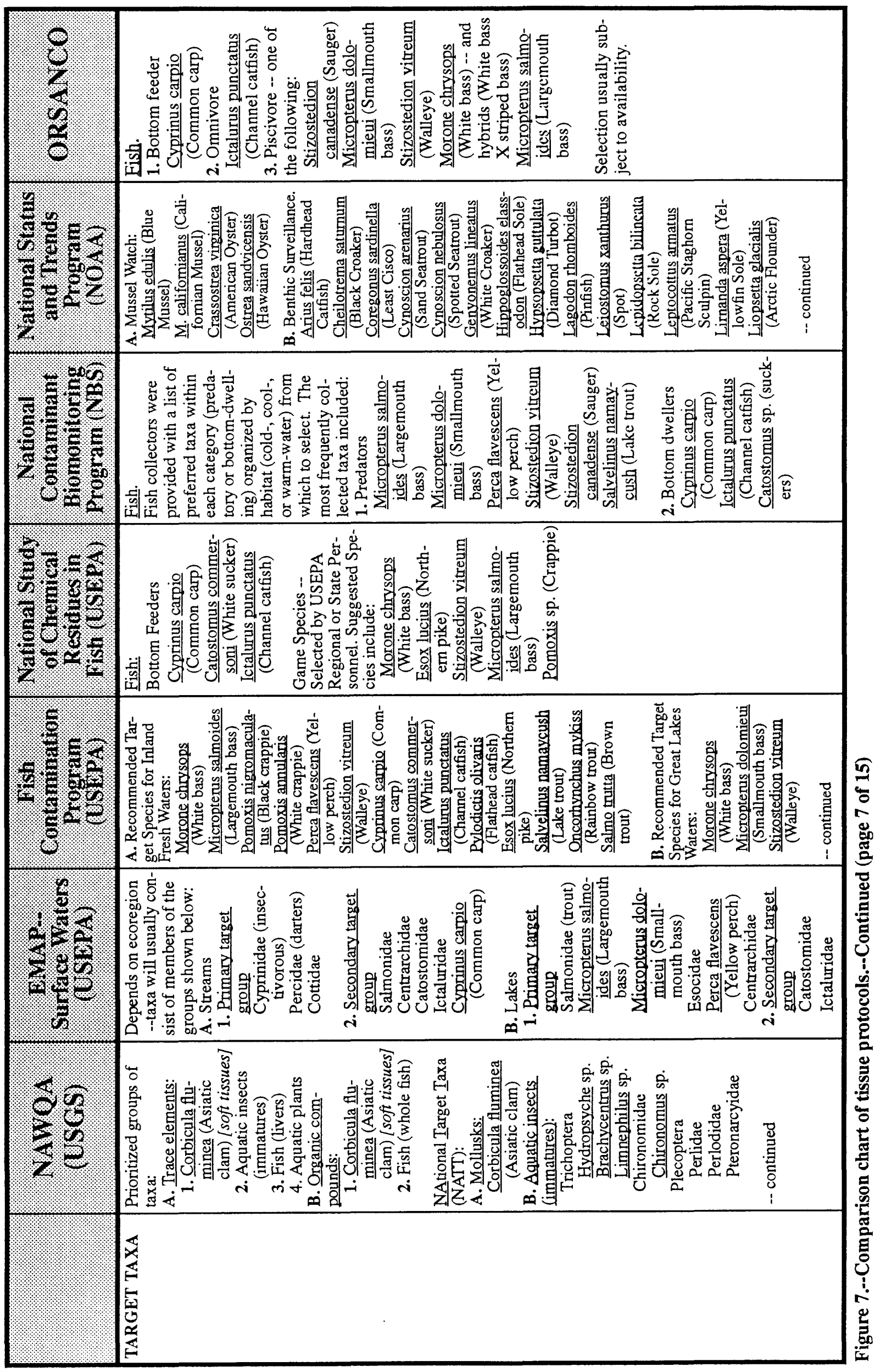




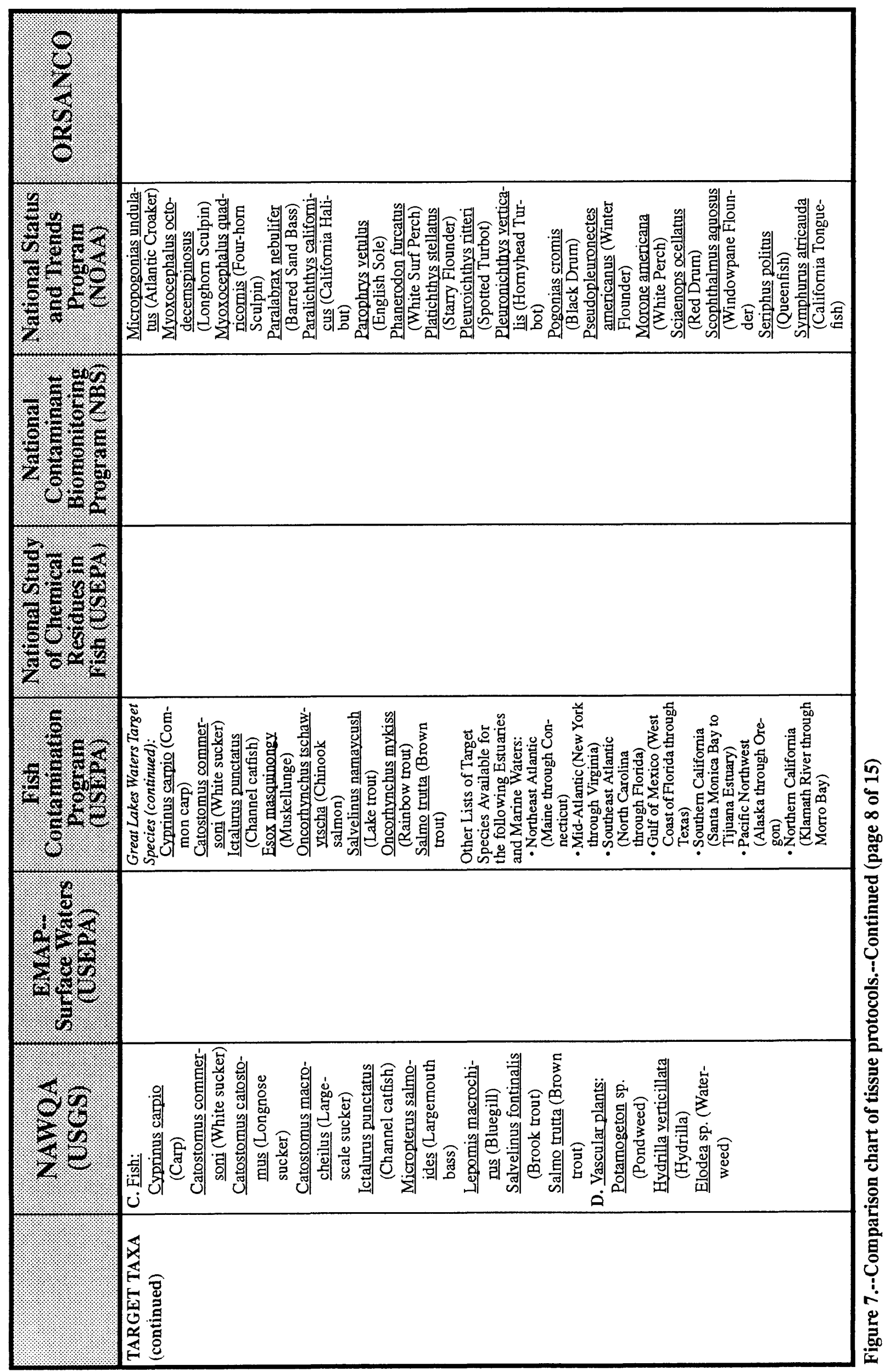




\begin{tabular}{|c|c|c|c|}
\hline$\frac{9}{8}$ & $\frac{\mathscr{g}}{8}$ & 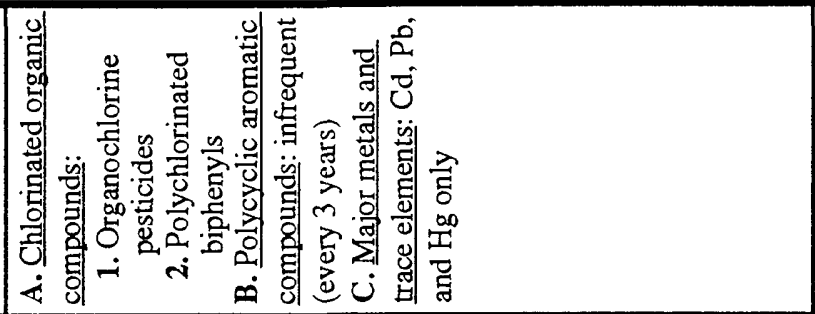 & 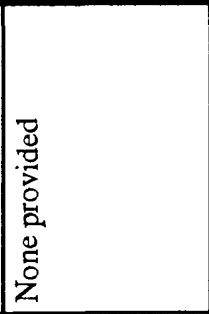 \\
\hline 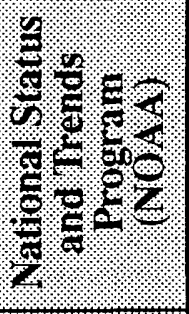 & $\begin{array}{l}\frac{2}{2} \\
0 \\
0 \\
0\end{array}$ & 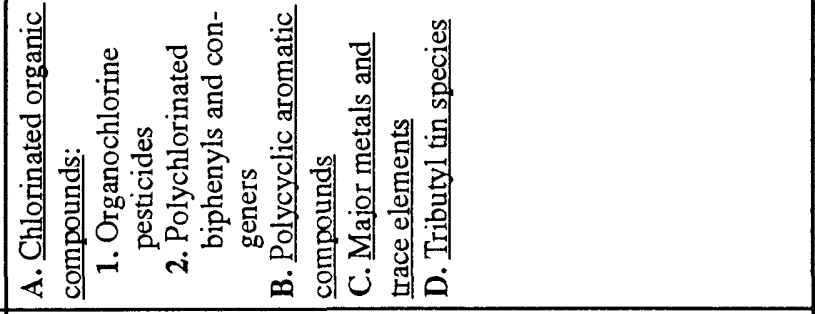 & 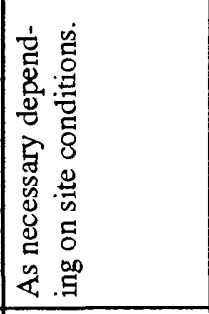 \\
\hline 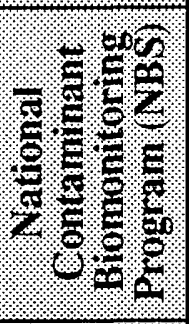 & 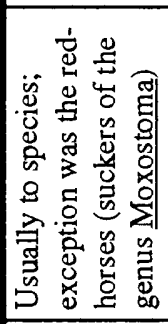 & 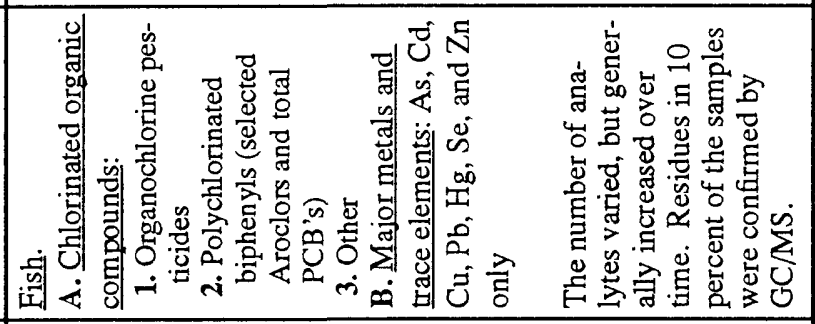 & 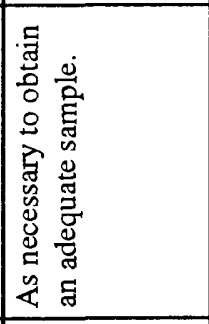 \\
\hline 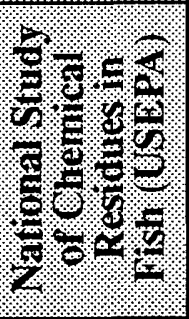 & 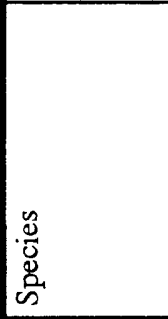 & 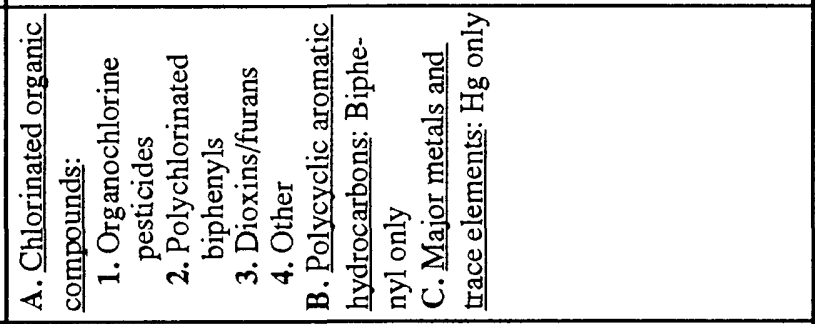 & 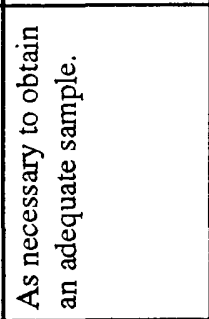 \\
\hline 날 & $\begin{array}{l}0 \\
0 \\
0\end{array}$ & 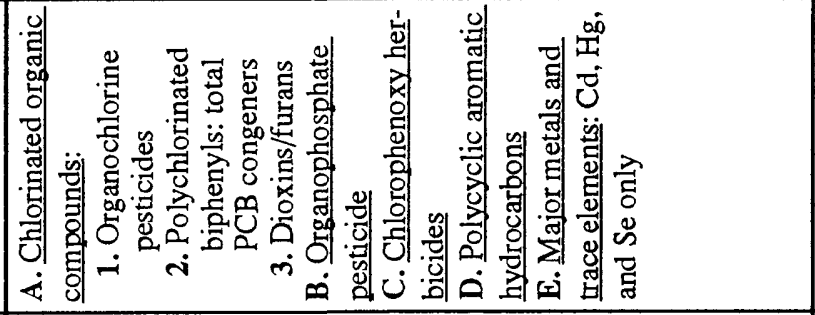 & 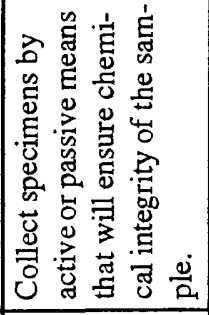 \\
\hline 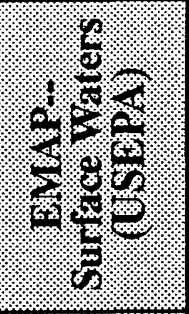 & 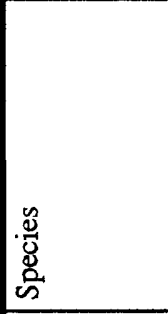 & 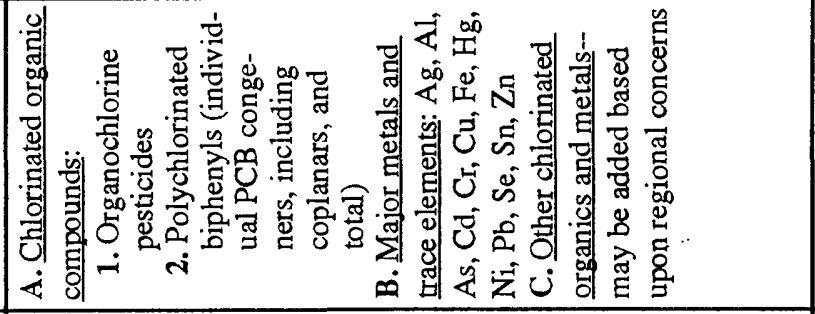 & 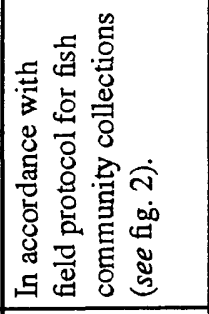 \\
\hline$\frac{3}{2} 8$ & 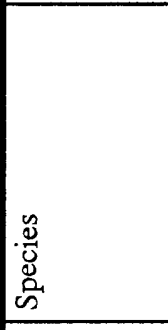 & 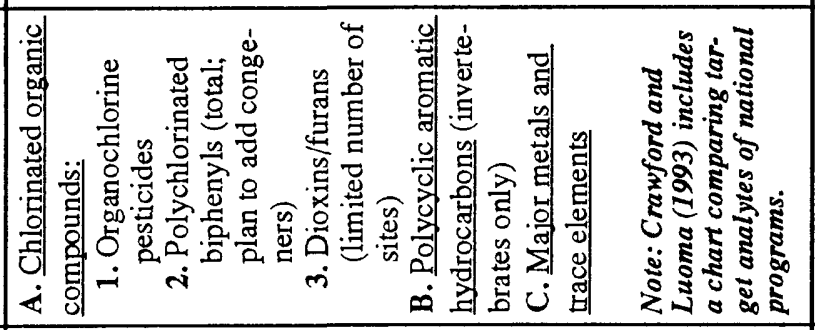 & 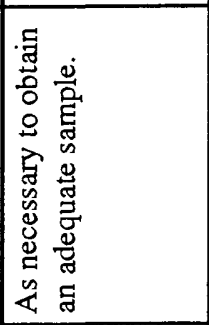 \\
\hline & 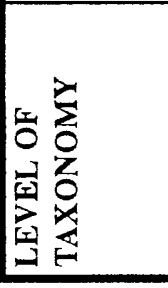 & 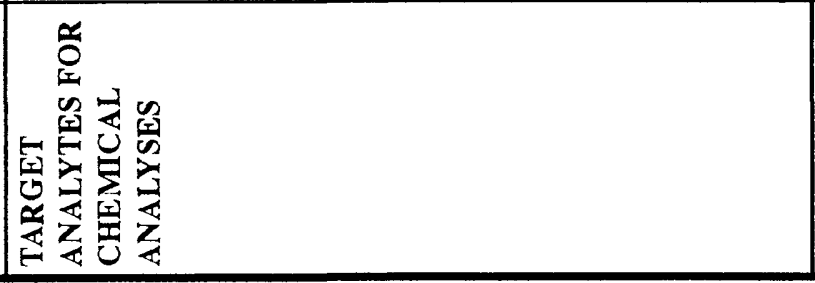 & 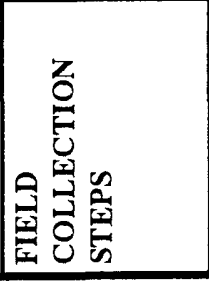 \\
\hline
\end{tabular}




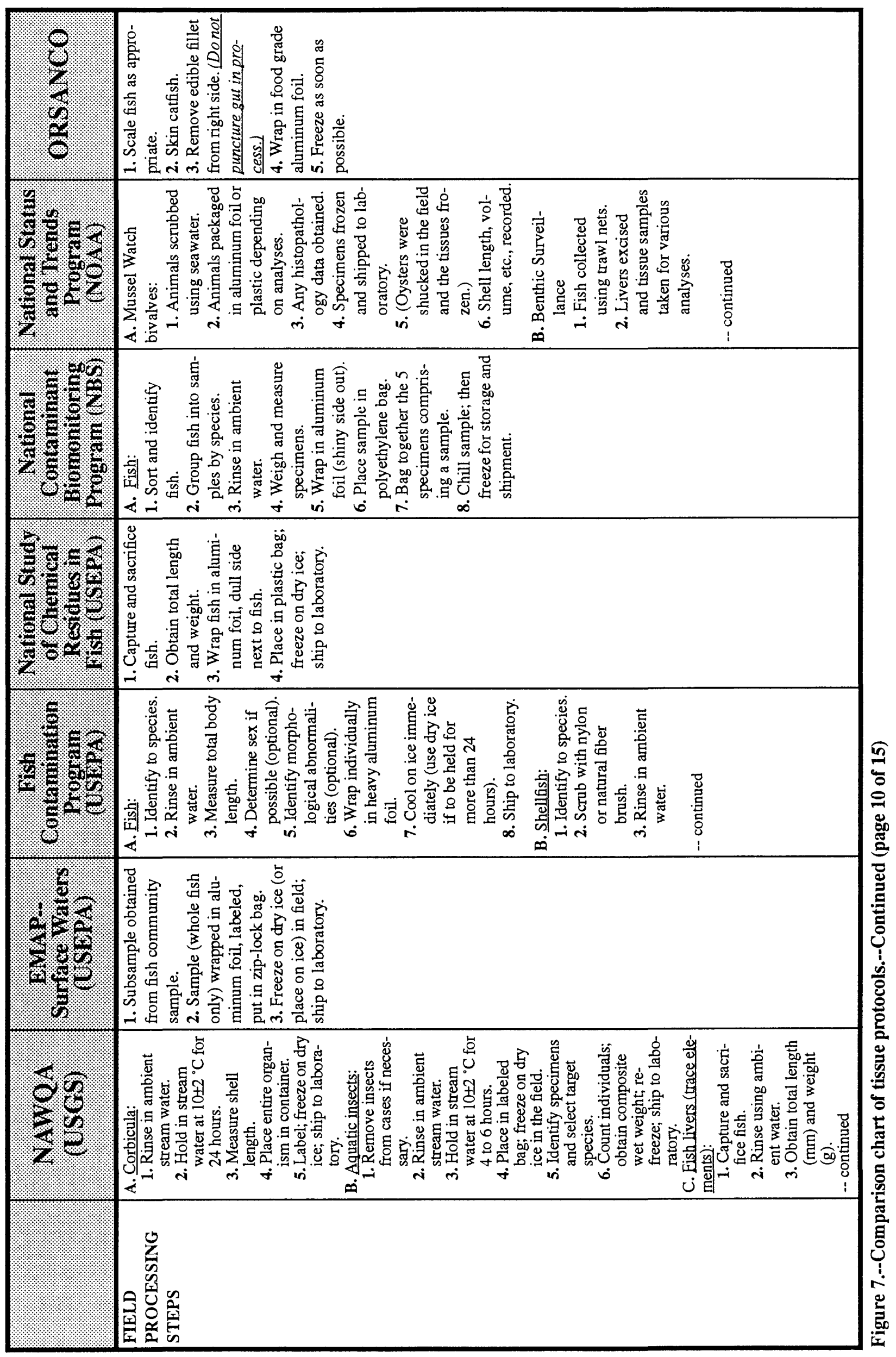




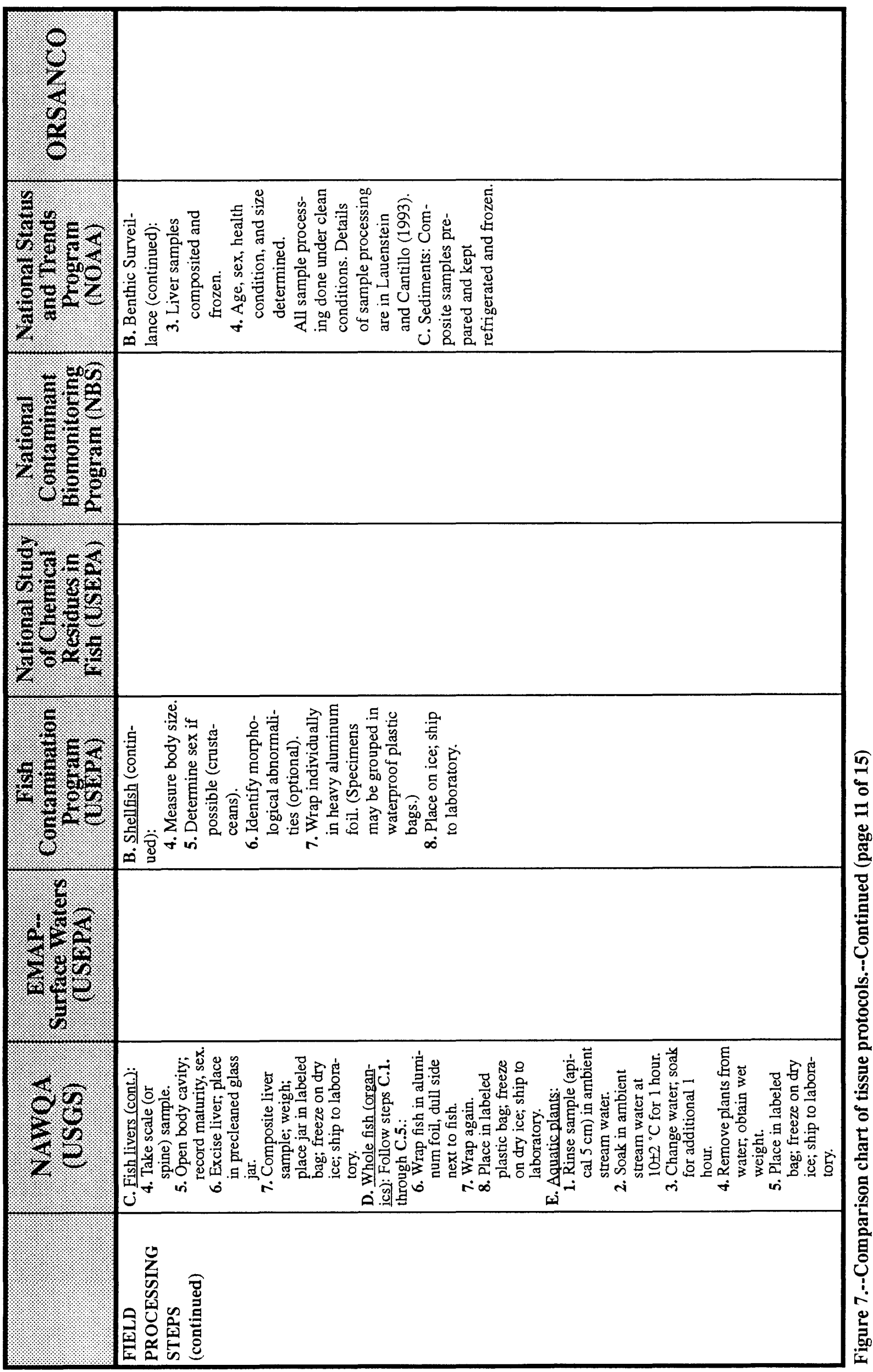




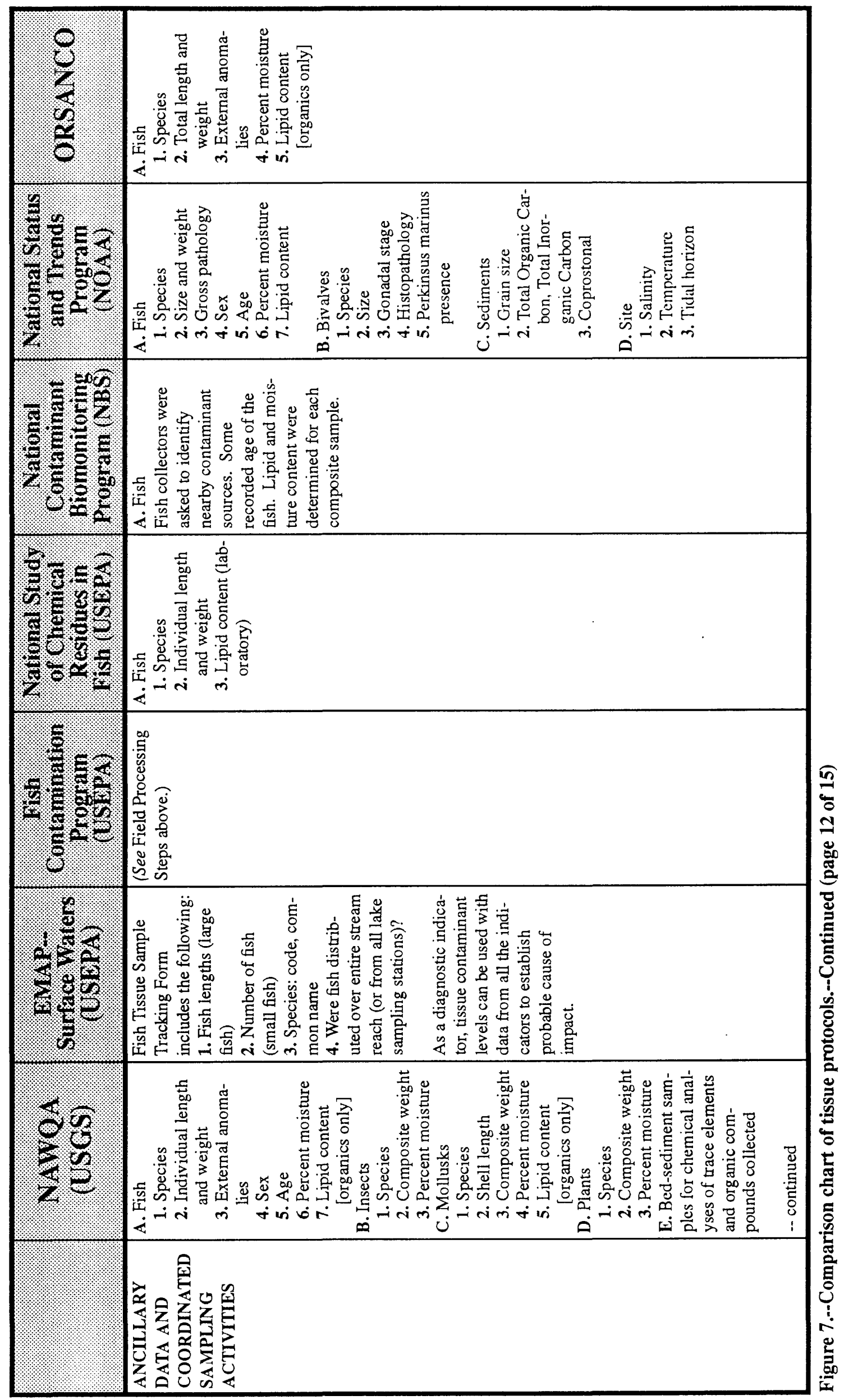




\begin{tabular}{|c|c|c|}
\hline$\frac{8}{2}$ & & 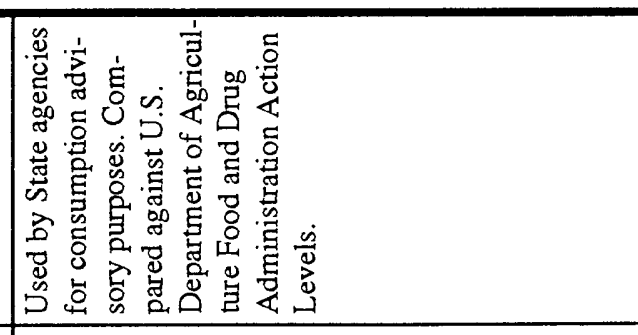 \\
\hline 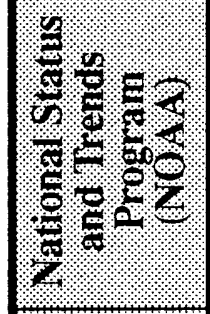 & & 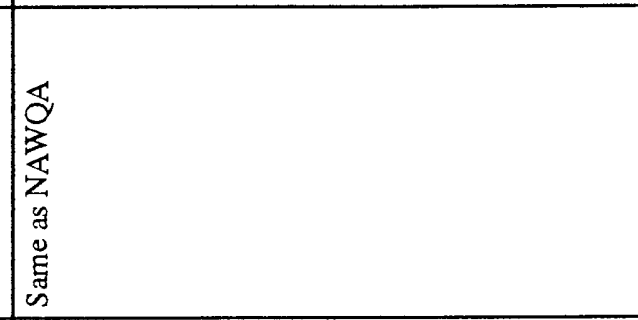 \\
\hline 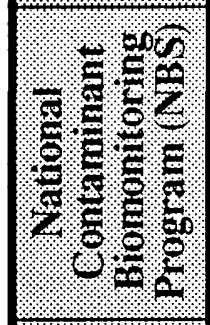 & & 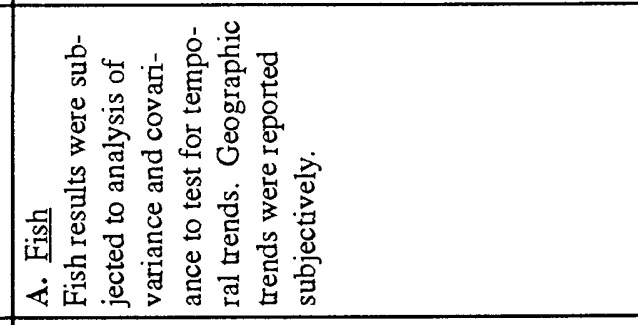 \\
\hline 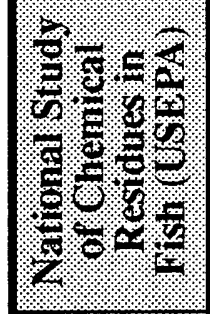 & & 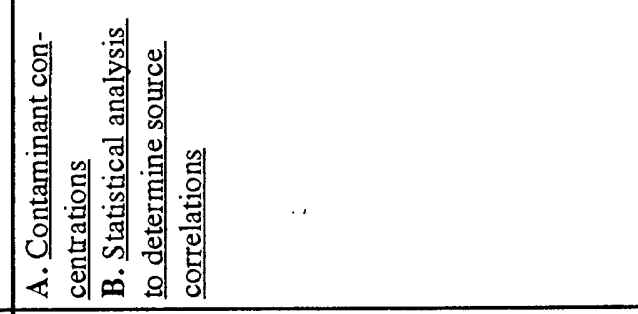 \\
\hline 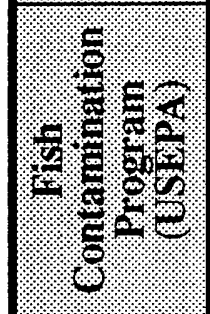 & & 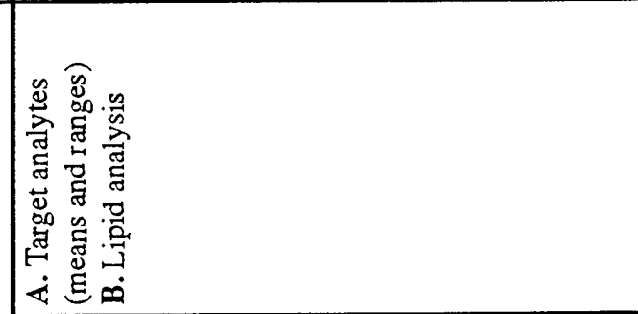 \\
\hline 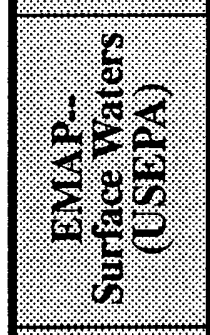 & & 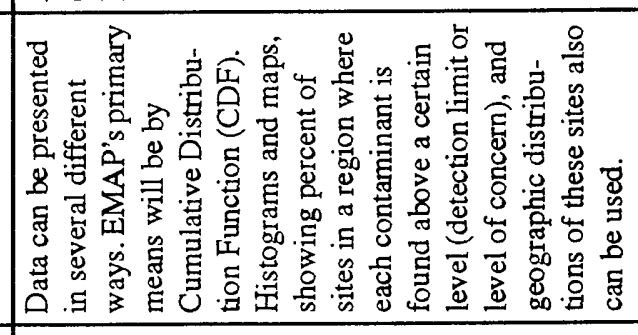 \\
\hline $\begin{array}{l}3 \\
2 \\
2 \\
2 \\
2\end{array}$ & 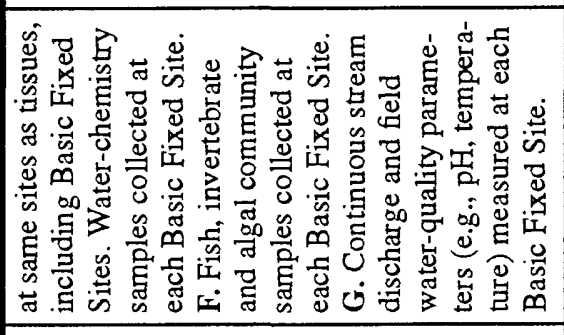 & 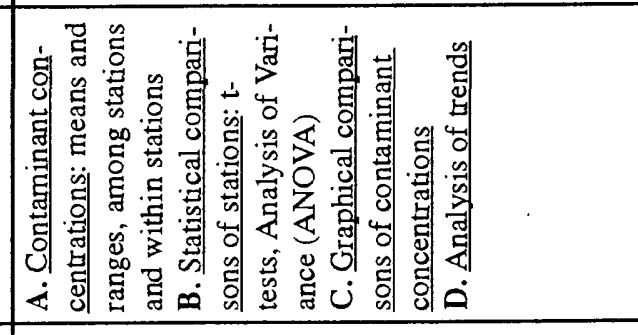 \\
\hline & 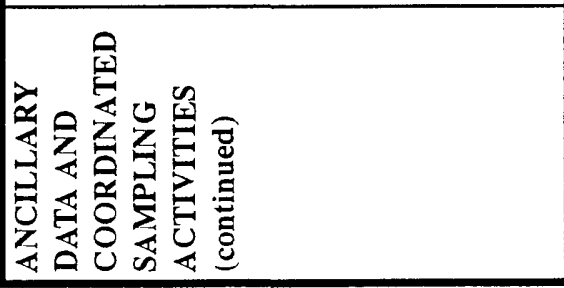 & 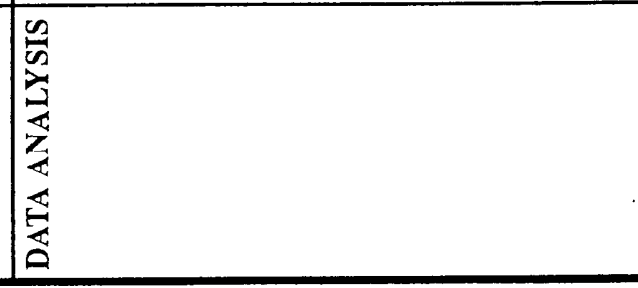 \\
\hline
\end{tabular}




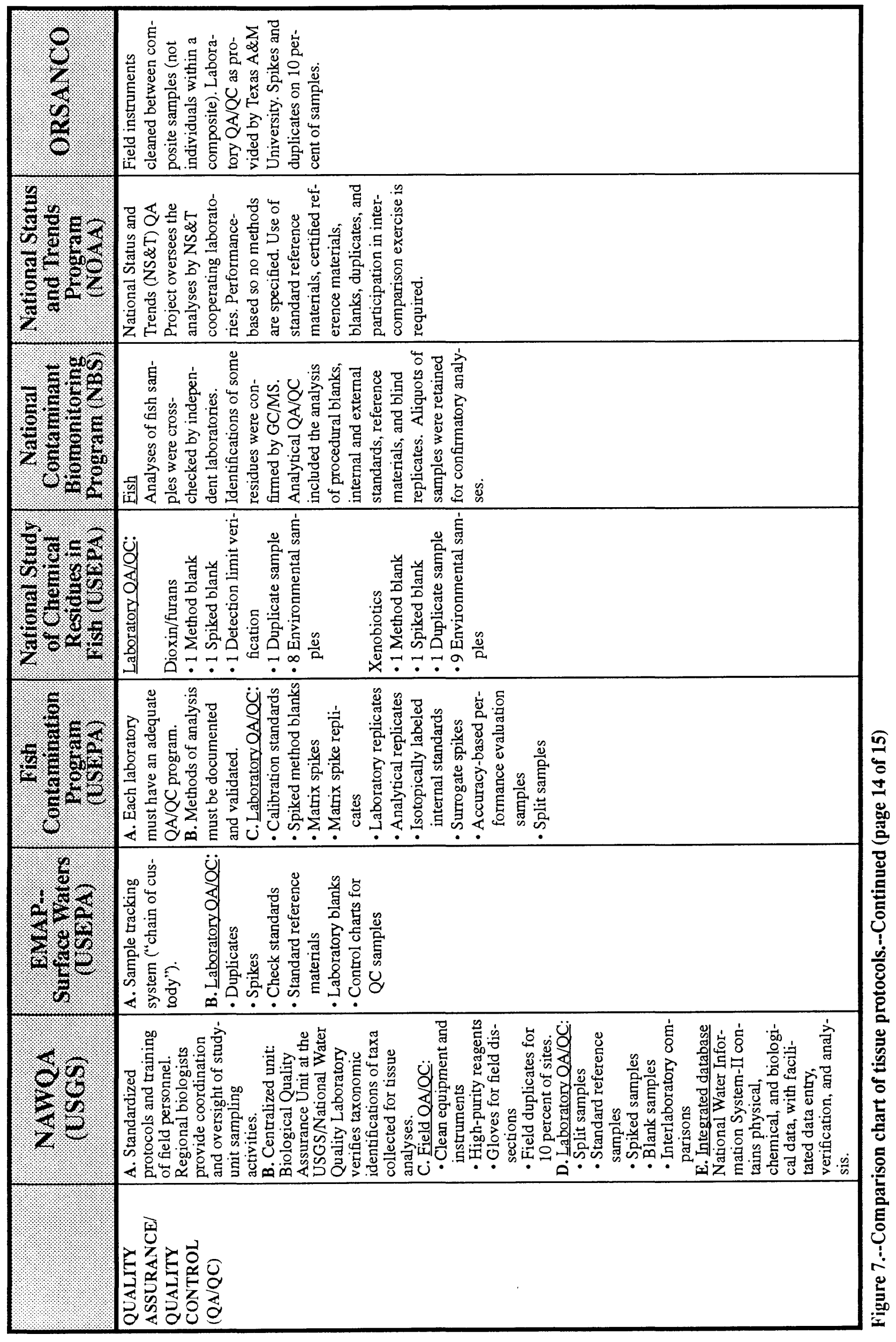




\begin{tabular}{|c|c|}
\hline 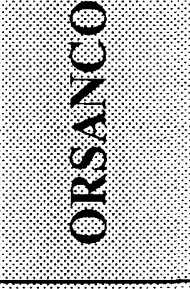 & 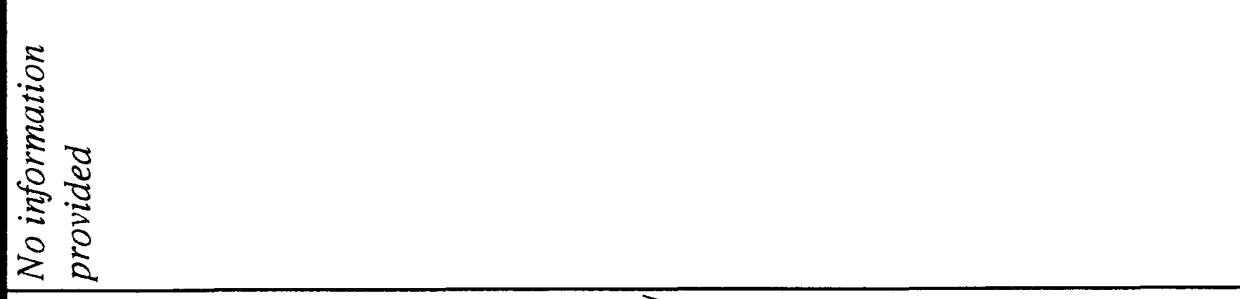 \\
\hline 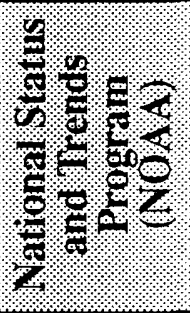 & 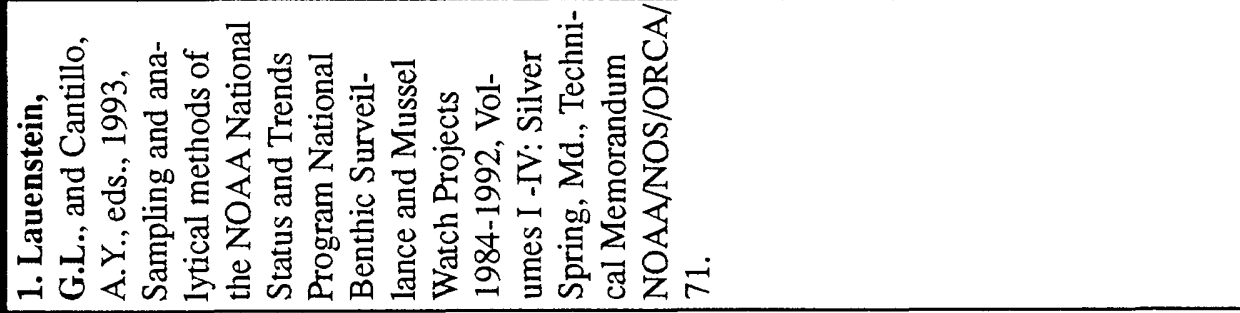 \\
\hline 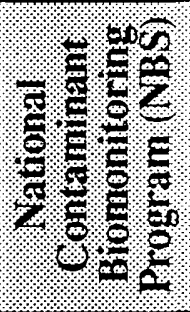 & 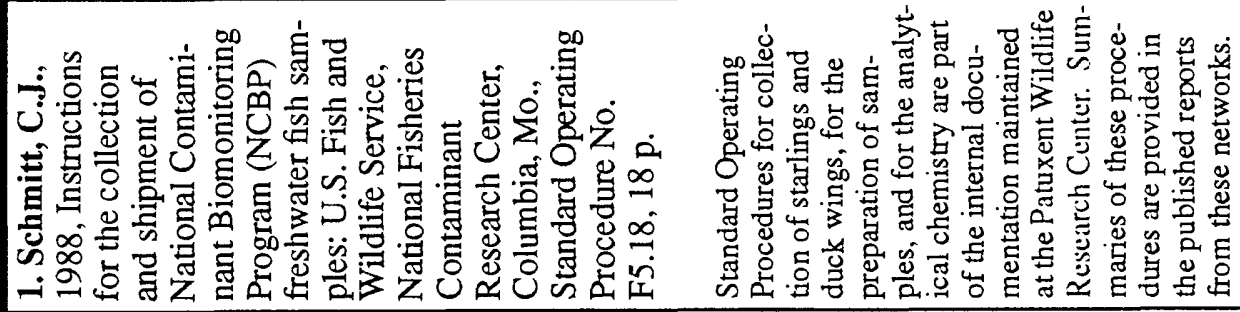 \\
\hline 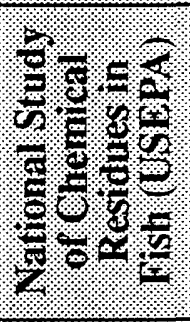 & 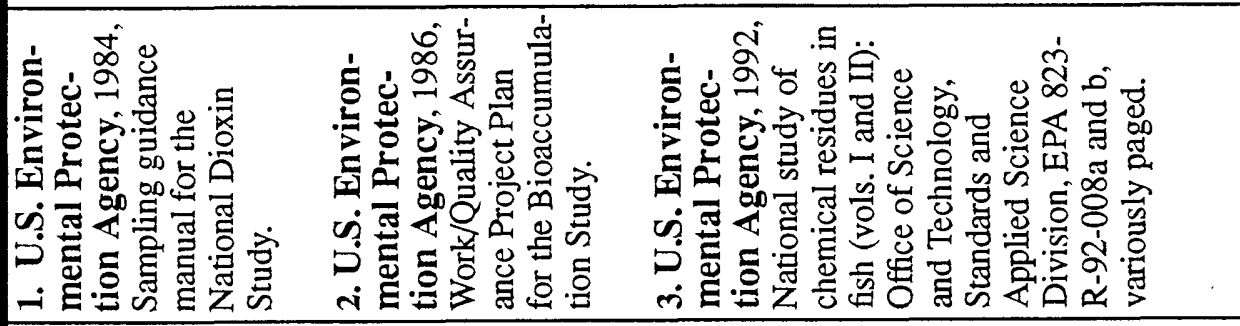 \\
\hline 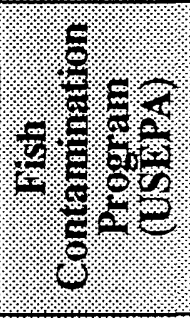 & 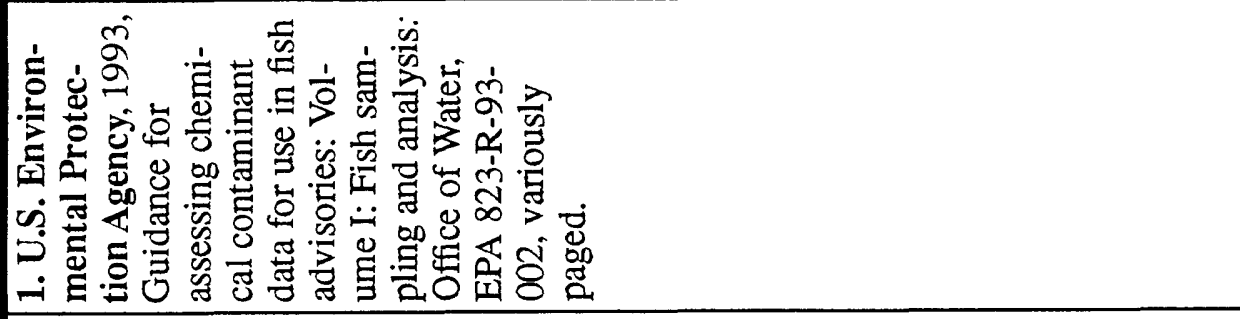 \\
\hline 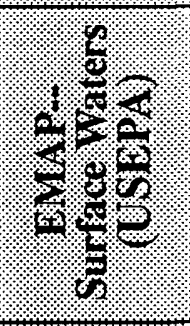 & 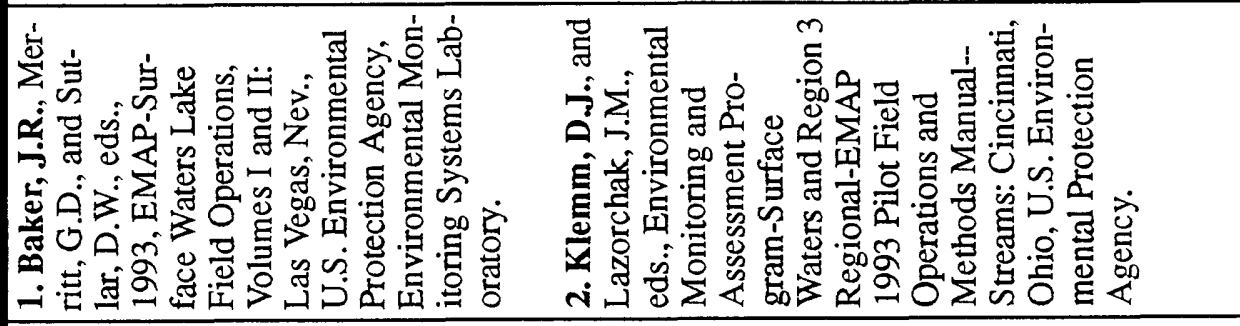 \\
\hline$\frac{4}{8}$ & 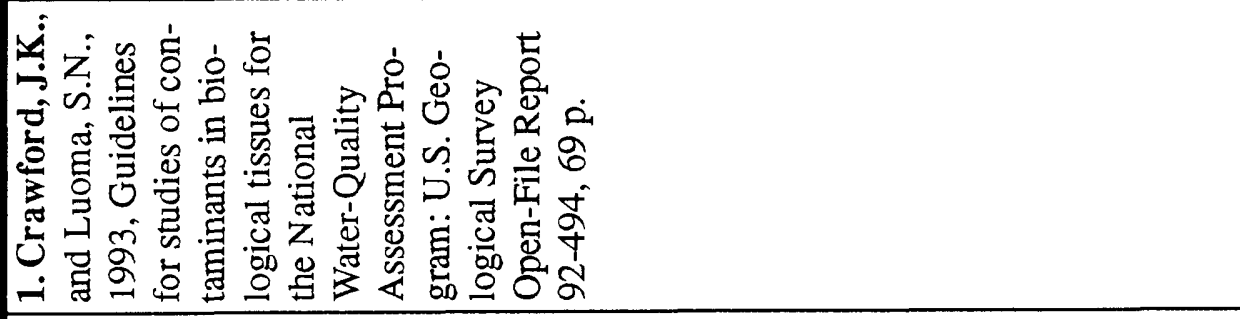 \\
\hline & 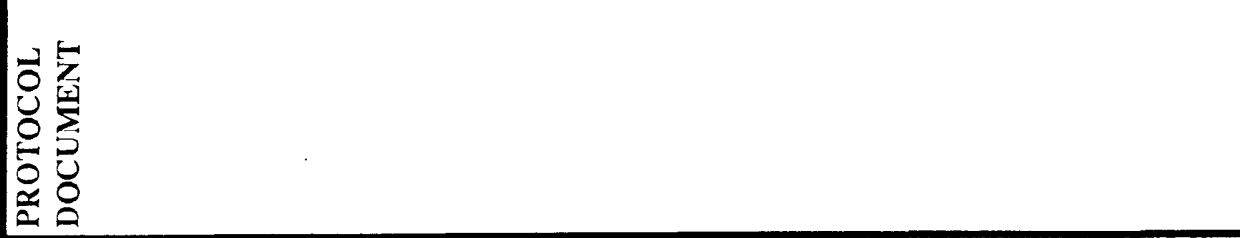 \\
\hline
\end{tabular}


APPENDIXES 


\section{APPENDIX I: Names and Addresses of Workshop Participants}

Federal Agencies--Department of the Interior

Bureau of Land Management

\begin{tabular}{|c|c|c|c|}
\hline Ron Huntsinger & $\begin{array}{l}\text { MS } 204 \\
1620 \text { L Street, NW } \\
\text { Washington, DC } 20036\end{array}$ & Ph: & (202) 452-7745 \\
\hline Rick Swanson & $\begin{array}{l}\text { Division of Wildlife and Fisheries } \\
\text { MS 204LS } \\
\text { 1849 C Street } \\
\text { Washington, DC } 20240\end{array}$ & $\begin{array}{l}\text { Ph: } \\
\text { Fax: }\end{array}$ & $\begin{array}{l}\text { (202) 653-9210 } \\
\text { (202) 653-9118 }\end{array}$ \\
\hline Mark Vinson & $\begin{array}{l}\text { Department of Fisheries and Wildlife } \\
\text { Utah State University } \\
\text { Logan, UT 84322-5210 } \\
\text { Internet: AQUA@cc.usu.edu }\end{array}$ & $\begin{array}{l}\text { Ph: } \\
\text { Fax: }\end{array}$ & $\begin{array}{l}\text { (801) } 797-2038 \\
(801) 797-1871\end{array}$ \\
\hline
\end{tabular}

Mark Nelson

Roy Irwin

Wade B. Bryant
P.O. Box 25007

Denver Federal Center

Denver, CO 80225

\section{National Park Service}

Water Resources Division 1201 Oak Ridge Drive, Suite 250

Fort Collins, CO 80525

\section{$\underline{\text { U.S. Fish and Wildlife Service }}$}

(presently with National Biological Survey)

c/o U.S. Geological Survey

Spalding Woods Office Park, Suite 160

3850 Holcomb Bridge Road

Norcross, GA 30092

Internet: wbbryant@usgs.gov

Steven L. Goodbred (presently with National Biological Survey)

c/o U.S. Geological Survey

Room W-2234, Federal Building

2800 Cottage Way

Sacramento, CA 95825

Internet: goodbred@usgs.gov
Ph: (303) 231-5190

Ph: (303) 225-3520

Fax: (303) 225-9965

Ph: (404) 409-7700

Fax: (404) 409-7725

Ph: (916) $978-4633 \times 351$

Fax: (916) $978-4633$ 
Thomas A. Muir

(presently with National Biological Survey)

c/o U.S. Geological Survey

Ph: (703) 648-5114

National Center, MS 413

Fax: (703) 648-5722

12201 Sunrise Valley Drive

Reston, VA 22092

Internet: tmuir@usgs.gov

Christopher Schmitt (presently with National Biological Survey) National Fisheries Contaminant

Research Center

4200 New Haven Road

Columbia, MO 65201

Stephen Zylstra Virginia Field Office

P.O. Box 480

Ph: $\quad$ (804) 693-6694

Mid-County Center

Route No. 17

White Marsh, VA 23183

Ph: (314) 875-5399

\section{U.S. Geological Survey}

\section{J. Kent Crawford 840 Market Street}

Lemoyne, PA 17043-1586

Ph: (717) 730-6975

Internet: crawford@usgs.gov

Fax: (717) 730-6997

Thomas F. Cuffney 3916 Sunset Ridge Road

Ph: (919) $571-4019$

Raleigh, NC 27607

Fax: (919) 571-4041

Internet: tcuffney@usgs.gov

Sarah Gerould

Martin E. Gurtz

Cliff R. Hupp

Michael R. Meador
National Center, MS 412

12201 Sunrise Valley Drive

Reston, VA 22092

Internet: sgerould@usgs.gov

3916 Sunset Ridge Road

Raleigh, NC 27607

Internet: megurtz@usgs.gov

Spalding Woods Office Park, Suite 160

3850 Holcomb Bridge Road

Norcross, GA 30092

Internet: crhupp@usgs.gov

3916 Sunset Ridge Road

Raleigh, NC 27607

Internet: mrmeador@usgs.gov
Ph: (919) 571-4018

Fax: (919) 571-4041

Ph: (404) 409-7709

Fax: (404) 409-7725

Ph: (919) $571-4020$

Fax: (919) 571-4041 
Denver Federal Center

Building 25, Box 25046, MS 406

Lakewood, CO 80225

Internet: sdporter@rcolka.cr.usgs.gov

Terry M. Short

Mail Stop 470

345 Middlefield Road

Menlo Park, CA 94025

Internet: tmshort@usgs.gov

Stephen K. Sorenson National Center, MS 433

12201 Sunrise Valley Drive

Reston, VA 22092

Internet: sorenson@usgs.gov

Marc A. Sylvester Mail Stop 470

345 Middlefield Road

Menlo Park, CA 94025

Internet: sylvest@usgs.gov
Ph: (303) 236-5950 ×216

Fax: (303) 236-5959

Ph: (415) 329-4324

Fax: (415) 329-4463

Ph: (703) 648-5113

Fax: (703) 648-5295

$\mathrm{Ph}: \quad$ (415) $329-4415$

Fax: (415) 329-4463

\section{Other Federal Agencies--}

Federal Coordinating Council for Science, Engineering and Technology

Penelope Firth Committee on Earth and Environmental Sciences

c/o National Science Foundation

Ph: (202) 357-7353

1800 G Street, NW

Washington, DC 20550

Internet: pfirth@nsf.gov

National Oceanic and Atmospheric Administration

$\begin{array}{lll}\text { Adriana Cantillo } & \text { SSMCIV, ORCA2 } & \text { Ph: }\end{array}$

Tennessee Valley Authority

Steven A. Ahlstedt $\quad$ (presently with U.S. Geological Survey) $\quad$ Ph: $\quad$ (615) 632-8748 400 West Summit Hill Drive

Fax: (615) 632-6855

WT8B

Knoxville, TN 37902-1499

Internet: ahlstedt@usgs.gov 


\section{U.S. Army Corps of Engineers}

Ed Theriot

Waterways Experiment Station

Ph: (601) 634-2398

3909 Halls Ferry Road

Fax: (601) 634-2398

Vicksburg, MS 39180

\section{U.S. Environmental Protection Agency}

Candace Brassard

Ryan Childs

Marjorie Coombs

Wayne S. Davis

Chris K. Faulkner
Office of Pesticides Programs \#7507C 401 M Street, SW

Washington, DC 20460

Internet: brassard.candace@epamail.epa.gov

Office of Water \#4305

$401 \mathrm{M}$ Street, SW

Washington, DC 20460

Office of Science and Technology

SASD \#4305

401 M Street, SW

Washington, DC 20460

Office of Policy, Planning, and Evaluation

\#2162

401 M Street, SW

Washington, DC 20460

Office of Wetlands, Oceans, and Watersheds \#4503F

Assessment and Watershed Protection Branch 401 M Street, SW

Washington, DC 20460

Internet: faulkner.chris@epamail.epa.gov

Office of Science and Technology

Health and Ecological Criteria Division \#4304 $401 \mathrm{M}$ Street, SW

Washington, DC 20460
Ph: (703) 305-5392

Fax: (703) 305-6309

Ph: (202) 260-7035

Fax: (202) 260-9830

Ph. (202) 260-9821

Fax: (202) 260-9830

Ph: (202) 260-4906

Fax: (202) 260-4903

Ph: (202) 260-6228

Fax: (202) 260-1977

Ph: (202) 260-7580 
Brian H. Hill

Office of Research and Development

Ph: (513) 569-7077

Environmental Monitoring Systems

Fax: (513) 569-7078

Laboratory

3411 Church Street

Cincinnati, OH 45244

Internet: hill.brian@epamail.epa.gov

\section{Skip Houseknecht (Deceased) *}

Susan Jackson

Biocriteria Program

Health and Ecological Criteria Division \#4304

Ph: (202) 260-1800

$401 \mathrm{M}$ Street, SW

Washington, DC 20460

James M. Lazorchak Office of Research and Development

Ph: (513) 569-7076

Environmental Monitoring Systems

Fax: (513) 569-7078

Laboratory

3411 Church Street

Cincinnati, OH 45244

Internet: lazorchak.jim@epamail.epa.gov

Frank H. McCormick Office of Research and Development

Ph: (513) 569-7097.

Environmental Monitoring Systems

Fax: (513) 569-7078

Laboratory

3411 Church Street

Cincinnati, OH 45244

Internet: mccormick.frank@epamail.epa.gov

Ron Parker

Office of Prevention, Pesticides,

Ph: (703) 305-5505 and Toxic Substances (H-7507C)

401 M Street, SW

Washington, DC 20460

Ronald Preston

Region III

Ph: (304) 234-0245

Environmental Services Division

Fax: (304) 234-0260

303-Methodist Building

11th and Chapline Streets

Wheeling, WV 26003

Mike Rexrode

Office of Prevention, Pesticides,

Ph: (703) 305-5578 and Toxic Substances

MS H-7507C

401 M Street, SW

Washington, DC 20460

* For information about the Fish Contamination Program, contact Tom Armitage at:

Office of Science and Technology

Ph: (202) 260-7301

Risk Assessment and Management Branch \#4305 Fax: (202) 260-9830 401 M Street, SW

Washington, DC 20460 


\section{U.S. Forest Service}

Ted Angradi Northeast Forest Experiment Station

Ph: (304) 478-2000

Box 404

Fax: (304) 478-8692

Parson, WV 26287

Kerry Overton

Intermountain Research Station

Ph: (208) 364-4357

316 Myrtle Street

Fax: (208) 364-4346

Boise, ID 83702

Dick Smythe

(also represented National Biological Survey implementation team)

Washington Office

Ph: (202) 452-7745

14th and Independence, SW

Washington, DC 20090-6090

\section{State and Private Agencies}

North Carolina Department of Environment, Health, and Natural Resources

David R. Lenat

DEM/Environmental Sciences Branch 4401 Reedy Creek Road

Raleigh, NC 27607

\section{Ohio Environmental Protection Agency}

Chris O. Yoder
Ph: (919) 733-6946

Fax: (919) 733-9959

\section{Tetra Tech. Inc.}

Michael T. Barbour 10045 Red Run Boulevard, Suite 110

Ph: (410) 356-8993

Owings Mills, MD 21117

Fax: (410) 356-9005 


\title{
Interagency Biological Methods Workshop
}

\author{
June 22-23, 1993 \\ U.S. Geological Survey \\ Reston, Virginia
}

Agenda

\section{Tuesday, June 22}

8:30 AM Welcome and Opening Remarks

-- Dallas Peck, Director, U.S. Geological Survey

8:45 AM An Overview of NAWQA Biology and Workshop Objectives

9:20 AM The ITFM Perspective on Biological Indicators

-- Marty Gurtz, U.S. Geological Survey

-- Chris Yoder, Ohio Environmental Protection Agency

9:40 AM Overview of State Agency Biomonitoring Programs

\section{0:00 AM Break}

-- Mike Barbour, Tetra Tech, Inc.

10:20 AM Brief remarks from participating agencies and programs

11:00 AM Objectives for Working Groups

11:15 AM Working Group Session I (assigned meeting rooms: Fish, Invertebrates, Algae, Habitat, Tissues)

Introductions and backgrounds of participants

11:45 AM -- 1:00 PM Lunch (with your Working Group)

1:00 PM Working Group Session II (assigned meeting rooms)

Compilation of protocol charts

Element-by-element discussion of protocol charts: note similarities, highlight differences; discuss reasons for differences among protocols

$\bigcirc$ Prepare brief narratives discussing similarities and differences

4:30 PM Reconvene in Auditorium: Review progress of Working Groups

\section{Wednesday, June 23}

8:30 AM Working Group Session III (assigned meeting rooms)

Continue discussions of protocol charts, if necessary

Future directions: opportunities for research and collaboration

11:45 AM $\quad--1: 00 \mathrm{PM}$

\section{Lunch}

1:00 PM Reconvene in Auditorium

Working Group Reports and Discussion

Wrap-Up and Open Discussion

4:00 PM Adjourn 
APPENDIX III: List of Participants in Each Workgroup

\section{Fish Workgroup}

Mike Meador (Facilitator)

Frank McCormick (Recorder/Reporter)

Ron Preston

Mike Rexrode

Charlie Saylor

Terry Short

Chris Yoder

Steve Zylstra

Invertebrates Workgroup

Tom Cuffney (Facilitator/Reporter)

Steve Ahlstedt

Marc Sylvester (Recorder)

Ted Angradi

Marjorie Coombs

Wayne Davis

Chris Faulkner

Brian Hill

Roy Irwin

Dave Lenat

Mark Nelson

Mark Vinson

\section{Algae Workgroup (June 22 only)}

Stephen Porter (Facilitator/Reporter)

Brian Hill (Recorder)

Marty Gurtz

Steve Sorenson

\section{Habitat Workgroup}

Cliff Hupp (Facilitator)

Mike Barbour (Recorder/Reporter)

George Gibson (Reporter)

Susan Jackson

Kerry Overton

Ron Parker

Stephen Porter

Dick Smythe

Rick Swanson

\section{Tissues Workgroup}

Kent Crawford (Facilitator)

Candy Brassard

Steve Goodbred (Recorder)

Adriana Cantillo

Chris Schmitt (Reporter)

Ryan Childs

Sarah Gerould

Skip Houseknecht

Roy Irwin

Jim Lazorchak

Steve Sorenson 